\title{
LAS RAZAS DE MANÍ DE PERÚ
}

\author{
ANTONIO KRAPOVICKAS ${ }^{1}$, RICARDO O. VANNI ${ }^{1}$, JOSÉ R. PIETRARELLI† ${ }^{2}$ \& CHARLES E. SIMPSON ${ }^{3}$
}

\begin{abstract}
Resumen: Krapovickas, A., R. O. Vanni, J. R. Pietrarelli \& C. E. Simpson. 2013. Las razas de maní de Perú. Bonplandia 22(1): 19-90.

En este estudio sobre maní se diferencian para Perú 47 razas de maní cultivado de las cuales 13 pertenecen a Arachis hypogaea ssp. hypogaea var. hypogaea, 2 a A. hypogaea ssp. hypogaea var. hirsuta, 15 a $A$. hypogaea ssp. fastigiata var. fastigiata, 15 a A. hypogaea ssp. fastigiata var. peruviana y 2 a $A$. hypogaea ssp. fastigiata var. aecuatoriana. Perú constituye un centro de variación independiente pues sus razas son exclusivas de su territorio, salvo muy pocas excepciones.
\end{abstract}

Palabras clave: Arachis hypogaea, Perú, biodiversidad, razas cultivadas, maní.

\begin{abstract}
Krapovickas, A., R. O. Vanni, J. R. Pietrarelli \& C. E. Simpson. 2013. The peanut landraces from Peru. Bonplandia 22(1): 19-90.

47 distinct landraces of Peruvian peanuts were identified and systematically described. 13 landraces belong to Arachis hypogaea ssp. hypogaea var. hypogaea, 2 to $A$. hypogaea ssp. hypogaea var. hirsuta, 15 to $A$. hypogaea ssp. fastigiata var. fastigiata, 15 to $A$. hypogaea ssp. fastigiata var. peruviana and 2 to $A$. hypogaea ssp. fatigiata var. aecuatoriana. With very few exceptions, the landraces encountered in Perú are entirely endemic to that country.
\end{abstract}

Key words: Arachis hypogaea, Perú, biodiversity, cultivated races, peanut.

\section{Introducción}

El mantenimiento de la colección de los maníes peruanos en la Estación Experimental Agropecuaria de Manfredi, practicamente comenzó en el año 1955 con las introducciones de Krapovickas, aumentó en 1957 con el material enviado por Mazzani, llegando a incrementarse notablemente con las muestras obtenidas durante las prospecciones realizadas en 1981 por el equipo formado por C. E. Simpson, J. R. Pietrarelli \& H. O. Zurita (Banks, 1985, Pietrarelli, 1982, Simpson, 1980 \& 1981, Simpson \& Higgins, 1984).
Fueron varias las colecciones de maní realizadas en este país andino (Fig. 1). El conocimiento que en diferentes regiones fueron cultivadas y todavía se cultivan razas diferentes de esta especie, data de mucho tiempo atrás. En especial por haberse hallado frutos enteros de maní en yacimientos arqueológicos a lo largo de la costa (Ancon, Trujillo, Huaca Prieta, etc.).

El tipo más común descubierto en estos restos fue el perteneciente a la subespecie hypogaea var. hirsuta Köhler. Cuyos frutos son muy diferentes de todos los conocidos y por ello fáciles de identificar.

${ }^{1}$ Instituto de Botánica del Nordeste IBONE, Corrientes, Argentina

${ }^{2}$ Estación Experimental INTA, Manfredi, Córdoba, Argentina

${ }^{3}$ Texas \& University, Stephenville, Texas, USA. 


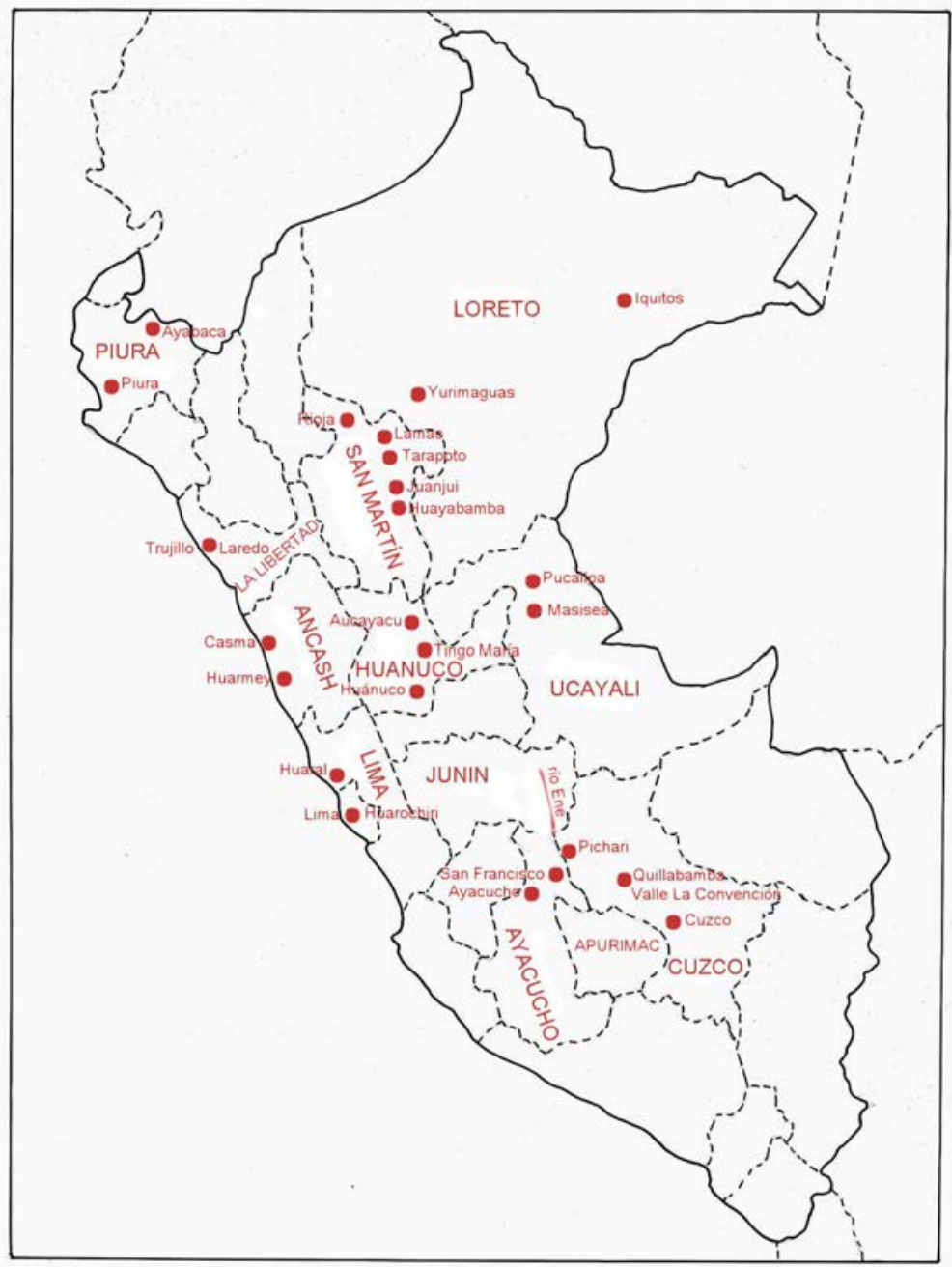

Fig. 1. Localidades donde se obtuvieron muestras de las razas de maní en Perú.

En los países andinos hay una regionalización de las razas locales manifiesta. Ecuador con 50 y Perú con 47 comparten dos razas. Perú y Bolivia con 61 conocemos solamente tres razas en común. Los maníes de Acre (Brasil), se diferencian tanto de los peruanos como de los bolivianos, a pesar de que colinda con estos dos países.

\section{Materiales y Métodos}

Este estudio para la clasificación de las razas de maní de Perú se llevó a cabo durante sucesivos ciclos experimentales realizados entre 1955 y 2007, en la Estación Experimental Agrícola Manfredi(EEA Manfredi), ubicada en el centro de la franja manicera de la provincia de Córdoba Argentina (31 $48^{\prime} \mathrm{S}, 63^{\circ} 40^{\prime} \mathrm{W}$ alt. 290 m.s.m.). Se trabajó con unas 250 entradas de maní de origen peruano que forman parte de la gran colección de germoplasma de Arachis mantenida por INTA en la EEA Manfredi, que cuenta con 3534 accesiones de maní cultivado de 40 países del mundo, de los cuales 1432 accesiones originarias de la región andina (Bolivia, Perú y Ecuador).

Uno de los desafíos que se enfrentó para la clasificación de las razas de maní es el hecho de la fructificación subterránea, porque cuando se analizan los frutos ya no existen las plantas y viceversa. Para superar este inconveniente, se registró cuidadosamente las características 
agromorfológicas de las plantas y de los frutos en sus respectivas temporadas y posteriormente juntar esta información de manera sistemática para lograr una clasificación práctica basada en el conjunto de dichas características.

En Manfredi, se registraban las accesiones según su lugar de origen, nombre de los coleccionistas y se les asignaba un número de registro RCM o US. El último catálogo (Sánchez et al. 2010) utiliza el código alfanumérico REM(registro de entradas de maní), donde a la colección de Perú le corresponde los REM 3601 al REM 3911. La mayoría de las colecciones originales estaban constituidas por mezclas de granos de diversos colores (Simpson \& Higgins, 1984, foto de tapa US-497).

El material fue ordenado en primer término por el sistema de ramificación, el porte, el color del grano y la forma del fruto o caja.

La colección se sembró en el campo según las afinidades morfológicas. Por ejemplo, todos los “Tingo María” juntos, todos los "Blanco Tarapoto” también juntos etc.

Se trató de uniformar las parcelas separando las plantas fuera de tipo. De esta manera la planta que se analizaba representaba a toda la parcela.

Este ordenamiento permitió apreciar pequeñas diferencias y afinidades que de otra manera serían difíciles de notar. Por ejemplo, al estar juntas todas las parcelas afines se vio claramente que la subsp. hypogaea tiene un color verde más intenso que la subsp. fastigiata.

De acuerdo a la ramificación, al tipo de caja y número de semillas por fruto se las separaba en las dos subespecies, hypogaea y fastigiata (A. Krapovickas \& V. A. Rigoni, 1960). A su vez se trataba de separar por variedades.

Reunida la colección de un país, en este caso Perú a las diferentes accesiones, se las sembraban en parcelas de $10 \mathrm{~m}$ de largo, 2 semillas cada $20 \mathrm{~cm}$. en la misma línea. Las líneas separadas a $70 \mathrm{~cm}$ entre surco o 1,40 m, dependiendo del tamaño de las plantas, con menor distancia entre surcos para las plantas de porte erecto de la subsp. fastigiata, y mayor distancia entre surcos para acomodar a las plantas rastreras de la subsp. hypogaea

La planificación de la siembra se realizaba durante el mes de octubre y en marzo del año siguiente o primeros días de abril, según las lluvias y temperaturas, se realizaba la observación de la colección en el campo para estudiar el tipo de planta (porte, color de los tallos, tipo de ramificación, presencia o ausencia de cerdas, características florales, precocidad, etc.).

En cada parcela, se tomaban observaciones. Después de la cosecha, en octubre, se estudiaban los caracteres de las cajas (frutos). A través de los años se fueron uniformizando las accesiones, las que presentaban similitud se sembraban en parcelas contiguas.

Para denominar las razas se respetaron los nombres de las muestras. De no tenerlos, se dieron nombres según la región de cultivo o en otros casos remarcando algún carácter exomorfológico distintivo de la planta, porte, tipo de caja, o color del tegumento de la semilla.

La EEA de Manfredi publicó varios catálogos de la colección de maníes, en 1959, 1976/77 y 1990. Uno reciente (Sánchez, 2010) que se publicó mientras se llevaba a cabo este estudio. En el último catalogo de 1990 figuran los números de parcela de la cosecha 1986/87. En el Anexo incluimos estos números para relacionar el presente ordenamiento con el publicado en 1990.

El catálogo de 2010, no lo pudimos utilizar por presentar algunas incongruencias. Para los maníes de Perú hay 24 procedencias repetidas, y una repetida 4 veces. Figuran 5 procedencias identificadas como var. vulgaris, variedad que no existe en Perú ni en Ecuador. Curiosamente casi todo el material de Paraguay 467 procedencias coleccionadas en 1959 figuran con fecha de entrada 16/06/1983.

En el herbario (CTES) del IBONE en Corrientes, se conserva una colección de frutos de maníes de Perú y los ejemplares de herbario de la cosecha 1986/87. Los resultados que se presentan aquí son las conclusiones realizadas desde el año 1979 y completadas con la cosecha 2006/7 En esta última se sembraron solo dos accesiones de cada raza y son las que sirvieron para las ilustraciones del presente trabajo

El Perú junto con Bolivia y Ecuador constituyen centros de variación del maní cultivado muy importantes por la cantidad de razas locales individualizadas. Estos tres países formaron parte del Imperio Incaico. Es digno de señalar que en los países vecinos la variabilidad del maní se reduce drásticamente. 
Tabla 1. Número de razas por países, entre paréntesis número de razas “exclusivas”.

\begin{tabular}{|c|c|c|c|c|c|c|}
\hline \multirow{2}{*}{$\underbrace{\text { País }^{\text {Subespecies }}}_{\text {Variedad }}$} & \multicolumn{2}{|c|}{ hypogaea } & \multicolumn{3}{|c|}{ fastigiata } & \multirow[b]{2}{*}{ Total } \\
\hline & hypogaea & hirsuta & fastigiata & peruviana & aequatoriana & \\
\hline Ecuador & $18(18)$ & $1(1)$ & $12(12)$ & $10(5)$ & $9(7)$ & 50 \\
\hline Perú & $13(12)$ & 2 & $15(14)$ & $15(11)$ & 2 & 47 \\
\hline Bolivia & $42(40)$ & -- & $17(17)$ & 2 & -- & 61 \\
\hline
\end{tabular}

En la Tabla 1, se señalan la cantidad de razas que se cultivan en estos países incaicos.

El gran número de razas de la var. hypogaea en Bolivia, (42), en contraposición a las de Perú (13), y de Ecuador (18) explicaría por qué ésta variedad con más caracteres de las especies silvestres tiene en Bolivia su centro de origen (Seijo et al.2004, Krapovickas, 2004).

Es interesante comparar la cantidad de razas que se han identificado en los tres países andinos, representados en la Tabla 1.

El análisis de las proteínas seminales (Grosso et al. 1988, 1994), muestra que en las dos subespecies el material de Bolivia tiende a separarse de las de los otros dos países andinos, en cambio la separación entre el material peruano y el ecuatoriano no es tan clara en la subespecie hypogaea. En cambio en la subespecie fastigiata en general las variedades botánicas y las procedencias se presentan diferenciadas.

En Perú se han identificado 47 razas pertenecientes a 5 variedades botánicas
(Krapovickas \& Rigoni, 1960, Krapovickas \& Gregory, 1994, 2007) (Fig. 2):

13 Correspondientes a la subsp. hypogaea var. hypogaea

2 a la subsp. hypogaea var. hirsuta

15 a la subsp. fastigiata var. fastigiata

15 a la subsp. fastigiata var. peruviana

2 a la subsp. fastigiata var. aequatoriana

La var. hypogaea está representada por 13 razas, todas menos una, "Rastrero de Huaral", se cultivan en el Oriente o Antisuyo, de las cuales salvo una, “Cojín colorado”,todas son de una sola localidad.

Casi todas las variedades botánicas están representadas con un grado de variabilidad notable, al Este de la cordillera de Los Andes. La única excepción es Arachis hypogaea susbp. hypogaea var. hirsuta, que fue coleccionada solo en la costa del Pacífico, desde Lima hacia el Norte. Esta variedad poco frecuente en la actualidad está presente en casi todos los hallazgos arqueológicos de Argentina y Perú.
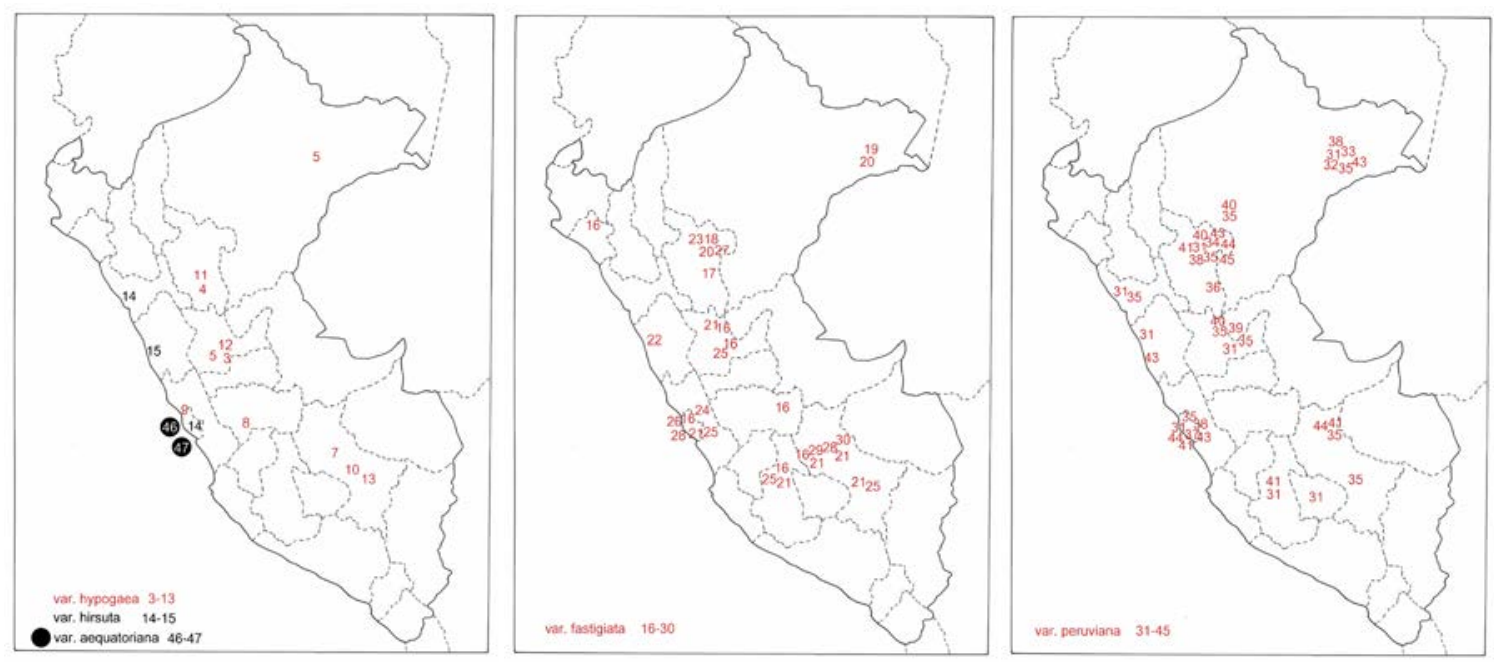

Fig. 2. Distribución geográfica de las razas de Arachis hypogaea de Perú. 
La distribución actual de la variedad hirsuta, se extiende desde Perú a Guatemala y México en América y a través de las cuencas del Pacífico y del Indico hasta Madagascar, coincidiendo en gran medida con la distribución de los Polinesios (Krapovickas, 1995) (Fig. 3).

La var. fastigiata, muestra tres centros de variación, uno en la región de Tarapoto, con cinco razas de las cuales cuatro son exclusivas. En el Sur, hay dos centros, uno en el río Urubamba, Valle de la Convención, y el otro en el río Apurimac, ambos con razas exclusivas.

La var. peruviana es la más difundida en el territorio peruano, con un total de quince razas, casi todas exclusivas, menos dos que también se cultivan en el NE de Bolivia. El centro más importante se encuentra en el área de influencia de Tarapoto, donde se cultivan casi todas las razas. Un segundo centro se encuentra en Iquitos, donde se coleccionaron seis razas, de las cuales dos son exclusivas. Es posible que el maní de Sipan (Alva, 1988), con nervaduras longitudinales sobresalientes y con dos granos, pertenezca a la var. peruviana.

La var. aequatoriana, solamente fue coleccionada en el mercado de Lima.
La formación de este importante banco de germoplasma de maní, fue posible gracias al apoyo de las siguientes instituciones: IBPGR (FAO), USDA (EE.UU.), INTA e IBONE (UNNE-CONICET).

Abreviaturas de los coleccionistas de Arachis en Perú:

Ar. O. Arriola, INIA, Cuzco, Perú.

As. Ashri, Rehovot, Israel.

B. D. J. Banks USDA, U.S.A.

Br. Bartra, Tarapoto, Perú.

Bo. D. Bonavía, Perú.

G. W. C. Gregoryt, U.S.A.

K. A. Krapovickas, IBONE, Corrientes, Argentina.

Ma. B. Mazzani, Maracay, Venezuela.

Mt. A. Martínez, Rioja, Dep. San Martín, Perú.

P. J. R. Pietrarellit, INTA, Manfredi, Córdoba, Argentina.

Sv. G. P. Silva, CENARGEN/EMBRAPA, Brasilia, Brasil.

S. C. E. Simpson, Texas A \& M University, Stephenville, Texas, U.S.A

Tr. L. D. Tripp, Agronomy Department, U.S.A., State University.

Z. H.O. Zurita.

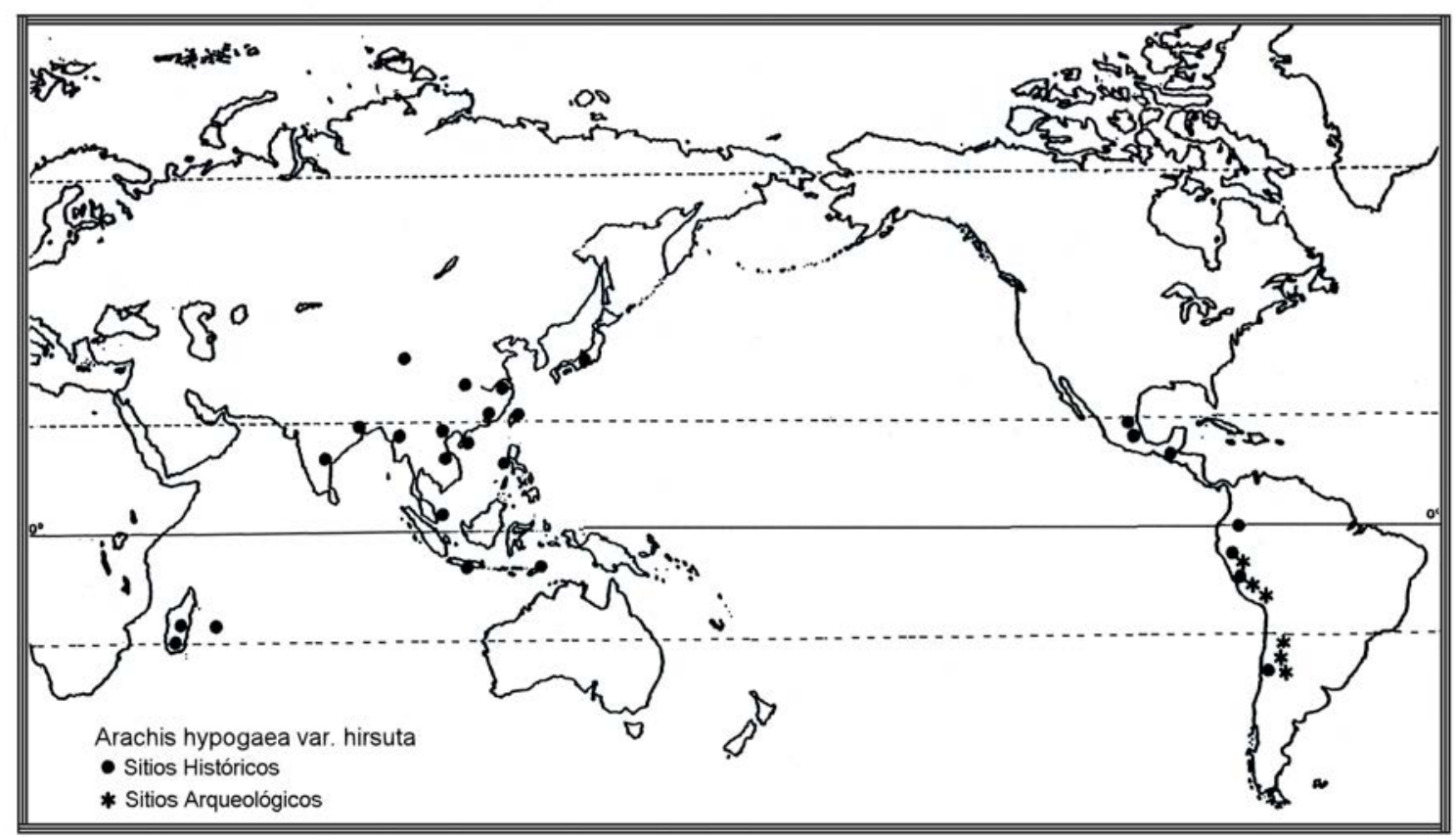

Fig. 3. Distribución de Arachis hypogaea var. hirsuta 


\section{Clave para distinguir los taxones de A. hypogaea L.}

A. Eje central sin flores, ramas $\mathrm{n}+1$ en las que alternan dos ramas vegetativas $\mathrm{y}$ dos reproductivas (ramificación alternada).

B. Folíolos con el envés glabro o con algunos pelos sobre el nervio medio.

subsp. hypogaea

var. hypogaea

B' Folíolos con el envés con pelos de 1 a 2 mm long., esparcidos en toda la superficie.

var. hirsuta

$\mathrm{A}^{\prime}$ Eje central con flores y ramas laterales en las que las ramas reproductivas y vegetativas no presentan ningún orden (ramificación secuencial).

C. Folíolos con el envés glabro o con pelos solamente sobre el nervio medio.

subsp. fastigiata

D. Frutos con el retículo suave o algo marcado, sin que se destaquen las costillas longitudinales. Ramas reproductivas por lo común breves y delgadas.

var. fastigiata

D’ Frutos siempre con retículo muy marcado y con costilas longitudinales sobresalientes. Ramas reproductivas largas 5-10 cm long., robustas, tanto en el eje central como en las ramas laterales.

var. peruviana

C`Folíolos con el envés con pelos de 1 a 2 mm long., esparcidos en toda la superficie. Ramas reproductivas largas, principalmente en las ramas laterales. Eje central por lo común con inflorescencias o ramas reproductivas breves.

var. aequatoriana

\section{Clave de las razas de maní de Perú}

\section{Arachis hypogaea L. subsp. hypogaea var. hypogaea}

A. Granos morados. Cajas de 2 granos, gruesas, cortas, redondeadas, irregulares, 3-4 cm long. x 1,7-2,2 cm lat., sin pico y sin constricción. "Bunch”, eje central no aparente. Estípulas sin cerdas.

1. Morado gigante

A’ Granos colorados.

B. Cajas por lo común de 2 granos (raro 3).

C. "Bunch", grande, eje central no aparente.

D. Cajas gruesas, cortas, redondeadas, irregulares, 3-4 cm long. x 1,7-2,2 cm lat., sin pico y sin constricciones. Estípulas con cerdas.

2. Rojo gigante

D’Cajas más delgadas, 2,8-3,5 cm long. x 1,4-1,6 cm lat., con pico y con frecuencia , con constricción. Estípulas sin cerdas.

3. Colorado de Huánuco

C' Plantas rastreras o cojines bajos.

E. Cajas cortas, redondeadas, sin pico y sin constricción, 2,5-3,3 cm long. x 1,3-1,7 cm lat. Eje central aparente. Estípulas con cerdas.

4. Huallaga

E'Cajas alargadas, con pico y con constricción, 2,5-3,5 cm long. x 1,2-1,7 cm lat. Eje central no aparente. Estípulas sin cerdas.

5. Cojín colorado 
B' Cajas con frecuencia con 3 granos (las cajas de 3 granos de 4-5,2 cm long. x 1,5-1,7 cm lat.). Plantas rastreras con eje central aparente. Estípulas con cerdas.

F. Follaje verde claro durante todo el ciclo. Cajas redondeadas, sin pico y sin constricción; dorso algo ondulado; nervaduras longitudinales hendidas.

6. Colorado rastrero verde claro

F' El follaje se aclara al final del ciclo. Cajas redondeadas, con pico pequeño; dorso algo ondulado; el tercer grano puede presentar constricción; nervaduras longitudinales no manifiestamente hendidas

7. Colorado rastrero La Convención

A" Granos salmón. Plantas rastreras.

G. Cajas con frecuencia con 3 granos, con constricción, con pico con carena dorsal y apical sobresaliente y nervaduras longitudinales algo más marcadas. Planta desparramada, eje central muy aparente. Estípulas con cerdas.

8. Rastrero grande de Huánuco

G' Cajas por lo común de 2 granos (raro 3), con constricción suave, con pico, sin carena dorsal; retículo suave, uniforme. Plantas rastreras compactas, casi cojines; eje central algo aparente. Estípulas sin cerdas.

9. Rastrero de Huaral

A"' Granos bicolores

H. Granos colorado y albo, el colorado en manchas.

J. Plantas rastreras. Cajas con frecuencia de 3 granos, de 3,0-5,0 cm long. x 1,4-1,7 cm lat., redondeadas, casi sin pico y con nervaduras longitudinales hendidas. Estípulas con cerdas.

10. Overo rastrero

J' Plantas erectas (bunch). Cajas de 2 granos (raro 3), con nervaduras longitudinales no hendidas.

$\mathrm{K}$. Cajas redondeadas, casi sin constricciones, de 2,5-3,5 cm long. x 1,5-2,0 cm lat., sin pico y con carena apical pequeña. Estípulas con cerdas.

11. San Martín

K' Cajas con constricción marcada, de 3,0-4,0 cm long. x 1,5-1,7 cm lat., con pico pequeño y carena apical grande. Estípulas sin cerdas.

12. Overo de Huánuco

H’Granos pálidos con vetas coloradas

13. Rastrero veteado

\section{Arachis hypogaea L. subsp. hypogaea var. hirsuta Köhler}
A. Granos morados 14. Criollo Trujillano
A’. Granos pálidos 15. Criollo Blanco de Casma

\section{Arachis hypogaea L. subsp. fastigiata Waldron var. fastigiata}

A. Granos colorados.

B. Ramas $\mathrm{n}+1$ con ramas reproductivas solamente.

C. Estípulas con cerdas. Cajas de 3-4 granos, reticuladas, con jorobas y carena apical, con pico algo marcado.

D. Cajas gruesas. Granos grandes.

D’ Cajas delgadas. Granos menores.

16. Colorado limeño

17. Rojo Huayabamba 
C'Estípulas sin cerdas.

E. Granos colorados con líneas o vetas más oscuras. Cajas reticuladas.

E' Granos de color uniforme.

18. Colorado con vetas

F. Cajas pequeñas, lisas, de 1-2 (raro3) granos. Planta baja de ramas rastreras.

F' Cajas poco reticuladas, con 3-4 granos.

19. Colorado de Iquitos

20. Colorado Tarapoto

B' Ramas $n+1$ con ramificaciones vegetativas $(n+2)$.

G. Planta bien desarrollada. Eje central aparente. Estípulas con abundantes cerdas.

H. Planta erecta.

21. Colorado La Convención

H' Planta decumbente.

22. Italiano de Casma

G’ Planta más pequeña. Eje central poco aparente. Estípulas con pocas cerdas. Hojas más amarillentas.

23. Copallín Tarapoto

A' Granos rosados. Ramas $n+1$ no ramificadas. Estípulas con cerdas.

24. Rosado Limeño

A" Granos pálidos.

I. Ramas $\mathrm{n}+1$ no ramificadas.

J. Clavo verde. Estípulas con cerdas.

J' Clavo violáceo.

25.Pálido clavo verde

K. Estípulas con cerdas. Cajas poco reticuladas, más o menos grandes, con pico poco marcado.

26. Pálido limeño

$\mathrm{K}^{\prime}$ Estípulas sin cerdas. Cajas reticuladas, con pico bien marcado, más o menos chicas, con 2-3 granos.

27. Pálido con pico

I' Ramas $\mathrm{n}+1$ com ramificaciones vegetativas $(\mathrm{n}+2)$. Estípulas con cerdas.

L. Planta abierta. Eje central aparente.

28. Pálido La Convención

L' Planta compacta, más ramificada. Eje central no aparente.

29. Pálido compacto

A"' Granos albos. Ramas $n+1$ con ramificaciones vegetativas.

30. Albo Quillabamba

\section{Arachis hypogaea L. subsp. fastigiata Waldron var. peruviana Krapov. \& W.C. Gregory}

A. Granos bicolores.

B. Granos pálidos con líneas cortas violáceas. Clavos verdes.

31. Tingo María

B’ Granos violáceos a pálidos, con manchas apicales más oscuras (la intensidad y extensión del violáceo varía). Clavo morado.

C. Estípulas sin cerdas. Eje central aparente, ramas decumbentes. Cajas por lo común hasta $4 \mathrm{~cm}$ long. (raro hasta $4,5 \mathrm{~cm}$ ), sin pico y sin jorobas.

32. Jaspeado sin cerdas 
C’Estípulas con cerdas. Eje central poco aparente, ramas casi erectas. Cajas con frecuencia hasta 5 cm long.(raro hasta 7,5 cm), con pico y jorobas.

33.Jaspeado con cerdas

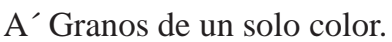

D. Granos blancos (albos). Estípulas sin cerdas. Clavos verdes.

34. Blanco marfil

D’ Granos pálidos. Clavos verdes.. Cajas por lo común no pasan de 4 cm long.

35. Blanco Tarapoto

D"' Granos violáceos.

F. Planta grande, eje central muy desarrollado y notable. Brote violáceo (pecíolo y envés de los folíolos).

G. Tallo verde. Cajas sin pico ni carena.

G’ Tallo violáceo. Cajas con pico y carena.

36. Morado Huayabamba

37. Negro grande

$\mathrm{F}^{\prime}$ Planta menor, el eje central aparente a poco aparente. Brote verde o a penas violáceo en el nervio medio de los folíolos plegados.

H. Estípulas sin cerdas.

I. Cajas menores de $4 \mathrm{~cm}$ long., sin pico.

I' Cajas menores, con pico.

38. Morado de Iquitos

39. Negro de Aucayacu

$\mathrm{H}^{\prime}$ Estípulas con cerdas.

J. Cajas hasta $4 \mathrm{~cm}$ long., sin pico.

K. Planta más ramificada, compacta. Eje central algo aparente.

41. Negro Tarapoto

$\mathrm{K}^{\prime}$ Planta poco ramificada (pocas $\mathrm{n}+1$ vegetativas). Eje central aparente.

40. Negro de pocas ramas

J' Cajas hasta $5 \mathrm{~cm}$ long., con jorobas, carena y pico.

L. Eje central no aparente. Planta muy ramificada, compacta, erecta.

42. Yungas

L’ Eje central aparente.

M. Planta bien ramificada, compacta; eje central algo aparente.

N. Planta compacta, ramificada, eje central aparente.

44.Catalán

N' Planta poco ramificada, eje central alto, aparente.

43.Catalán planta abierta

$\mathrm{M}^{\prime}$ Planta poco ramificada. Eje central aparente.

45. Negro erecto

\section{Arachis hypogaea L. subsp. fastigiata Waldron var. aequatoriana Krapov. \& W. C. Gregory}

A. Granos violáceos, punta clara. Planta semierecta.

46. Zaruma

A’ Granos negros. Planta semirastrera.

47. Huasquillo 


\section{1.- Morado gigante}

Planta: erecta, compacta (bunch). Eje central no aparente. Estípulas sin cerdas.

Cajas: grandes, gruesas, cortas, redondeadas, irregulares, sin pico y sin constricción. Dos granos con tegumento morado, casi negro.

Obs. Cajas muy parecidas a las del Rojo Gigante, pero con nervaduras longitudinales más prominentes y agudas.
Manfredi 07/08 2001
87/ 2622
PI 393525
La Molina

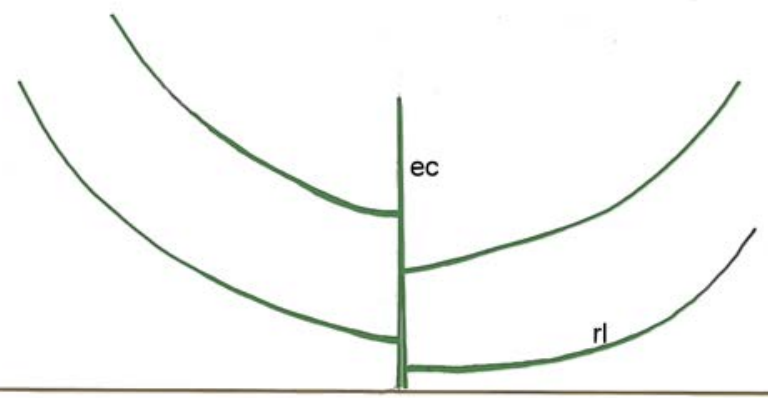

$\sqrt{0} \begin{aligned} & 0 \\ & \exists\end{aligned}$

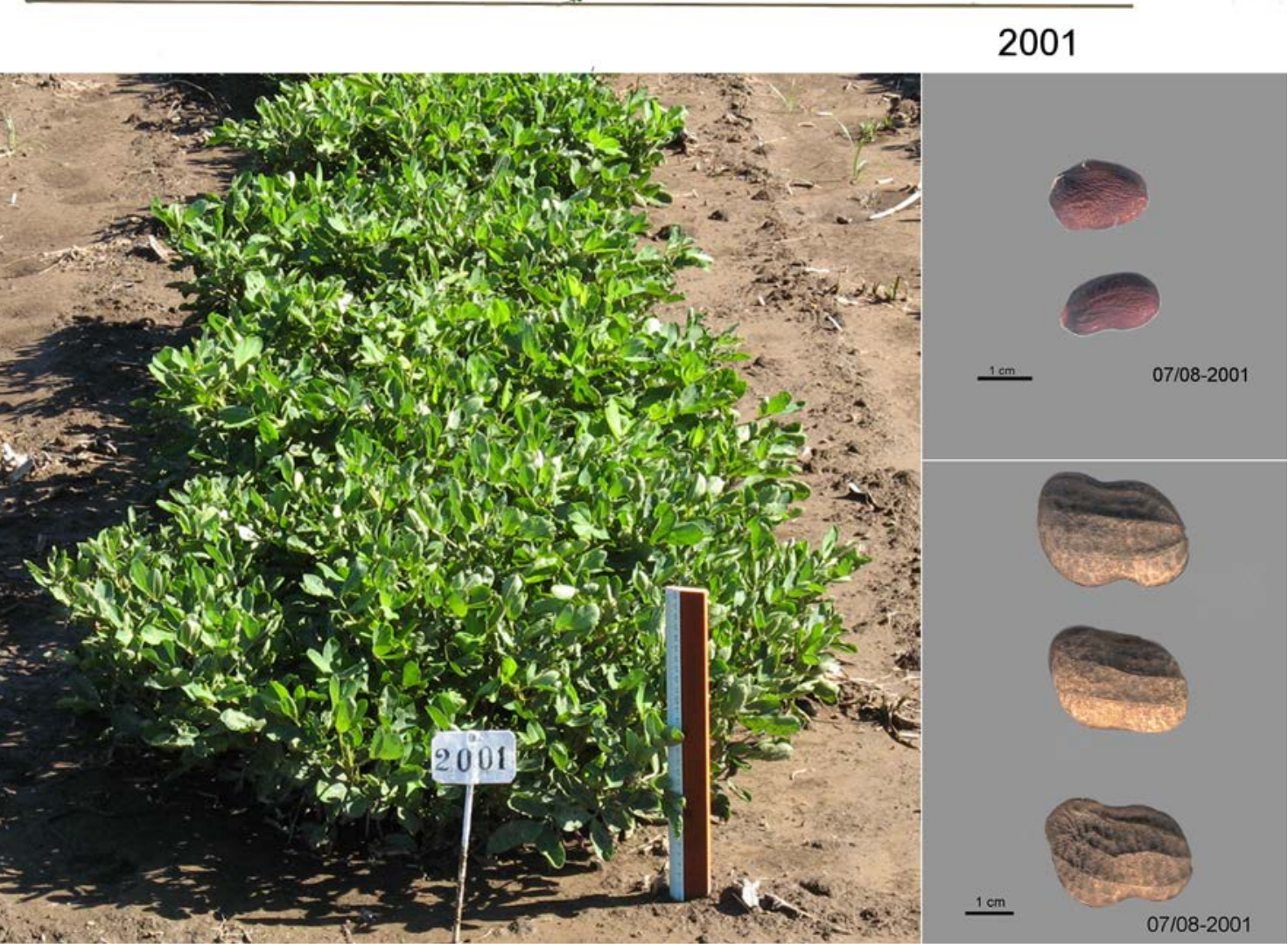




\section{2.- Rojo gigante}

Planta : erecta, compacta, (bunch), grande. Eje central no aparente. Estípulas con cerdas.

Cajas: Redondeadas, sin pico, sin constricción, con carena apical pequeña; retículo grueso, más o menos marcado. Granos 1-2 (raro 3), con tegumento colorado.
Manfredi 07/08 2002
$87 / 2624$
PI 393527
La Molina

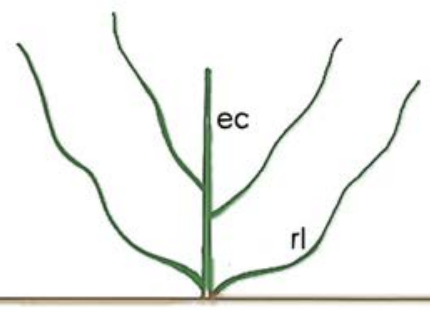

] $\begin{aligned} & \overrightarrow{0} \\ & 3\end{aligned}$

\section{2}

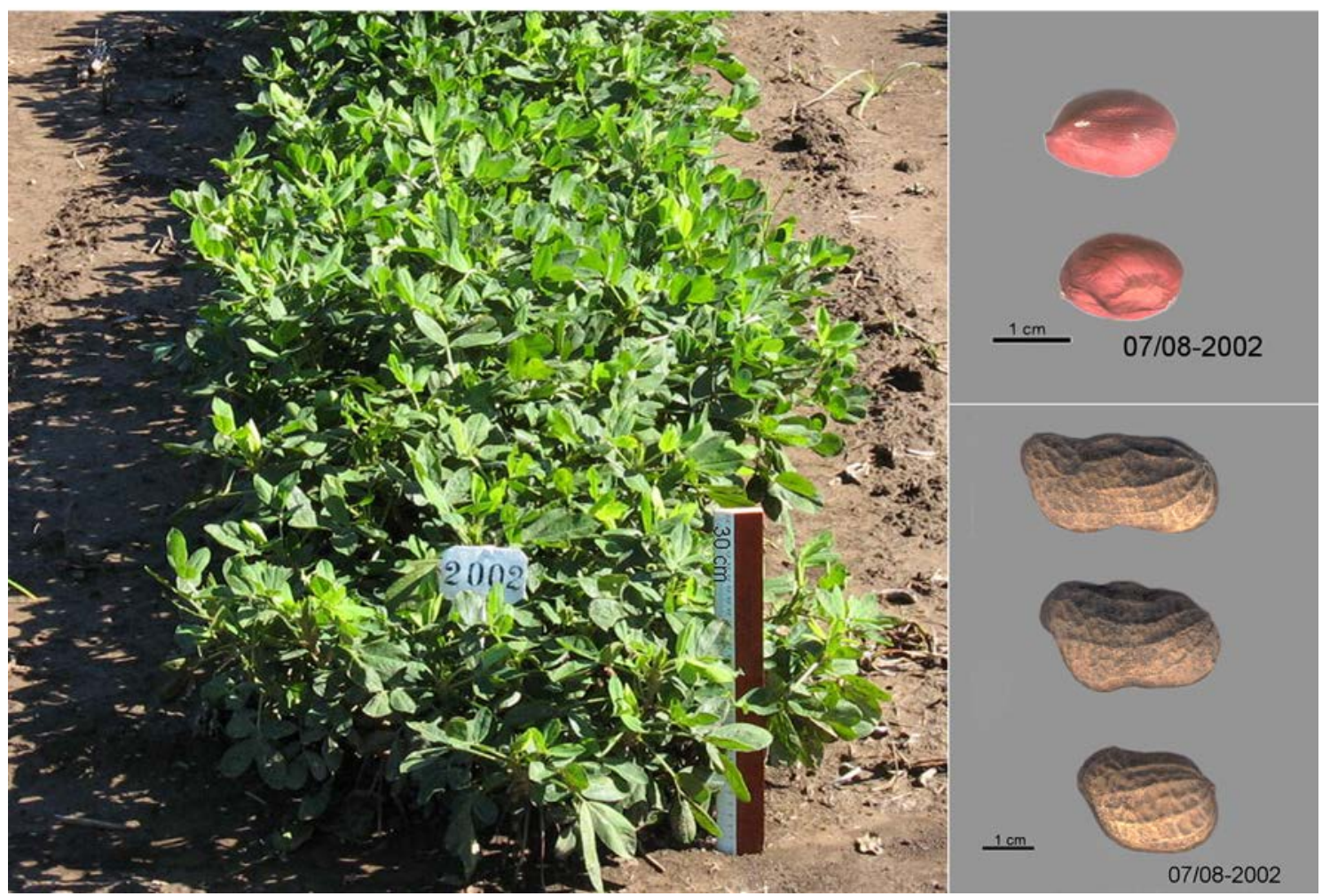




\section{Colorado de Huánuco}

Planta: erecta, grande, muy ramificada, algo desparramada, abierta. Eje central no aparente, a veces con algunas flores. Ramas $n+1$ con alternancia de 2 vegetativas y 2 reproductivas. Ramas $\mathrm{n}+2$ con muchas reproductivas. Estípulas sin cerdas.

Cajas: con frecuencia con constricción, con pico pequeño, con carena apical y dorsal, retículo más o menos uniforme, con nervaduras agudas. Con dos granos, con tegumento colorado fuerte.
Manfredi 07/08 2003
87/2623
US-462
Huánuco
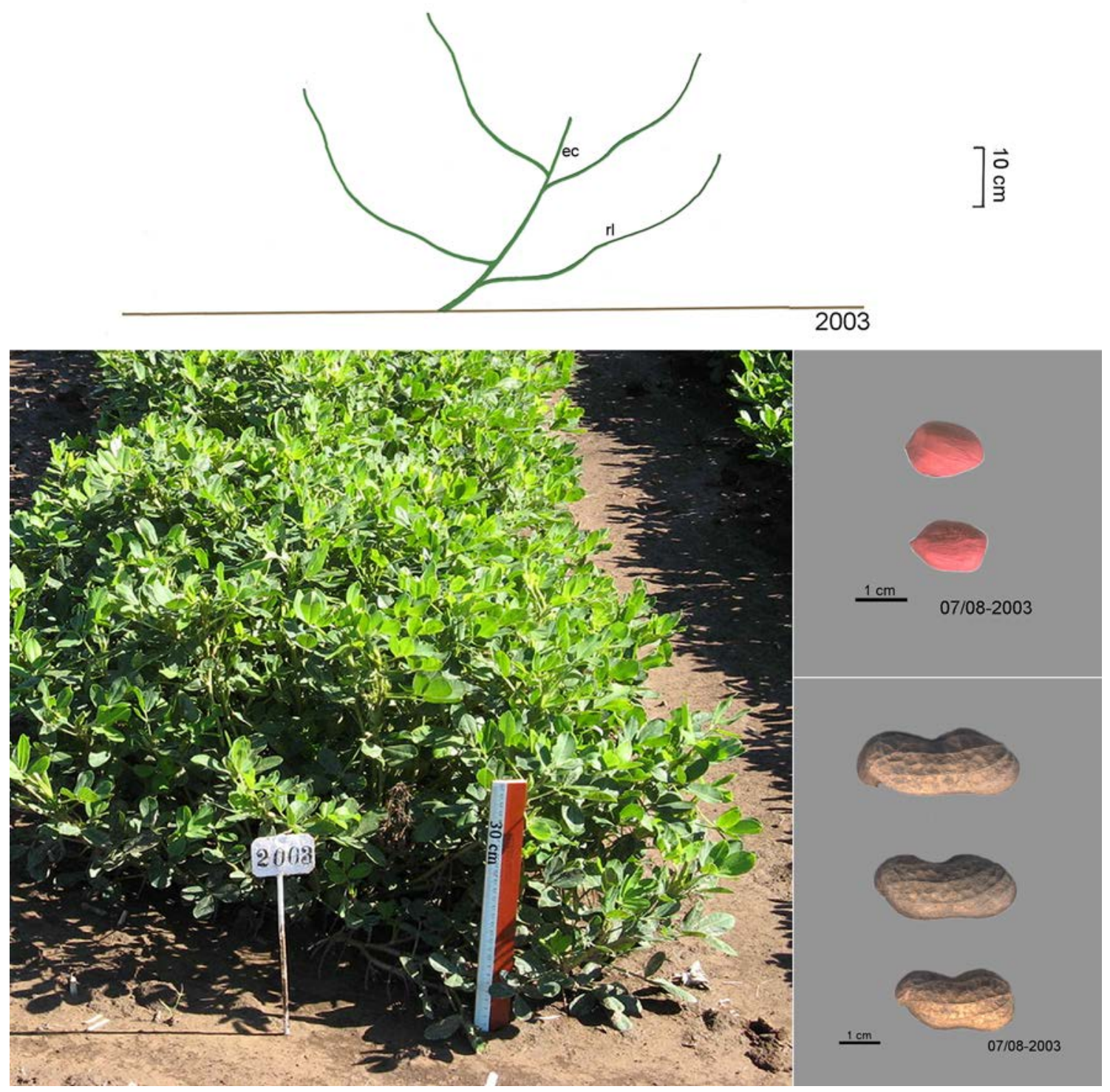


\section{Huallaga}

Planta: rastrera, compacta. Eje central aparente. Estípulas con cerdas.

Cajas: Redondeadas, levemente estranguladas, sin pico, con carena apical pequeña, retículo poco marcado, suave. Dos granos con tegumento colorado.
Manfredi 07/08
2006
$87 / 2601$
PI-393522
La Molina

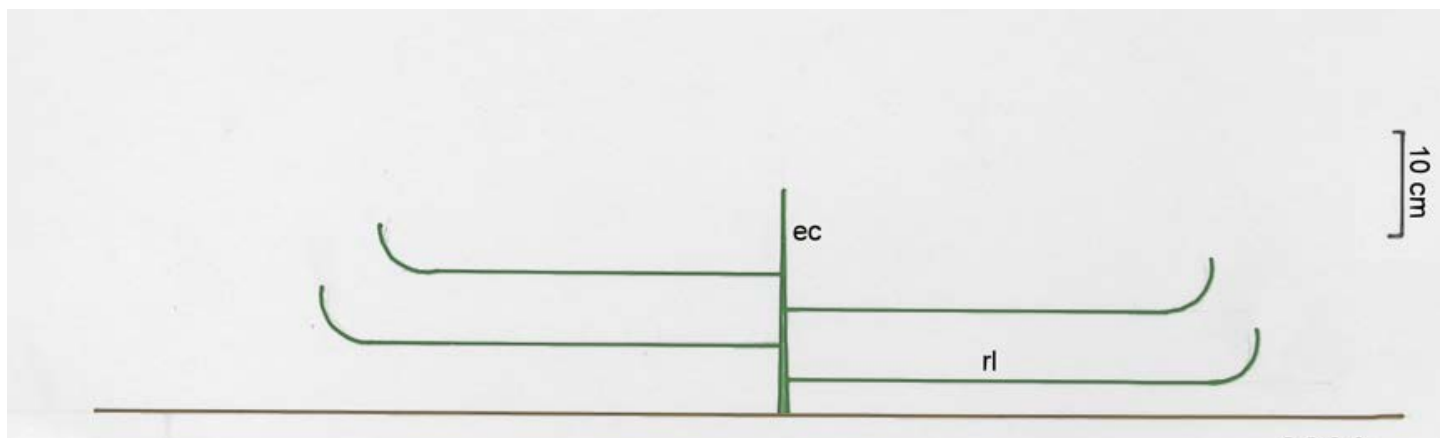

2006

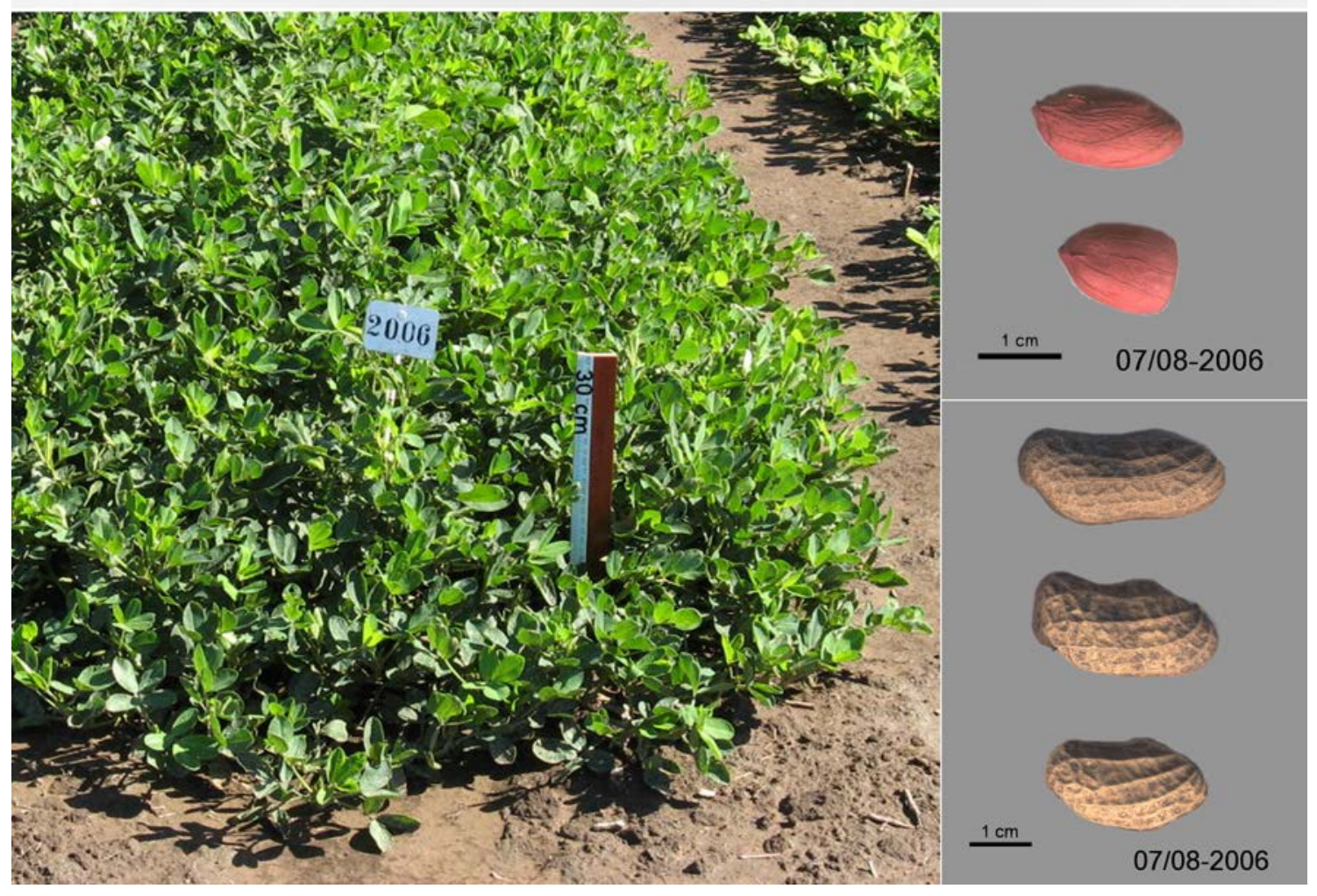




\section{Cojin colorado}

Planta: cojin compacto. Eje central no aparente. Estípulas sin cerdas.

Cajas: con constricción, con pìco y carena apical poco marcada; retículo suave, con relieve. Con 2 (raro 3), granos, con tegumento colorado.
Manfredi 07/08 2004
$87 / 2615$
US-499
Iquitos
Manfredi 07/08 2005
$87 / 2610$
US-464
Huánuco

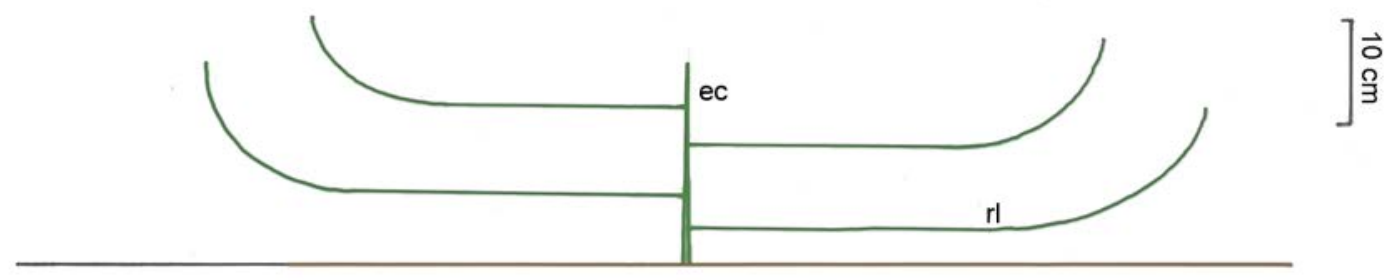

2005

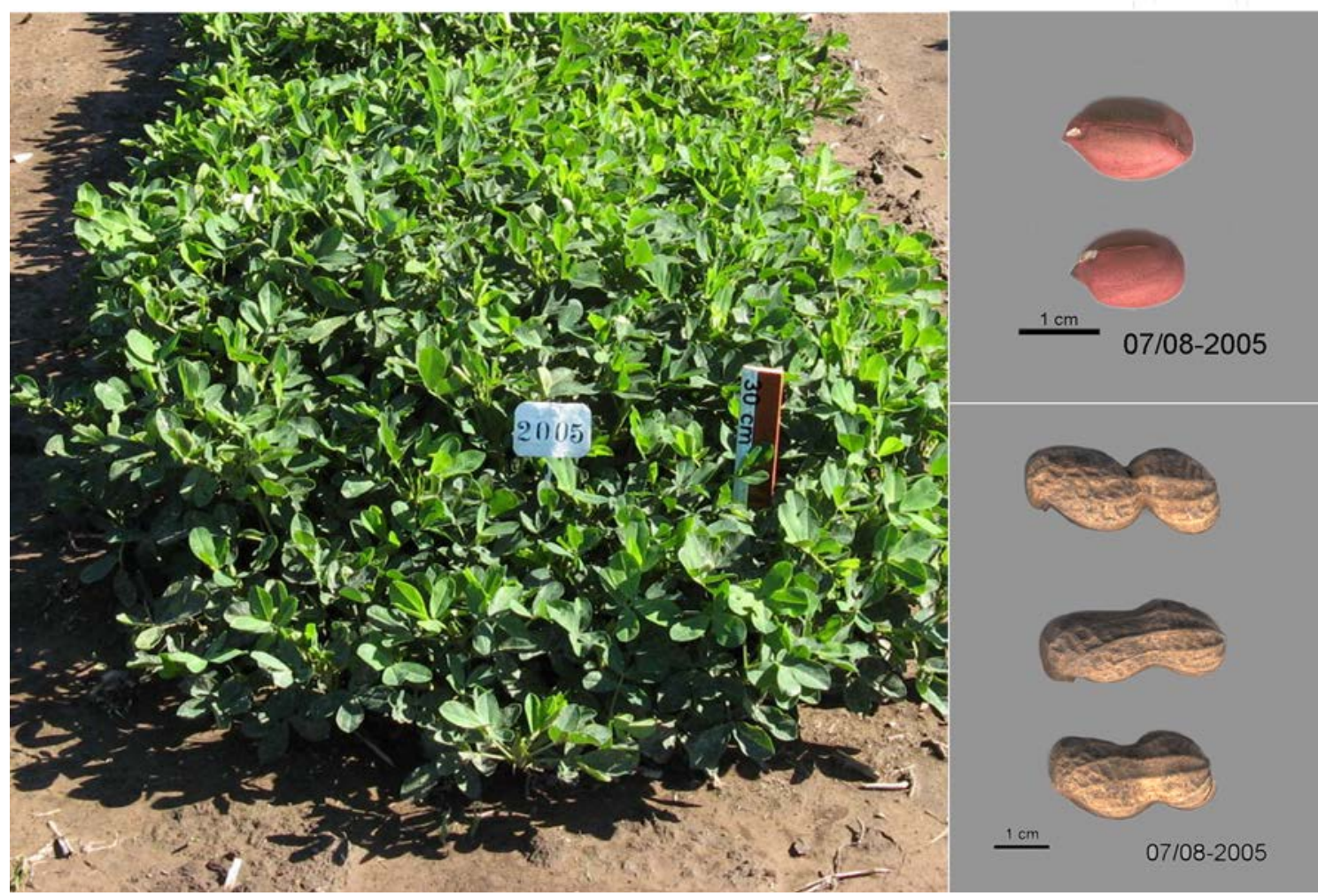

87/2609

US 463

Huánuco 


\section{Colorado rastrero verde claro}

Planta: rastrera, compacta. Eje central aparente. Follaje verde claro durante todo su crecimiento. Estípulas con cerdas.

Cajas: redondeadas, sin cosntricciónes, sin pico y sin carena; dorso algo ondulado; nervaduras longitudinalmente hendidas. Con 2-3 granos con tegumento colorado fuerte.
Manfredi 07/80 2007
$87 / 2607$
59/419 1422 K 1955
Lima

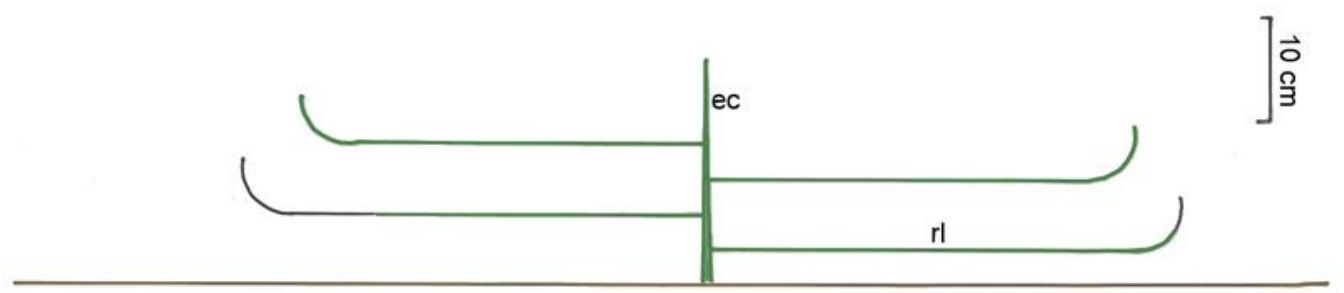

2007

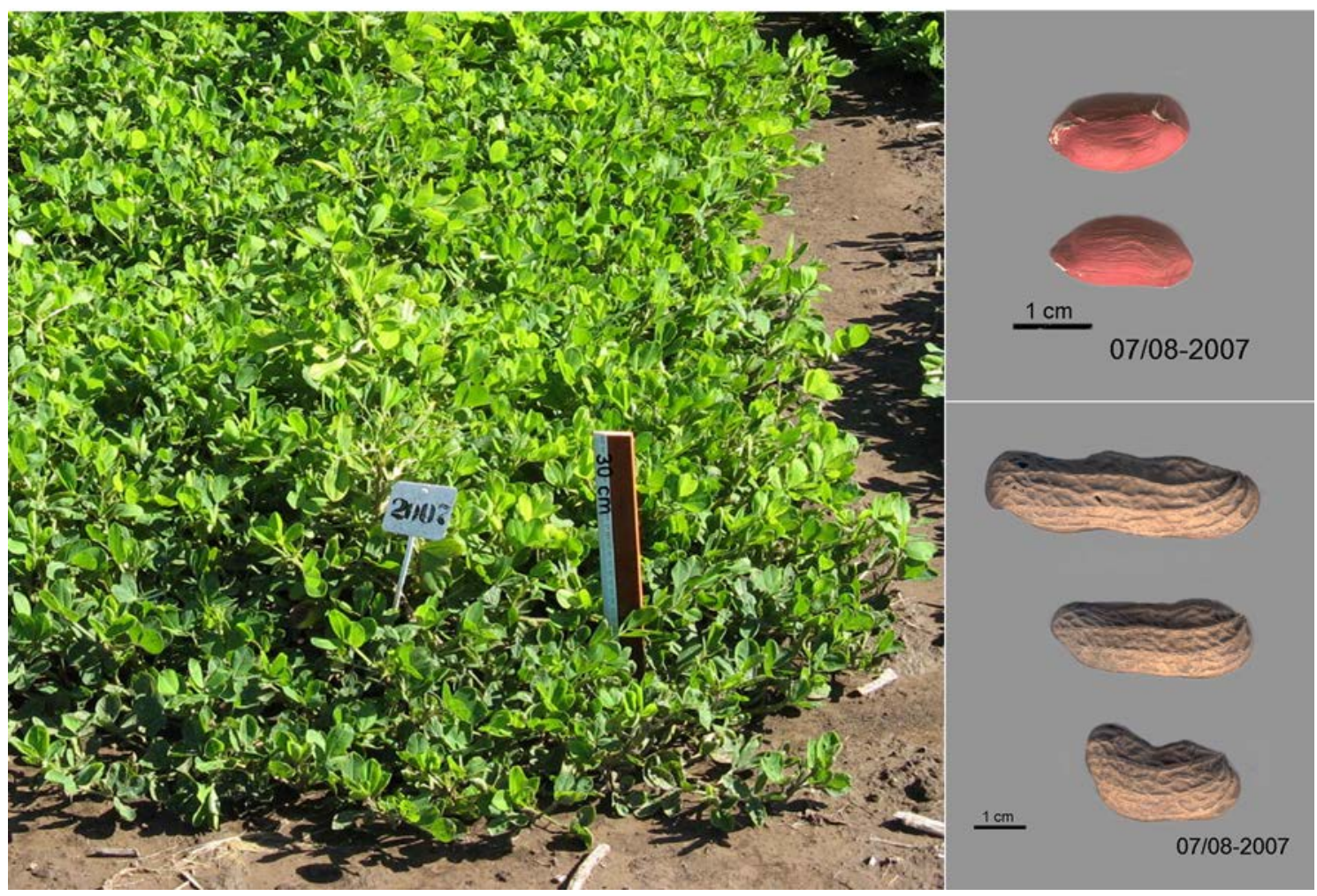

Obs: Las cajas son muy parecidas a las del “ Colorado rastrero La Convención”. 


\section{Colorado rastrero La Convención}

Planta: semirastrera, compacta. Eje central aparente. Estípulas con cerdas.

Cajas: redondeadas, sin carena, con pico pequeño, dorso algo ondulado; retículo suave, nervaduras longitudinales algo hendidas. El tercer grano puede presentar constricción. Con 2-3 -4 granos, con tegumento colorado fuerte.
Manfredi 07/08 2008
$-87 / 2602$
US-406
Cuzco
Manfredi 07/08 2009
$87 / 2603 / 4$
US-422
E.E.Sahuayaco

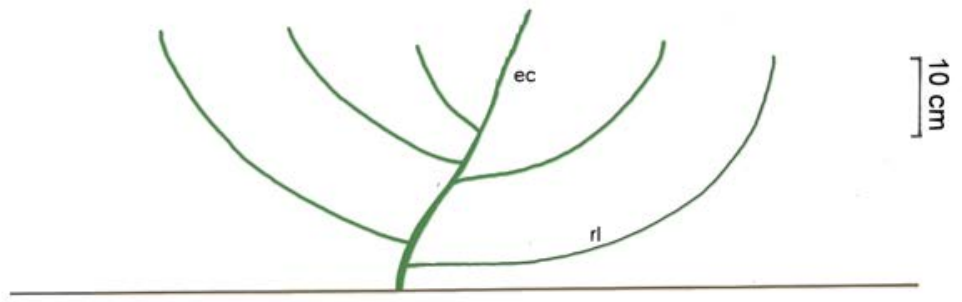

2008
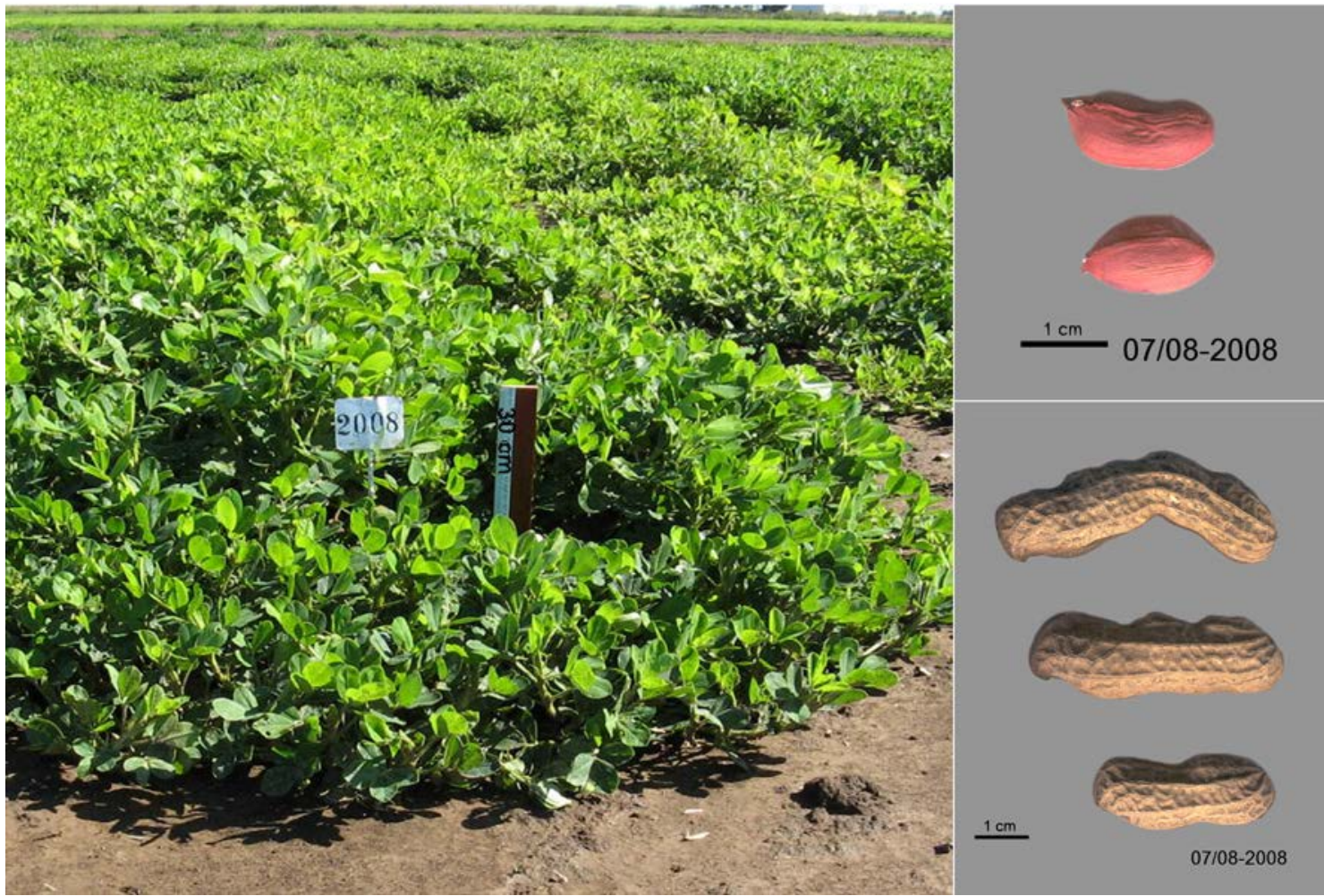

$87 / 2606$

US 417

$87 / 2605$

K1(1982)

Chirumbia

Cuzco 


\section{Rastrero grande de Huánuco}

Planta: rastrera a semirastrera, desparramada. Ramas sinuosas. Tallo violáceo. Eje central muy aparente. Estípulas con cerdas.

Cajas: con constricción, con pico, con carena apical y dorsal, con jorobas; retículo sobresaliente, nervaduras longitudinales algo más marcadas. Con 2-3 granos, con tegumento salmón oscuro.
07/08-2010 87/2608
US-461
Huánuco

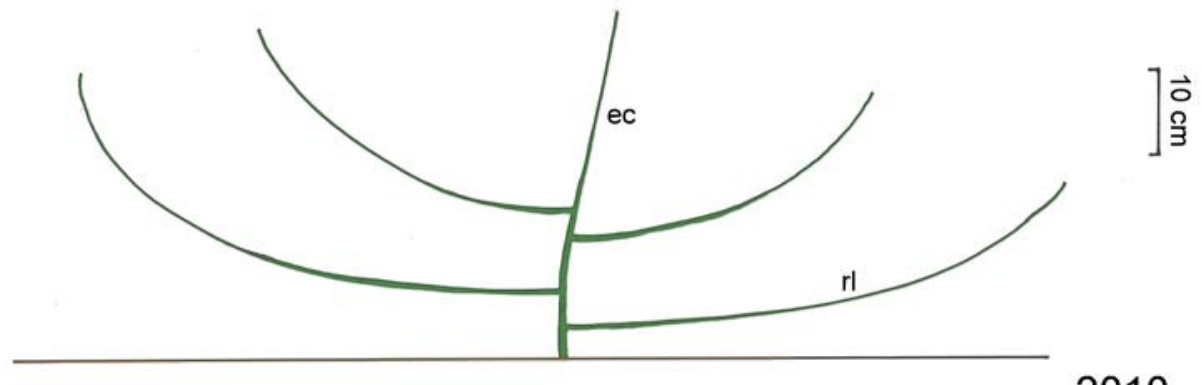

\section{0}

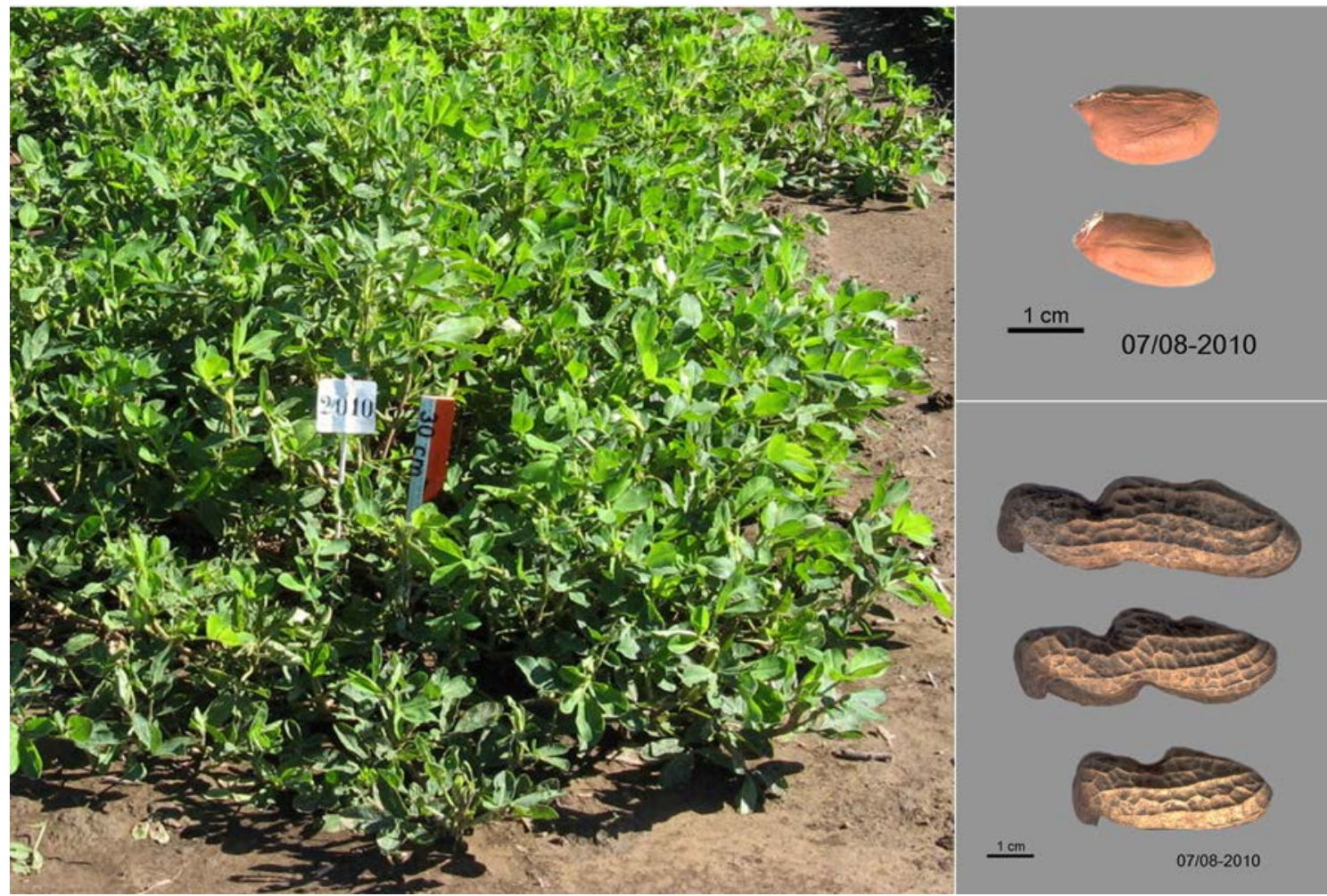

Obs. El follaje es algo más claro que en el resto de la var. hypogaea, pero no tanto como el "Colorado rastrero verde claro". 


\section{Rastrero de Huaral}

Planta: rastrera. Eje central algo o no aparente. Estípulas sin cerdas.

Cajas: con constricción, con pico y carena apical algo marcados; retículo suave, 2-3 granos con tegumento salmón
Manfredi 07/08 2011
$87 / 2611$
RCM-1409
K 1955 Huaral
Manfredi 07/08-2012
$87 / 2613$
RCM-1410
K 1955 Lima

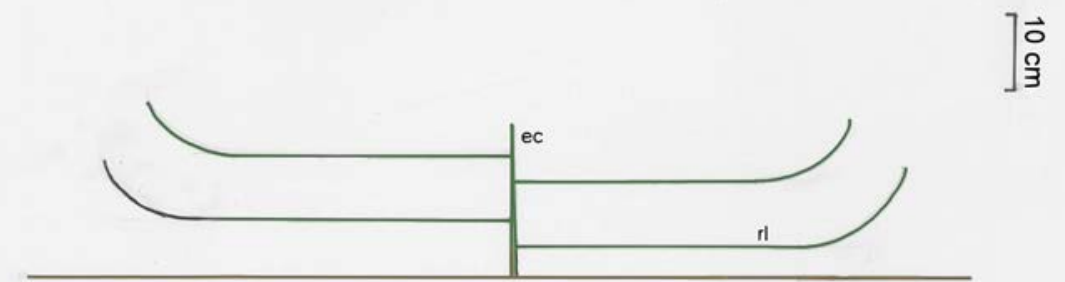

2012

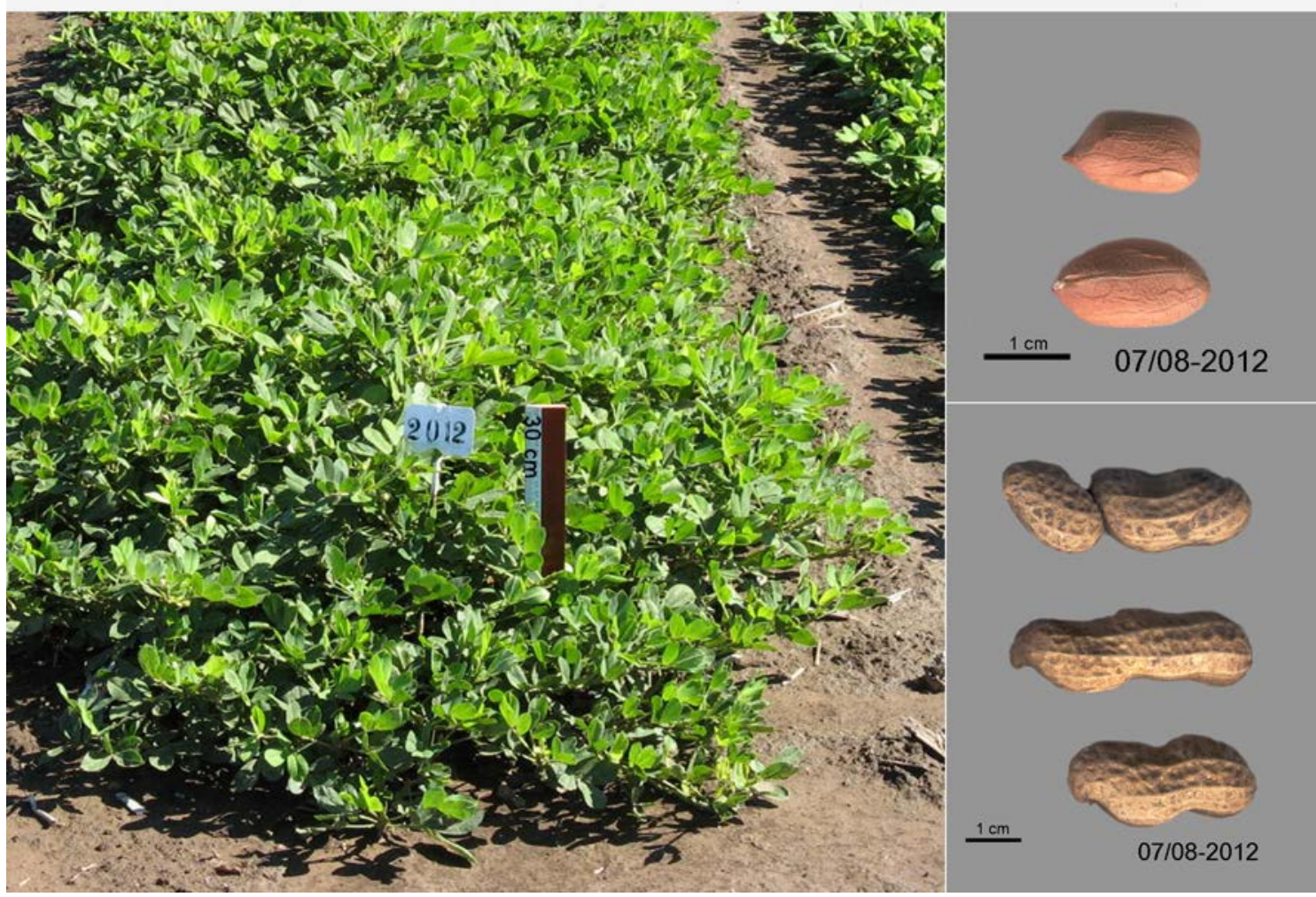

$87 / 2614$

RCM $1411 \quad \mathrm{~K}(1955)$

Lima 


\section{Overo rastrero}

Planta: rastrera. Eje central bien aparente. Estípulas con cerdas.

Cajas: redondeadas, con pico marcado, con carena apical y con jorobas suaves; retículo suave, nervaduras longitudinales hendidas. Con 2-3 granos. Tegumento albo con líneas rojas.
Manfredi 07/08 2013
$87 / 2616$
K-2 (1982)
Cuzco

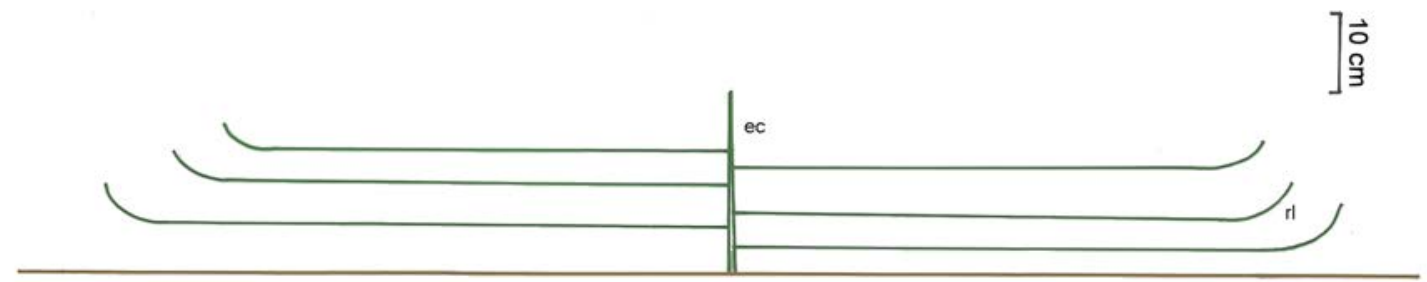

2013

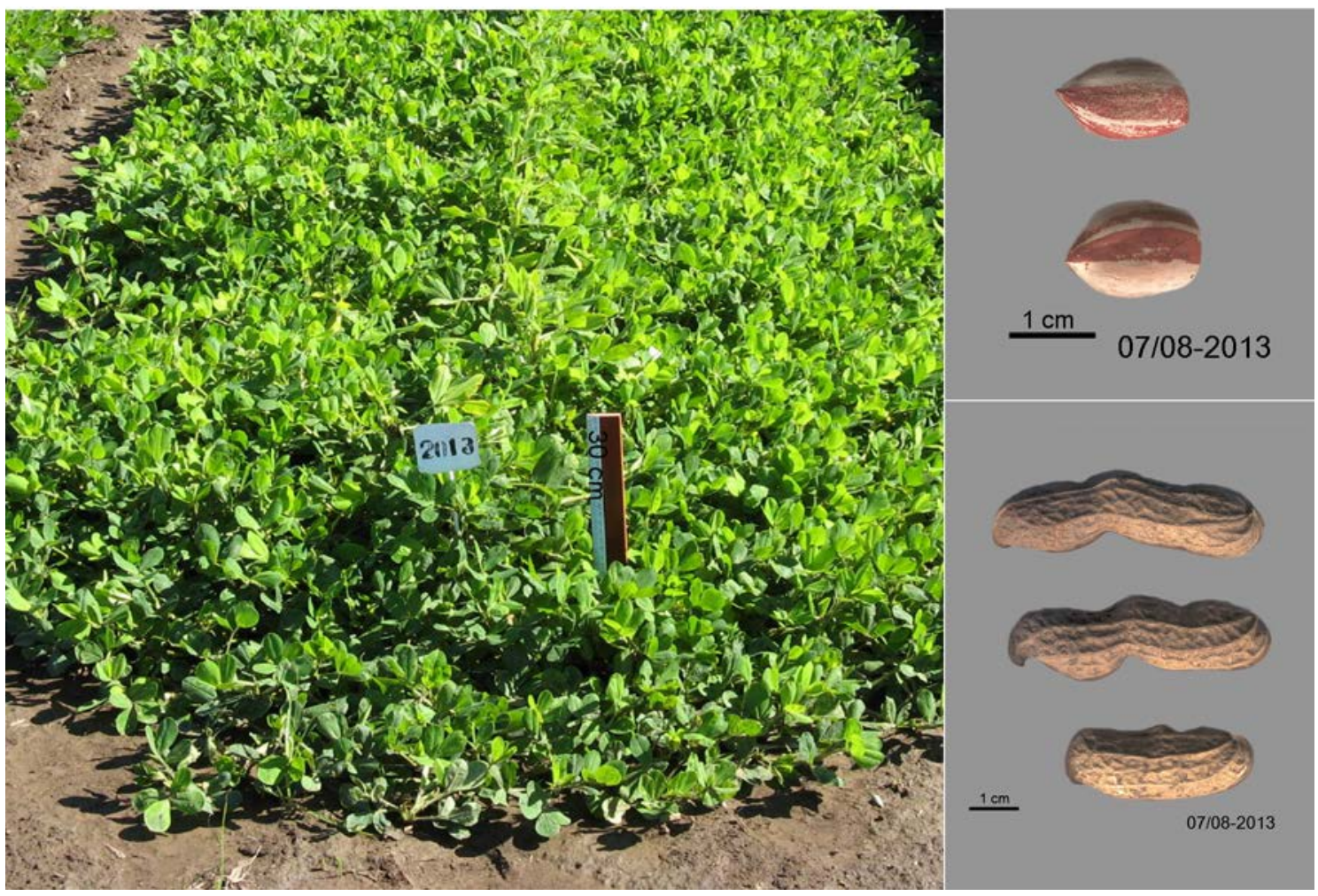




\section{San Martin}

Planta: “Bunch”, grande a cojín, compacta. Eje central no aparente. Estípulas con cerdas.

Cajas: redondas, casi sin constricción, con pico, con carena apical pequeña; retículo suave. Con 2 (raro 3) granos, con tegumento colorado y albo.
Manfredi 07/08 2014
$87 / 2621$
PI-393529
La Molina

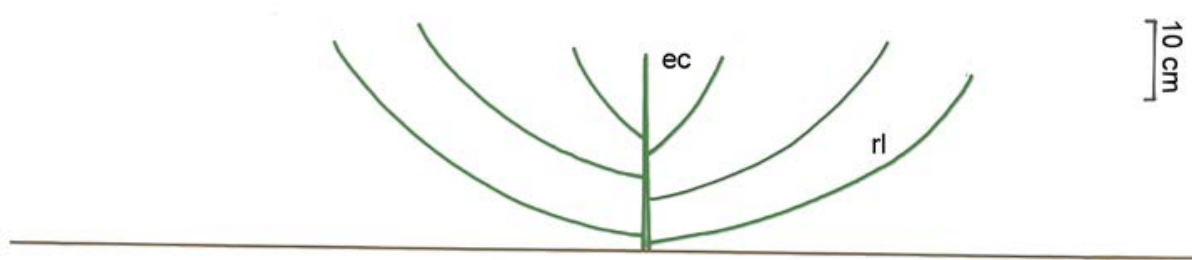

2014

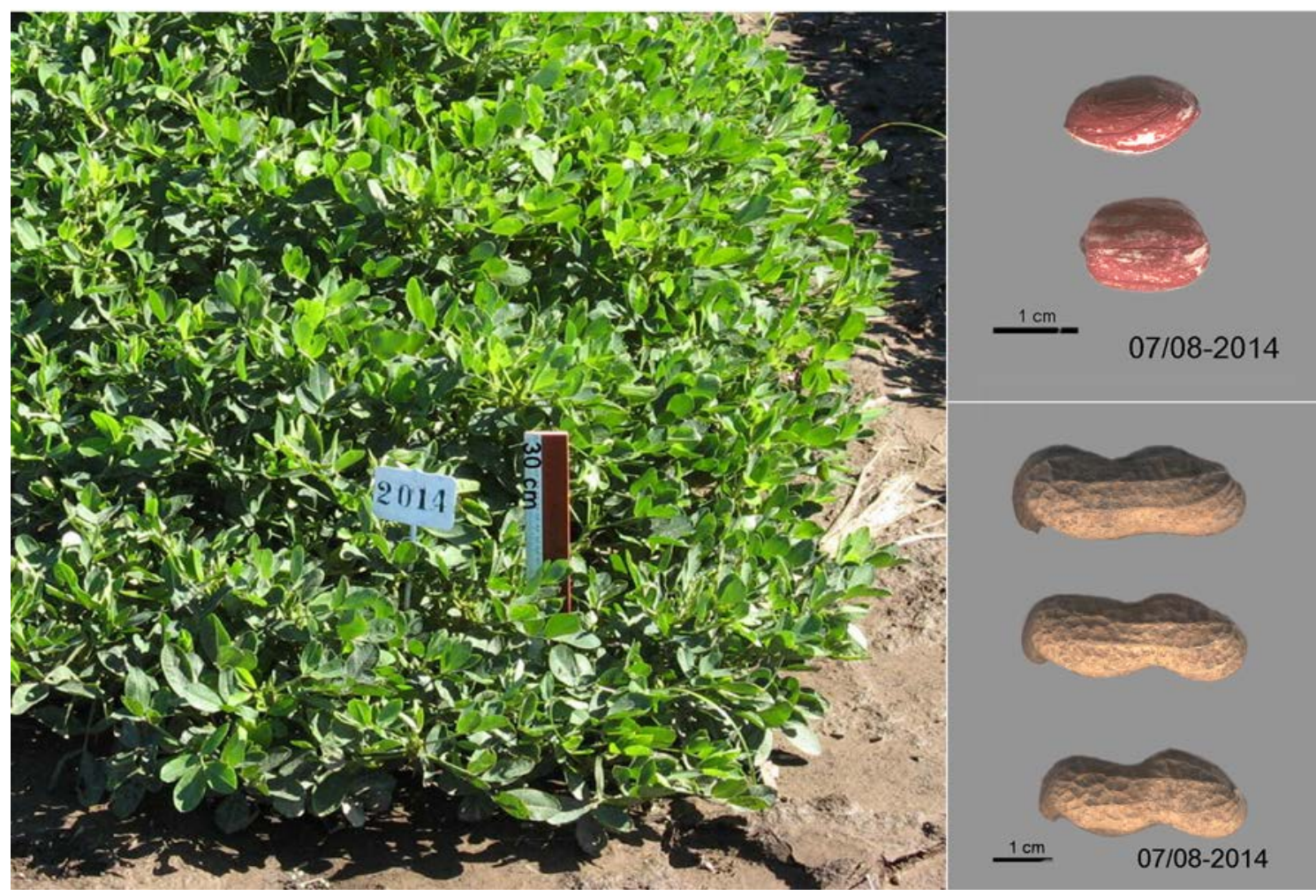




\section{Overo de Huánuco}

Planta: "Banch", algo desparramada. Eje central algo o no aparente, a veces con algunas flores. Estípulas sin cerdas.

Cajas: con constricción marcada a muy marcada, 3,0-4,0 cm long.x 1,5-1,7 cm lat. con carena apical grande, con pico pequeño o sin éste; retículo suave. Con 2 (raro 3) granos. Tegumento albo y colorado.
Manfredi 07/08 2015
$87 / 2617$
US-462
Huánuco

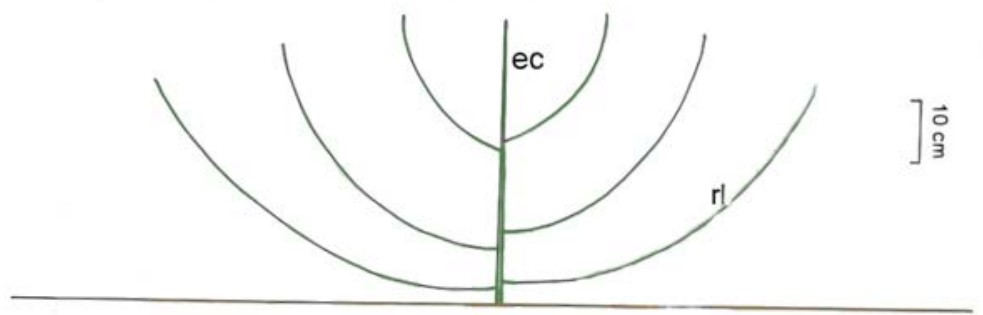

\section{5}

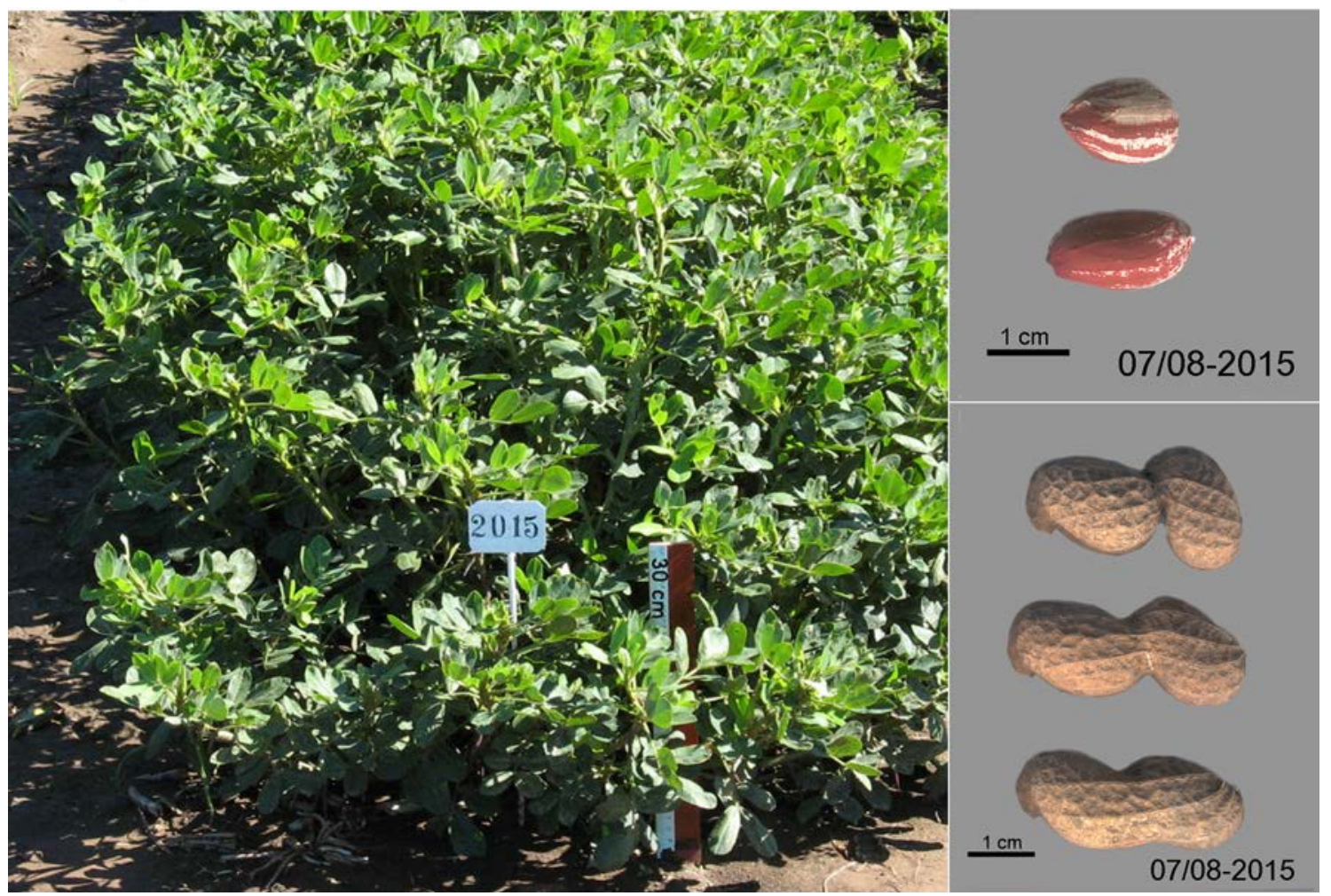




\section{Rastrero veteado}

Se perdió.

\section{Criollo Trujillano}

Planta: semirastrera, eje central erecto (40 cm long.) a ca. $1 \mathrm{~m}$ long., tendido,. Tallos violáceos, ramas sinuosas. Flor con estandarte morado, alas moradas en el ápice.

Cajas: 3-4 granos violáceos.

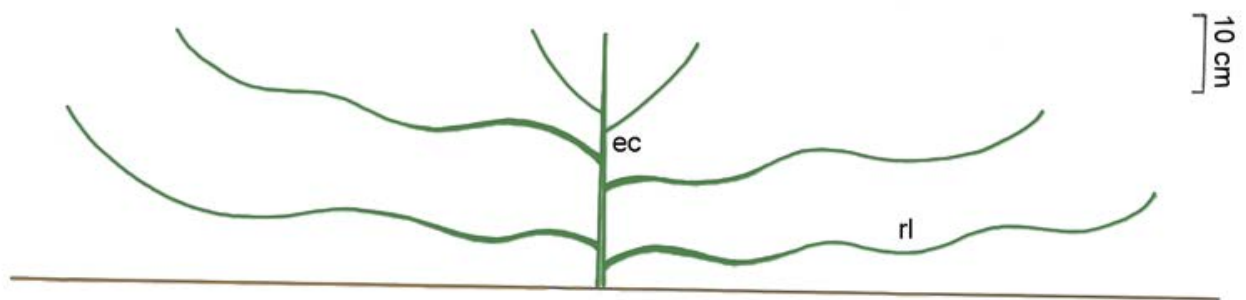

\section{6}

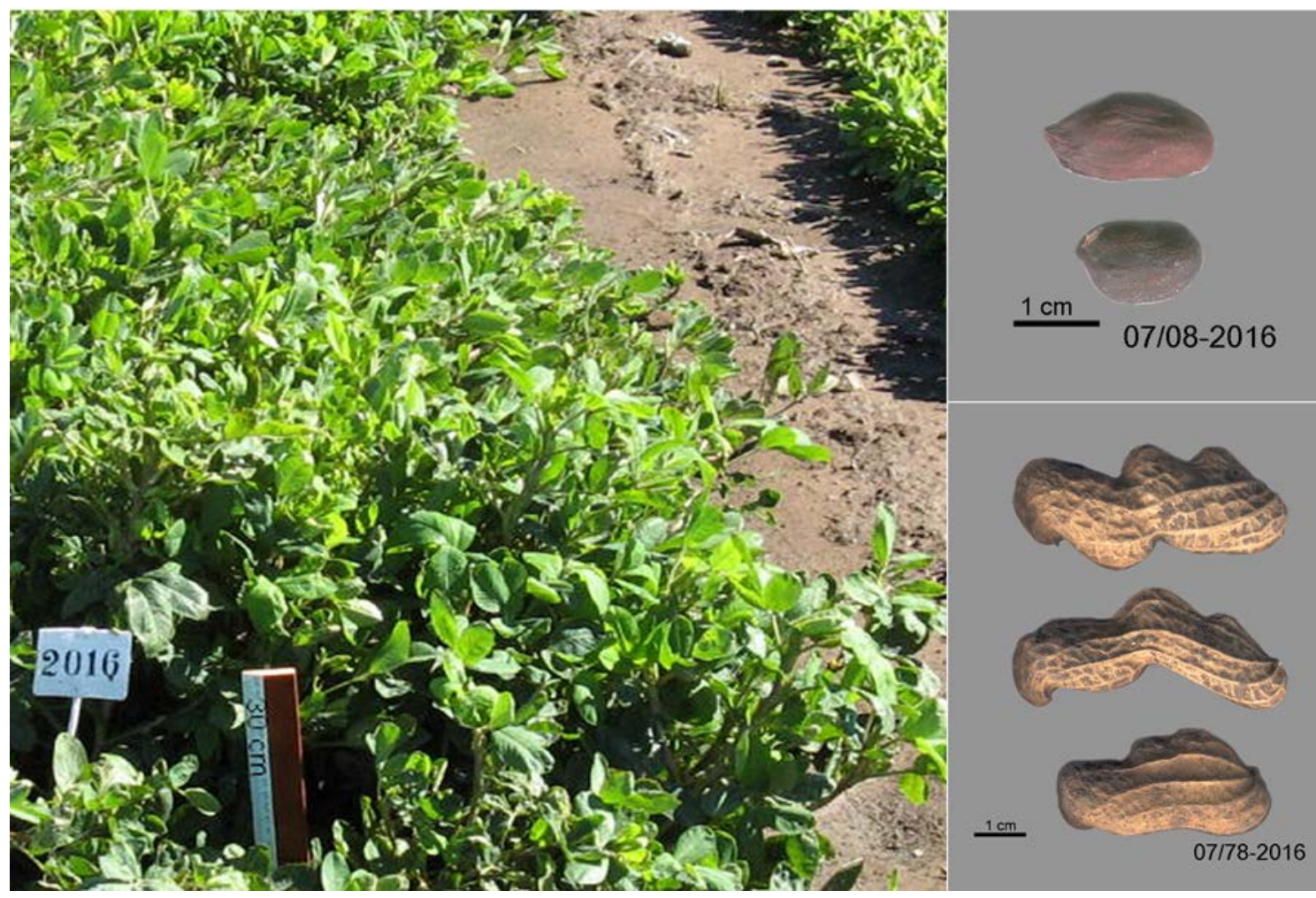

$87 / 2434$

Cat. 59/396
Bonavia $6 \mathrm{~A}$

K(1955)
Lima fábric. de aciete

Lima mercado 


\section{Criollo blanco de Casma}

Planta: semirastrera. Eje central erecto $40 \mathrm{~cm}$ long. Tallo verde, ramas sinuosas. Estandarte sin aro.

Cajas, 2-3 grs. Pálidos

Manfredi 07/08 2017

$87 / 2627$

Bonavia 4 A

Casma

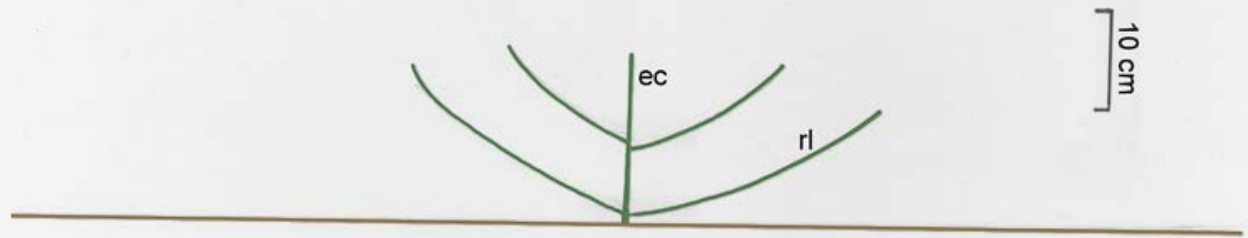

2017

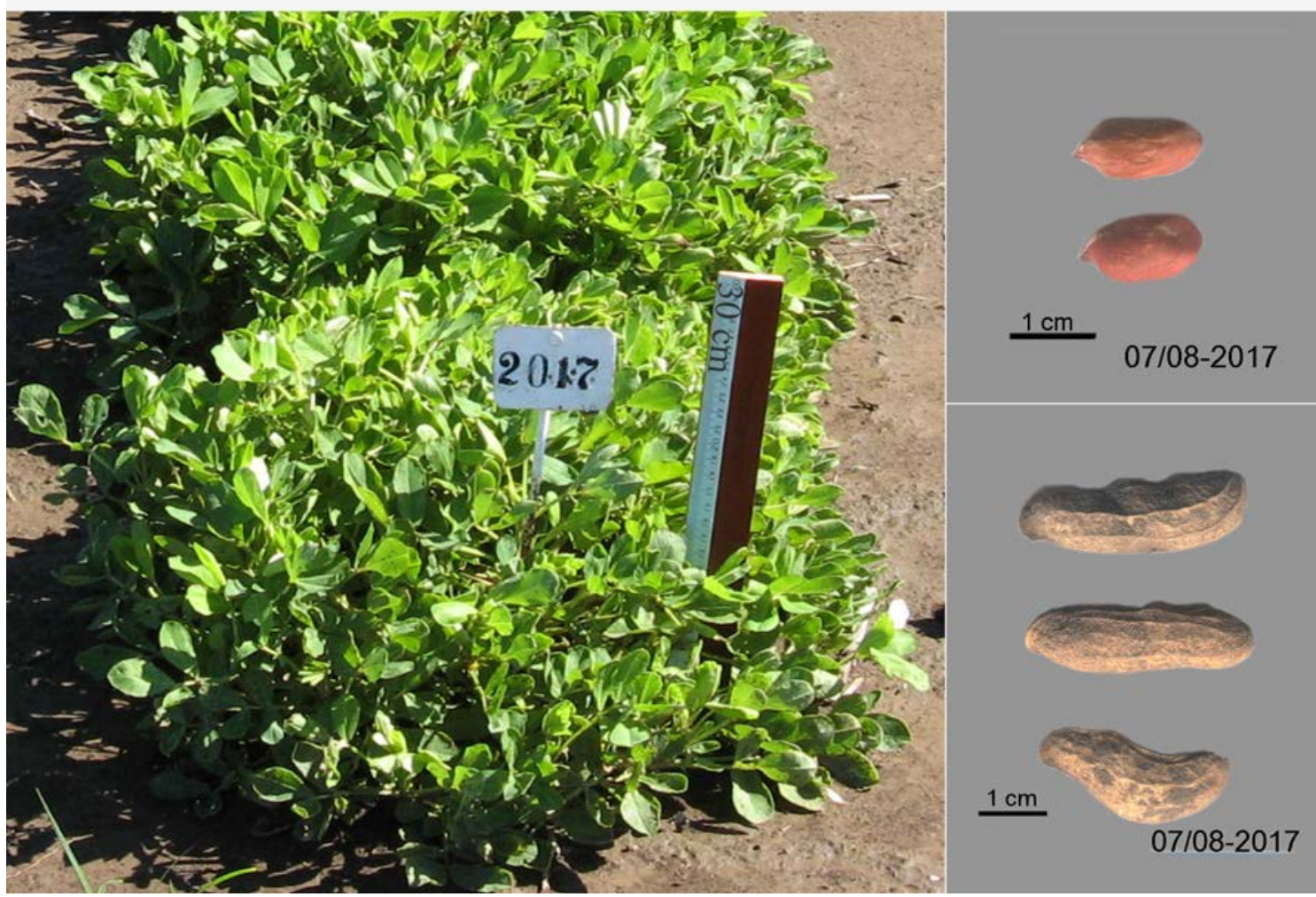




\section{Colorado limeño}

Planta: desparramada. Tallo morado. Eje central aparente. Ramas $n+1$ con ramificaciones reproductivas unicamente. Follaje verde oscuro. Estípulas con cerdas. Folíolos grandes ondulados, gruesos.

Cajas: Gruesas, irregulares, con jorobas, con algo de pico y de carena; nervaduras longitudinales algo sobresalientes. 3-4 granos, colorado clarete

\begin{tabular}{|c|c|}
\hline 018 & $87 / 2630$ \\
\hline Manfredi 07/08 2019 & $87 / 2631$ \\
\hline
\end{tabular}

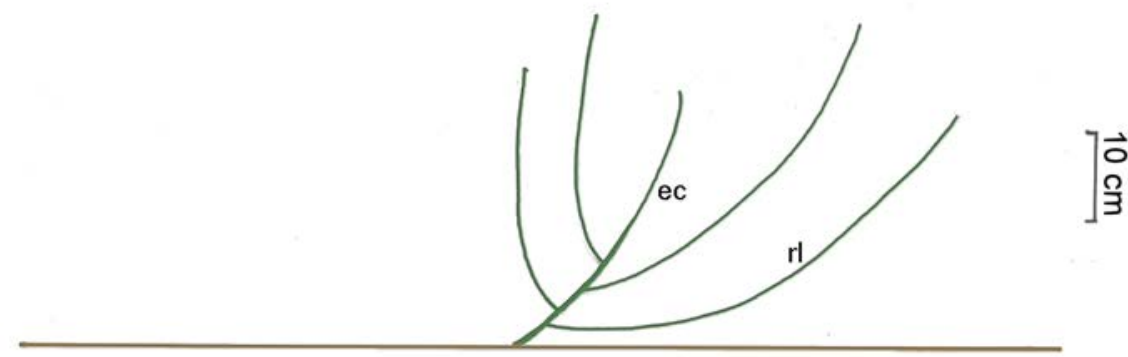

2019

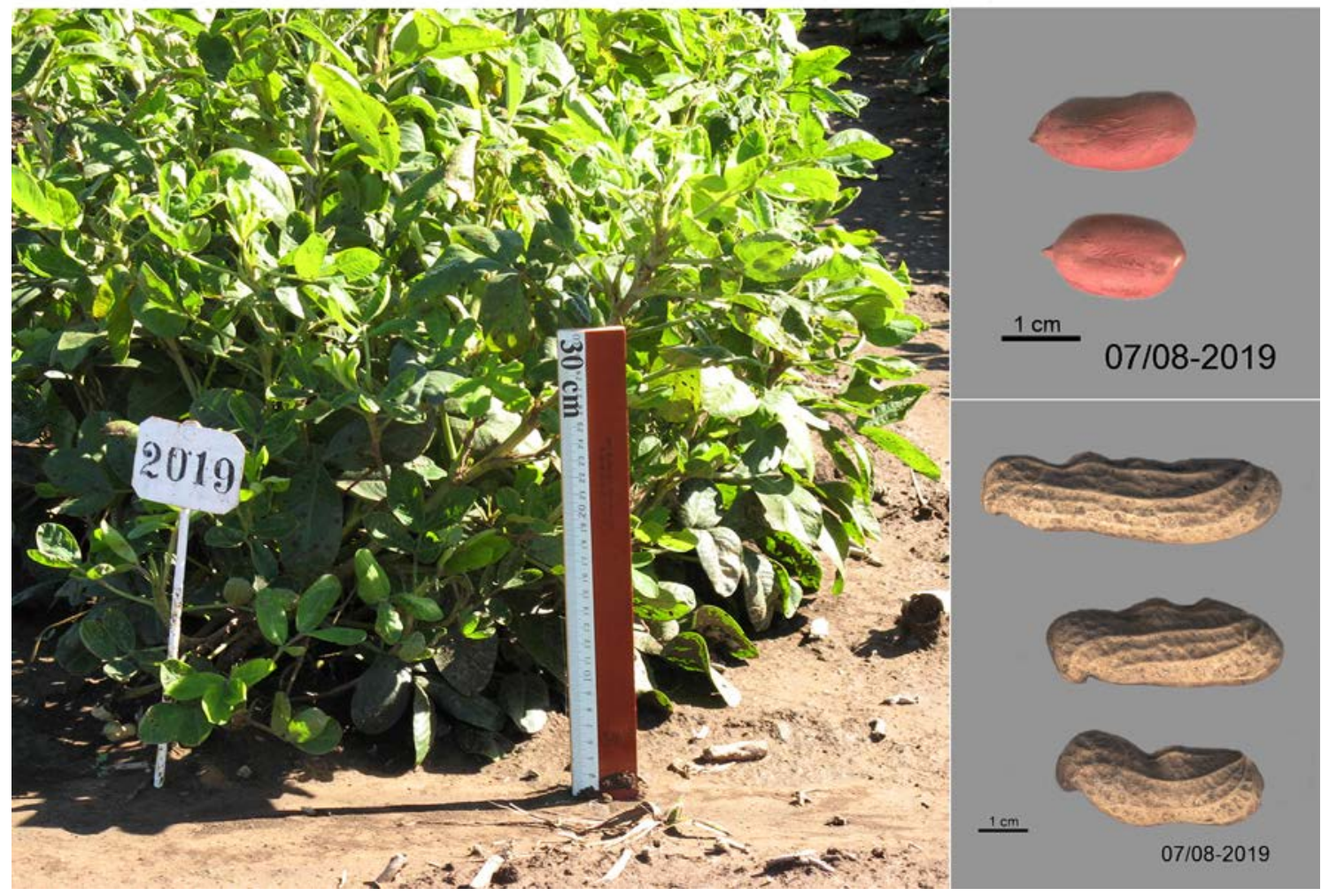

$\begin{array}{lll}\text { 87/ 2632 } & \text { RCM 1424 } & \text { Ayabaca } \\ \text { 87/2633 } & \text { PI-393642 } & \text { rio Ene (Junin) } \\ 87 / 2635 & \text { US-423 } & \text { Lima } \\ 87 / 2636 & \text { US-425 } & \text { “ }\end{array}$


A. Krapovickas \& al., Las razas de maní de Perú

$\begin{array}{llc}87 / 2638 & \text { US-426 } & \text { Lima } \\ 87 / 2640 & \text { US-427 } & \text { “ } \\ 87 / 2641 & \text { US-428 } & \text { “ } \\ 87 / 2643 & \text { US-429 } & \text { Aucuyacu } \\ 87 / 2644 & \text { US-456 } & \text { Tingo María } \\ 87 / 2645 & \text { US-460 } & \text { Ayacucho } \\ 87 / 2646 & \text { US-507-1 } & \text { “ } \\ 87 / 2658 & \text { US-508 } & \text { “ } \\ 87 / 2647 & \text { US-509 } & \text { Sta. Rosa } \\ 87 / 2653 & \text { US-510 } & \text { Ceatanrumi } \\ 87 / 2648 & \text { US-512-1 } & \text { S. Francisco } \\ 87 / 2666 & \text { US- 513 } & \text { “ } \\ 87 / 2660 & \text { US-514 } & \\ 87 / 2649 & \text { US-515-1 } & \\ 87 / 2650 & \text { US-516 } & \text { “ } \\ 87 / 2661 & \text { US-517-1 } & \end{array}$




\section{Rojo de Huayabamba}

Planta: desparramada, tallo verde. Ramas $\mathrm{n}+1$ no ramificadas. Estípulas con cerdas.

Cajas: Angostas, con jorobas, pico y carena. Nervaduras longitudinales algo marcadas. 2-4 granos colorados.

Manfredi 07/08 2020 87/2634
PI-393528 Tripp

La Molina
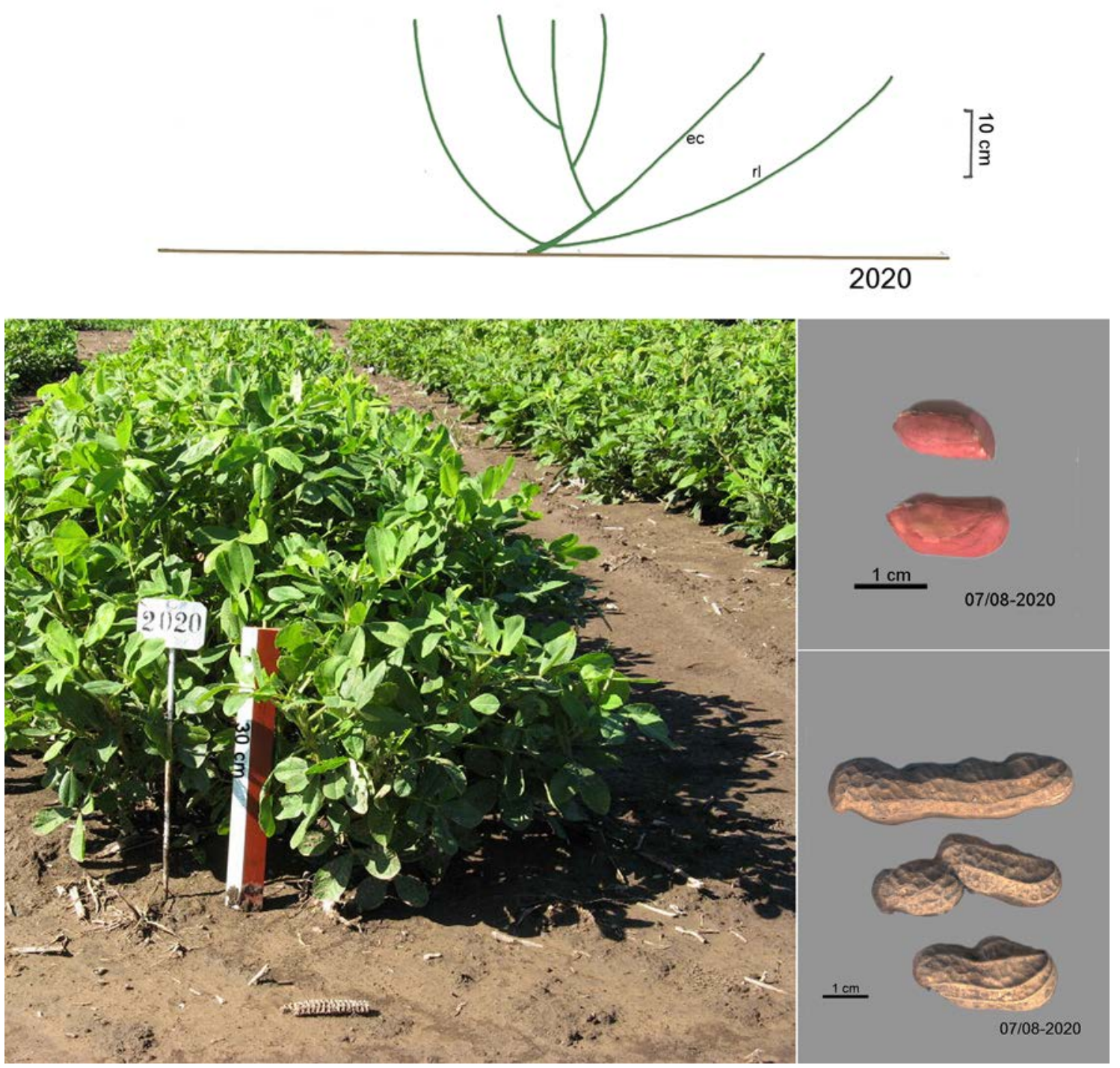


\section{Colorado con vetas}

Planta: poco ramificada. Eje central alto. Ramas arqueadas y luego erectas. Tallo verde. Follaje verde oscuro. Folíolos algo más pequeños que en el “Colorado limeño”. Estípulas sin cerdas.

Cajas: hasta 3,90 cm long., con retículo más o menos suave, uniforme, sin nervaduras longitudinales marcadas; con pico pequeño y sin carena. Con 3-4-2-1 granos. Tegumento colorado con líneas o vetas más oscuras.
Manfredi 07/08
2021
$87 / 2726$
US-466-1
Tarapoto

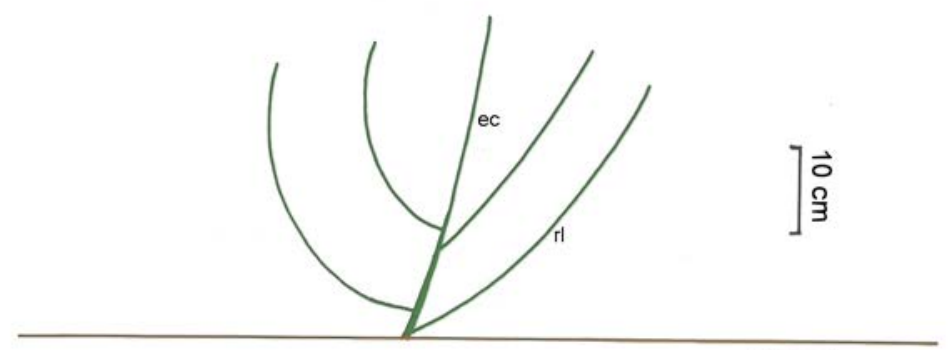

2021

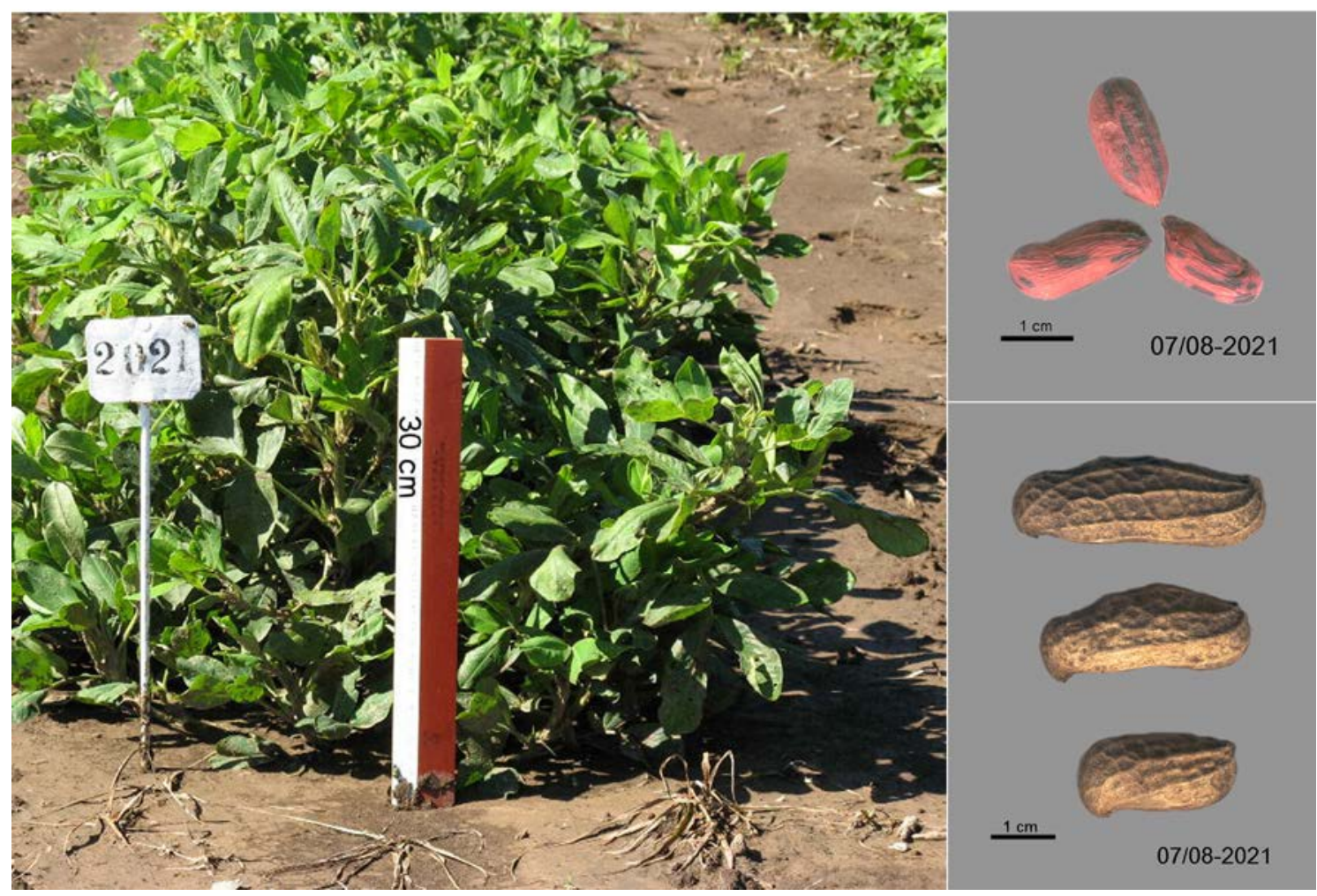




\section{Colorado de Iquitos}

Planta: baja, tallo verde. Eje central corto, aparente. Ramas $n+1$ rastreras, con ramificaciones $\mathrm{n}+2$ reproductivas, breves, solamente. Follaje verde claro. Estípulas sin cerdas. Clavo morado claro.

Cajas: pequeñas, hasta 3,50 cm long., redondeadas, sin pico, con algo de carena. Retículo marcado. Con 2-3-1 granos; tegumento colorado claro.
Manfredi 07/08 2022
$87 / 2724$
US-489
Iquitos (río Napo)

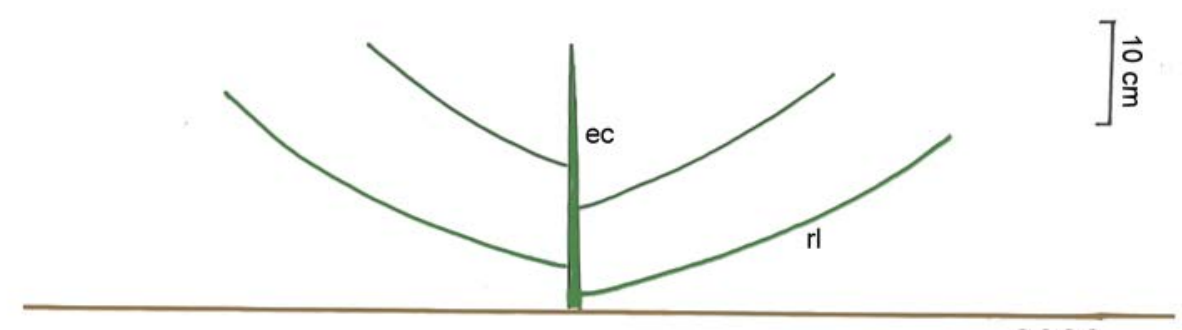

2022

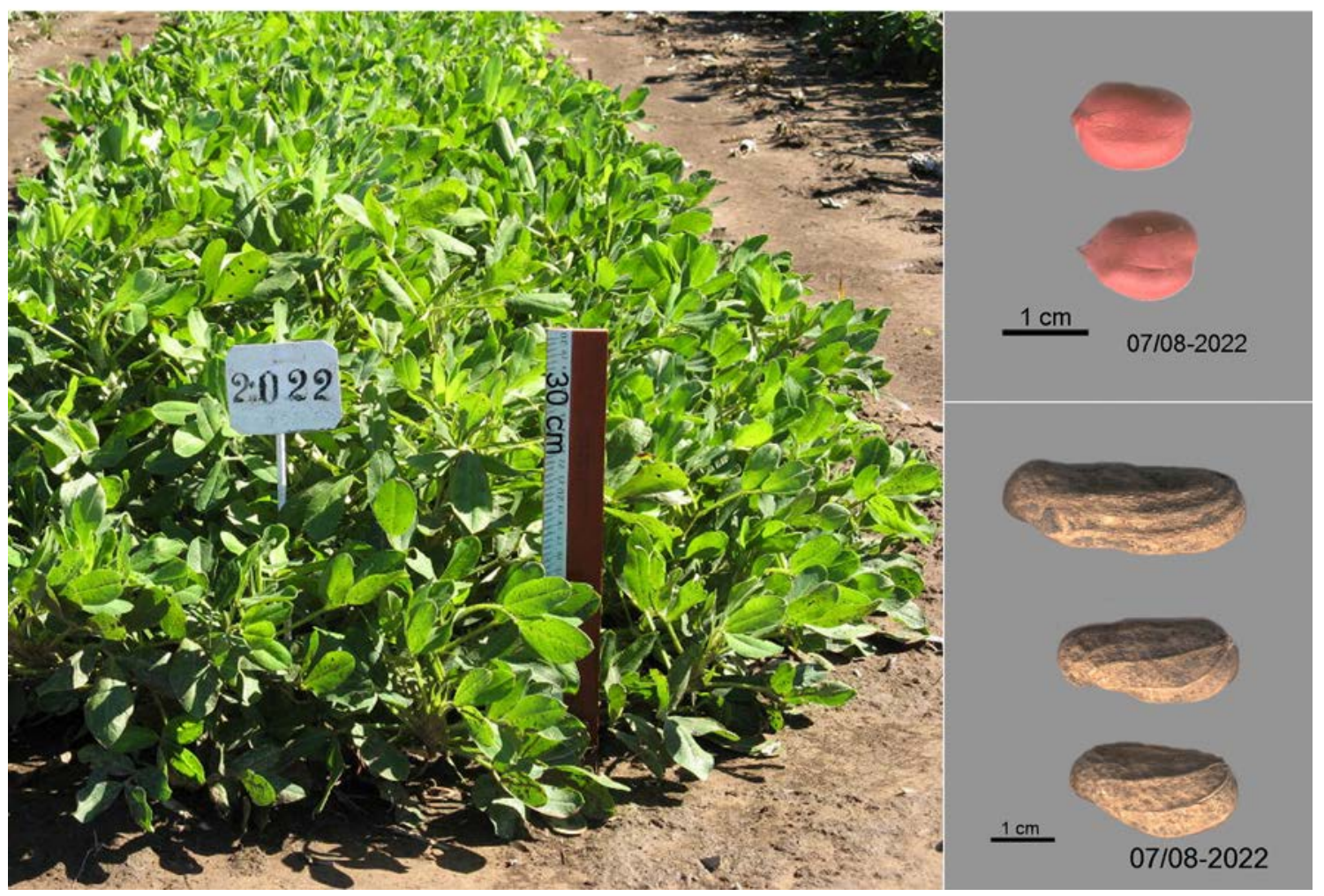




\section{Colorado Tarapoto}

Planta: eje central aparente. $\mathrm{n}+1$ con ramas reproductivas solamente. Estípulas sin cerdas. Folíolos grandes, con ondulaciones transversales.

Cajas: hasta 4,30 cm long., lisas (nervaduras longitudinales no marcadas). 3-2-4-1 granos, hasta $1,40 \mathrm{~cm}$ long., con tegumento colorado y colorado claro.

$\begin{array}{lllll}\text { Manfredi 07/08 } & 2023 & 87 / 2654 & \text { US-466 } & \text { Tarapoto } \\ \text { Manfredi } 07 / 08 & 2024 & 87 / 2656 & \text { US-469 } & \text { Tarapoto }\end{array}$

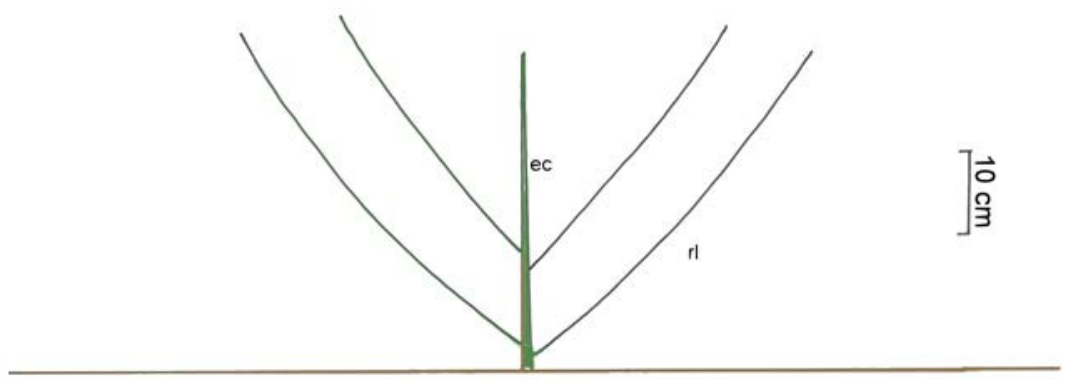

2024

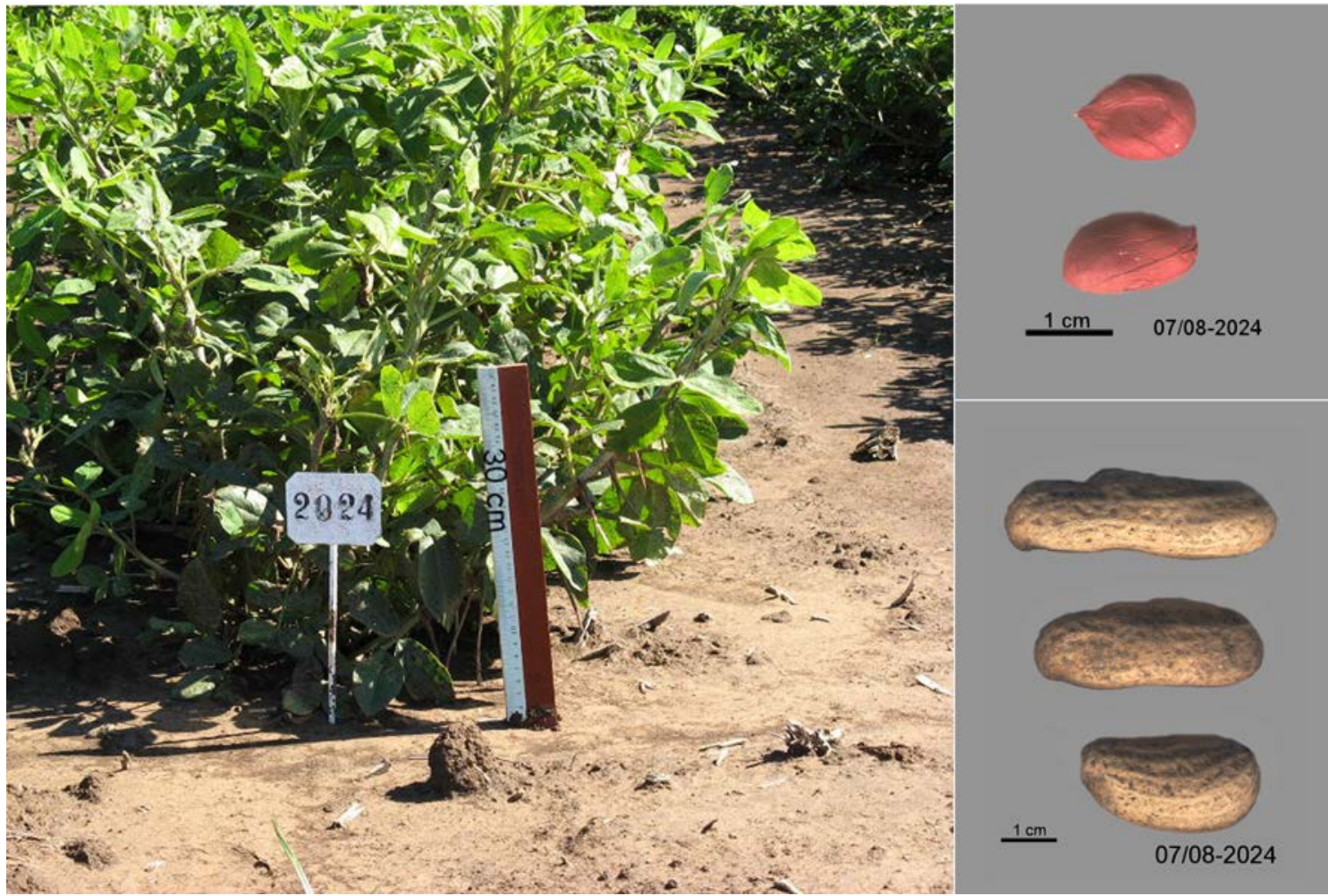

$87 / 2664$

$87 / 2657$

$87 / 2652$
US-488

US-491-1

Bartra-2
Iquitos

Tarapoto 


\section{Colorado La Convención}

Planta: erecta, bien desarrollada. Eje central aparente, ramas $n+1$ con ramificaciones $(n+2)$. Tallo morado. Estípulas con abudantes cerdas.

Cajas: lisas, con 3-4 granos. Tegumento colorado fuerte.
Manfredi 07/08 2025 87/2673
US-405
Cuzco
Manfredi 07/08 2026 87/2674
US-406
Cuzco
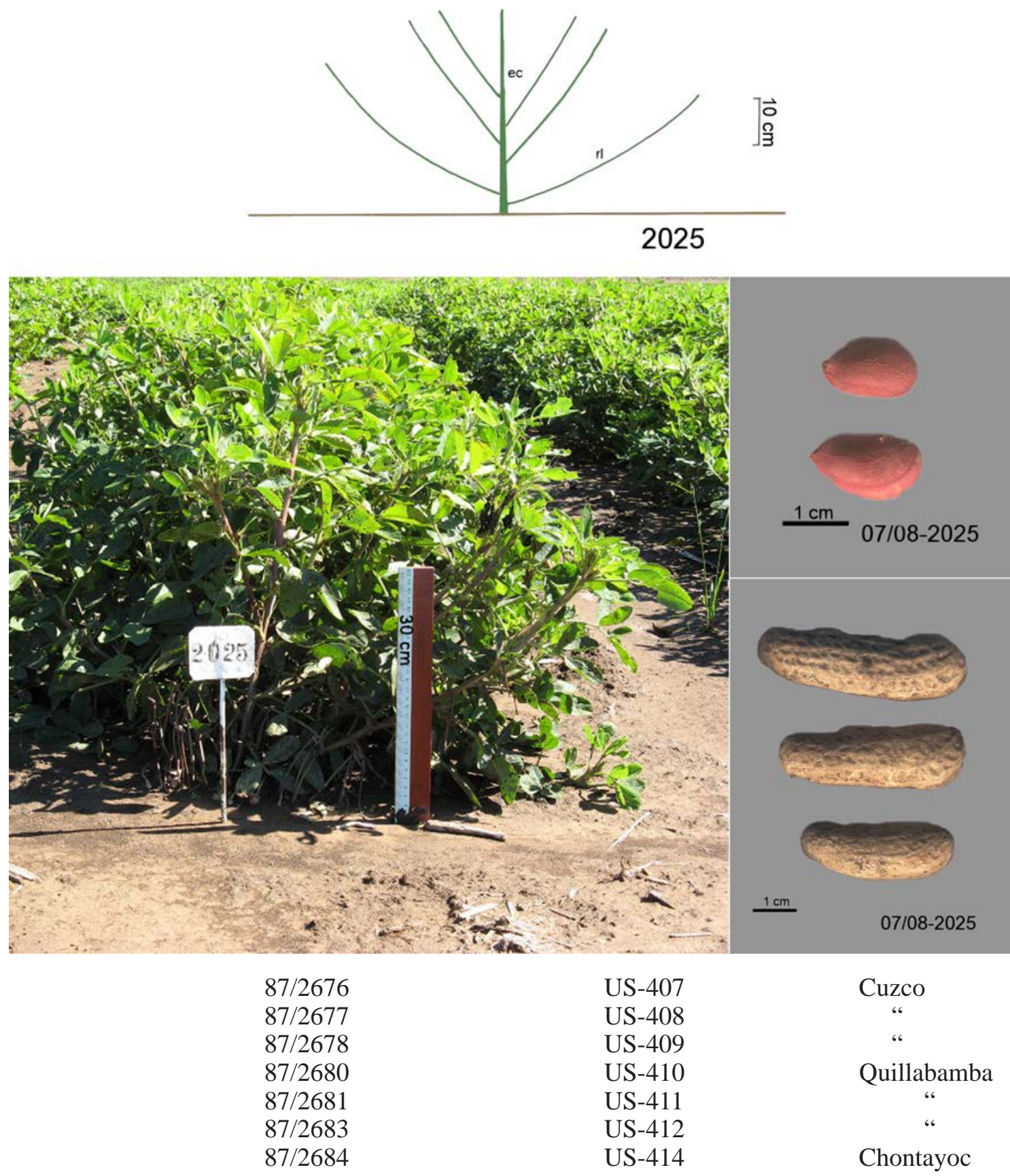
A. Krapovickas \& al., Las razas de maní de Perú

$87 / 2685$

$87 / 2686$

$87 / 2687$

$87 / 2688$

87/2689

$87 / 2698$

87/2662

$87 / 2699$

$87 / 2700$

$87 / 2701$
US-415

US-416

US-418

US-420

US-421

US-510

US-518

K-1 (1982)

K-3

$\mathrm{K}-2$
Misalniyoc

Maniccys

Chirumbia

Loroquacha

Chirumbia

Ayacucho

S. Francisco

Cuzco

6

66 


\section{Italiano de Casma}

Planta: erecta, bien desarrollada. Eje central aparente, Ramas $n+1$ con ramas $(n+2)$ vegetativas y reproductivas. Tallo morado. Con cerdas.

Cajas: lisas, hasta 4,30 cm long., con 3-2-4-1 granos colorados.
Manfredi 07/08 2027
$87 / 2668$
RCM-1426
Manfredi 07/08 2028 87/2669
PI-393523
Casma

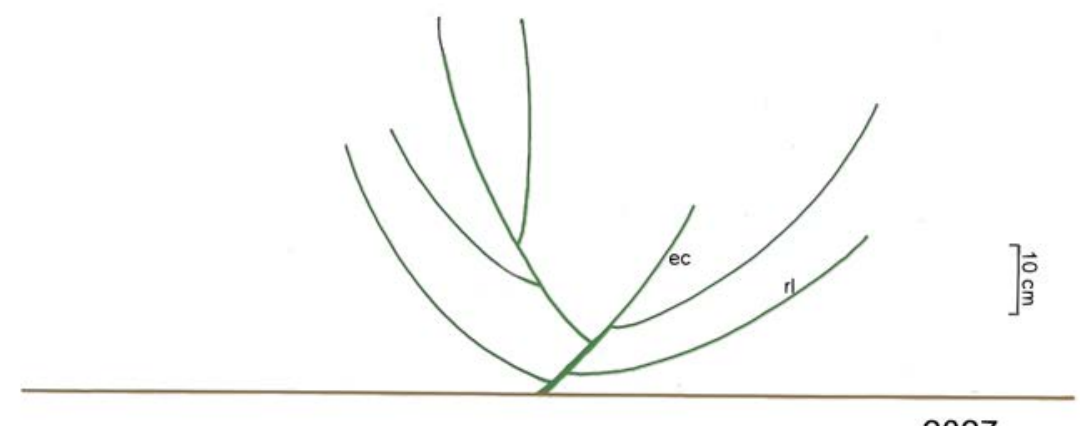

2027

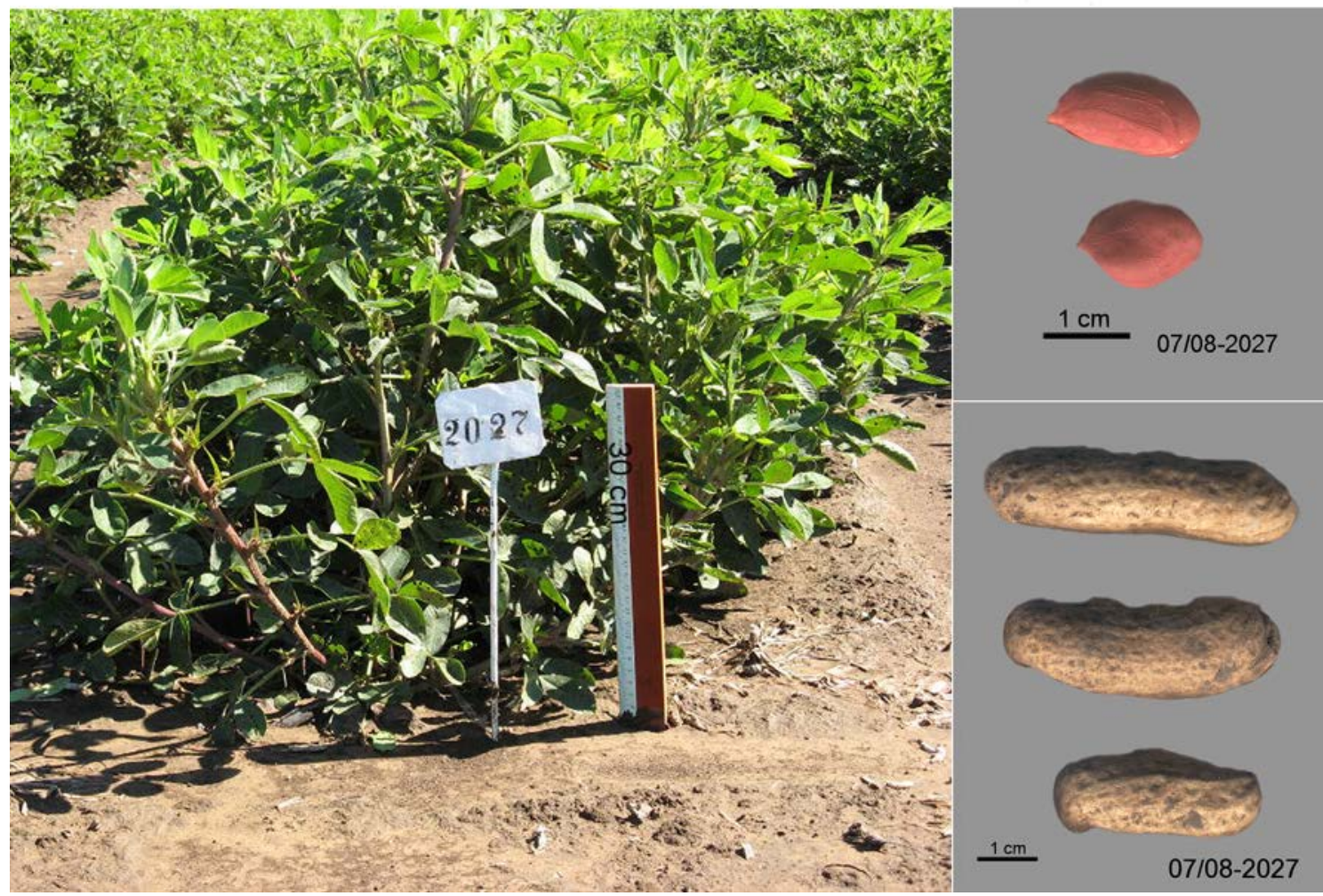

$87 / 2670$

$87 / 2671$

87/2672

$87 / 2690$

$87 / 2691$
Bonavia- $5^{\mathrm{a}}$

US-403

US-404

US-424

US-451
Lima

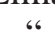

66

Casma 
A. Krapovickas \& al., Las razas de maní de Perú

87/2693

$87 / 2694$

$87 / 2695$

$87 / 2696$

$87 / 2697$
US-452

US-453

US-454

US-455

US-456
Casma 6

Lima

“

Aucuyacu 


\section{Copallin Tarapoto}

Planta: erecta, ramificada, pequeña, eje central poco aparente. Hasta 3,80 cm long.Estípulas con pocas cerdas. Hojas amarillentas, folíolos chicos.

Cajas: lisas, con 3-2-4-1granos. Granos colorados, hasta 1,55 cm long.
Manfredi 07/08 $2029 \quad 87 / 2667$
PI-393521 Copallin Tarapoto La Molina

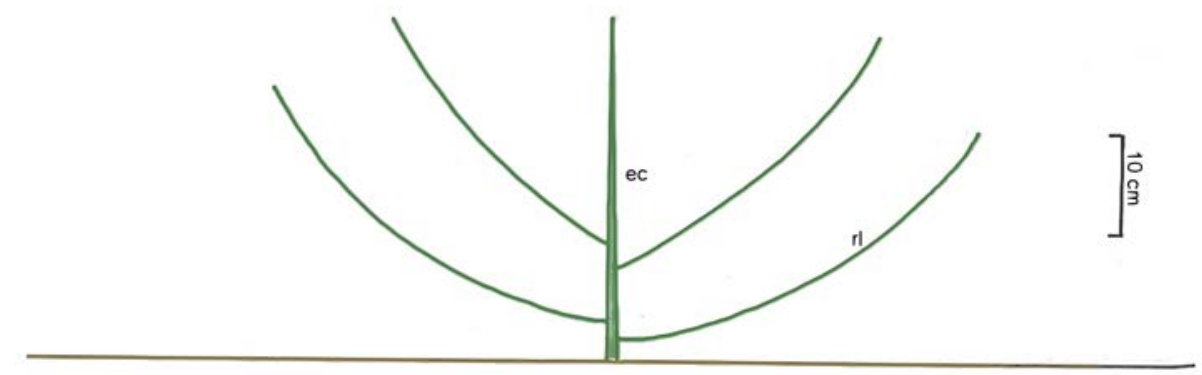

2029

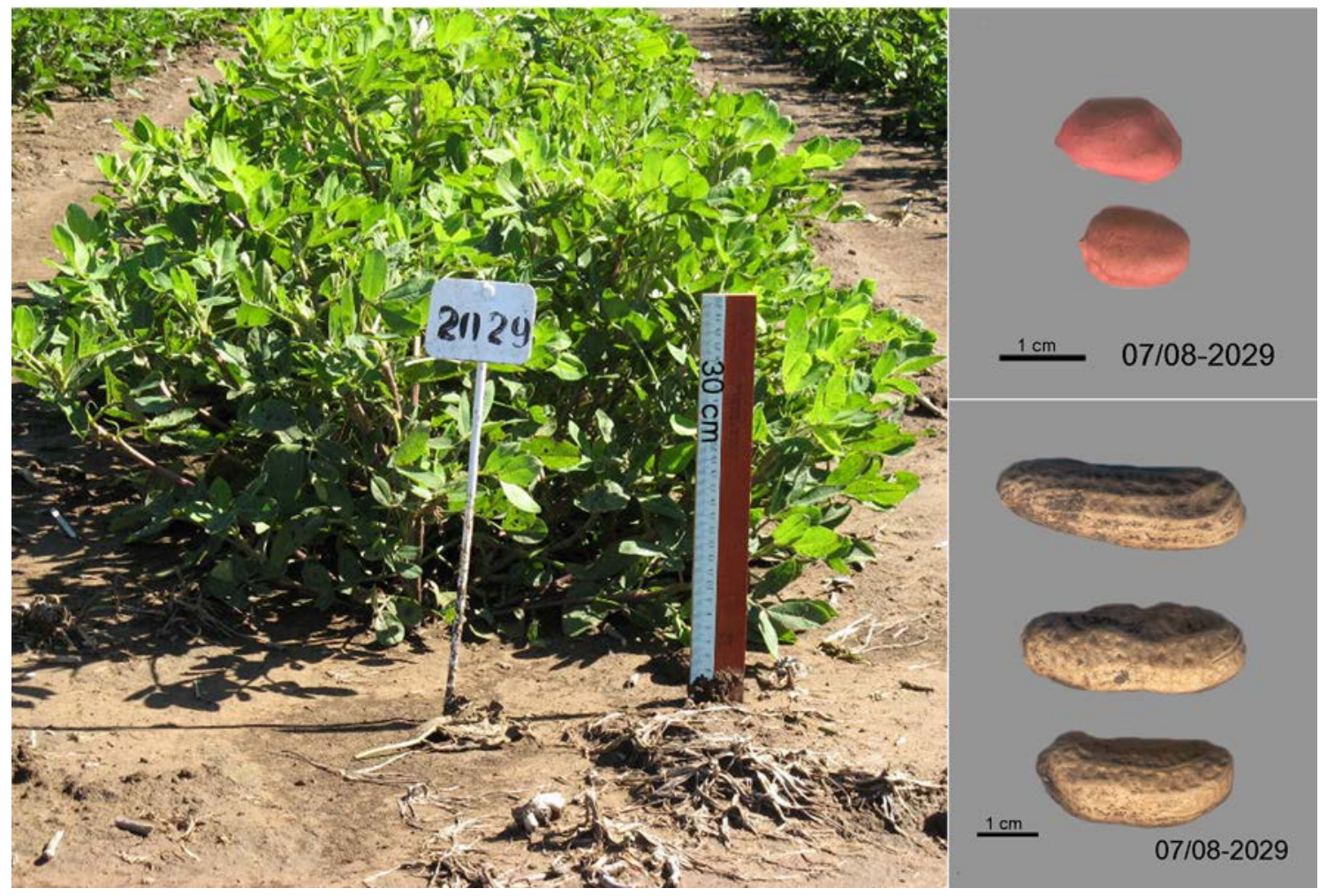

Obs.Algo más chica que el "Colorado la Convención”, al que se parece por el tamaño y forma de las hojas. El eje central es menos aparente y el follaje es algo amarillento, como en el “Colorado limeño”. 


\section{Rosado limeño}

Planta: tipo "Colorado Limeño"., erecta, algo ramificada; ramas $n+1$ sólo con ramas $n+2$ reproductivas. Eje central algo aparente. Estípulas con cerdas.

Cajas: Más o menos grandes, hasta 4,90 cm long., irregulares, con 3-4-2-1 semillas, con algo de pico y quilla; nervaduras algo marcadas (algo más lisas y redondeadas que el " Colorado Limeño”). Granos rosasdos, hasta 1,48 cm long.
Manfredi 07/08 2030
$87 / 2703$
US-428-
Lima

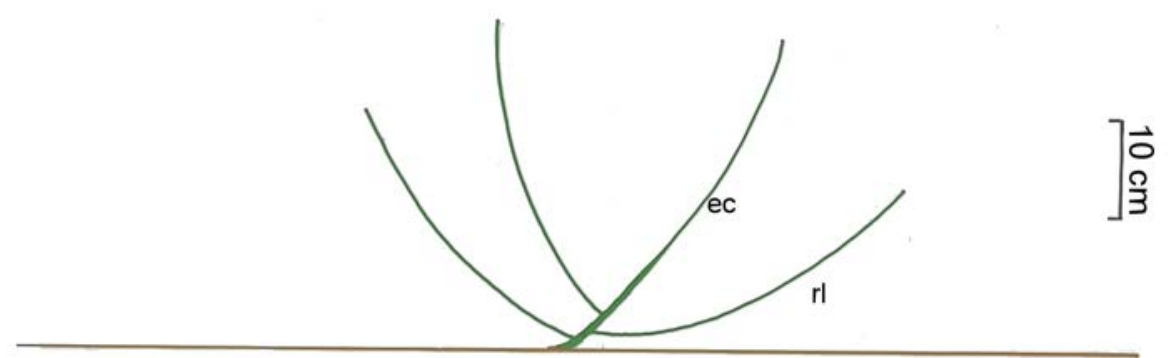

2030

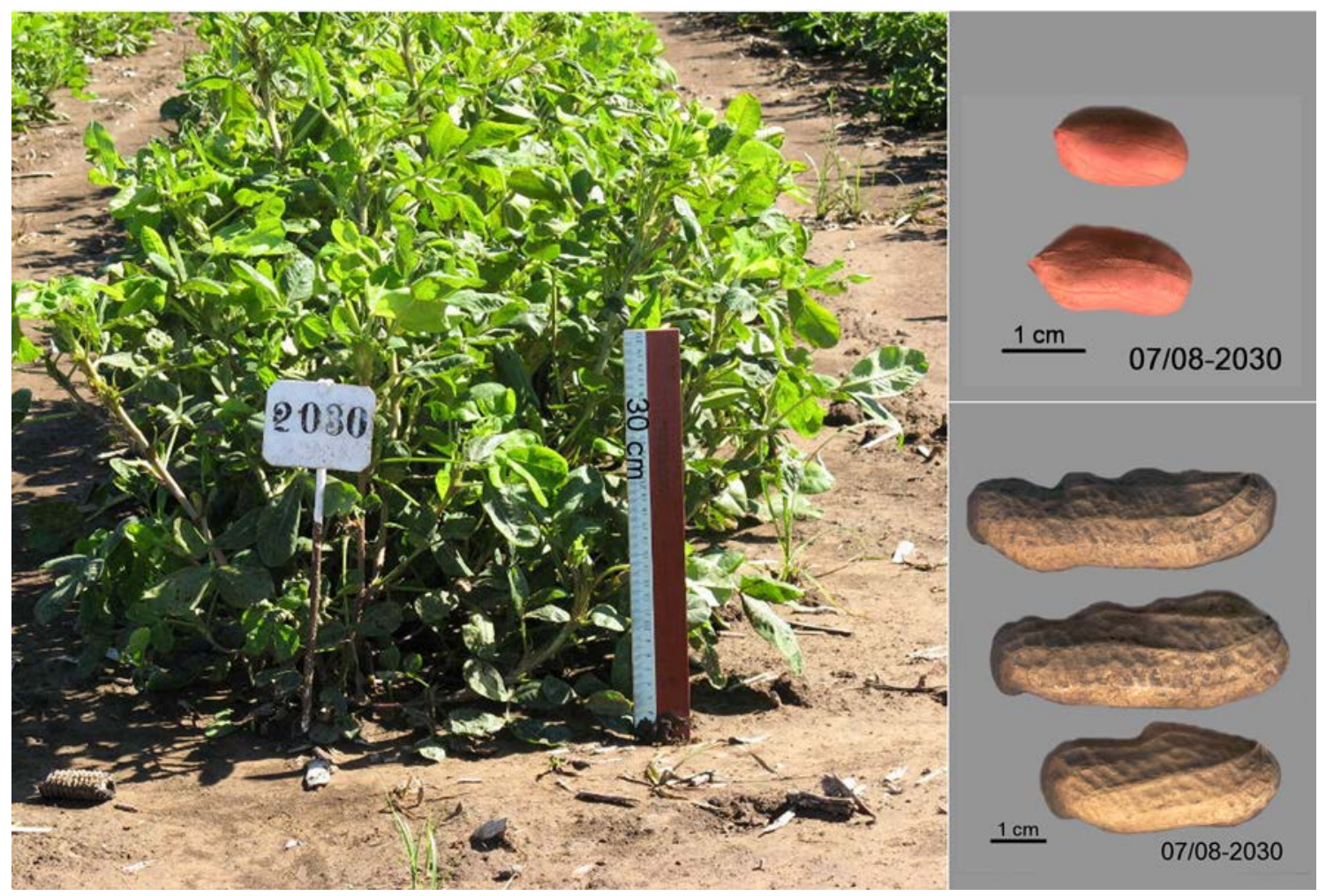




\section{Pálido clavo verde}

Planta: tipo "Colorado Limeño". Semierecta, algo abierta; ramas n+1 sólo con ramas n+2 reproductivas. Tallo verde, clavo verde. Estípulas con cerdas. Folíolos grandes.

Cajas: más o menos grandes, con 3-4-2-1 granos, hasta 4,70 cm long., con jorobas, con algo de pico y quilla, lisas, casi sin retículo. Granos hasta 1,60 cm long., tegumento pálido, con tinte violáceo y con líneas longitudinales oscuras.
Manfredi 07/08 2031 87/2709
US-408
Cuzco
Manfredi 07/08 2032 87/2710
US-424-2
Lima
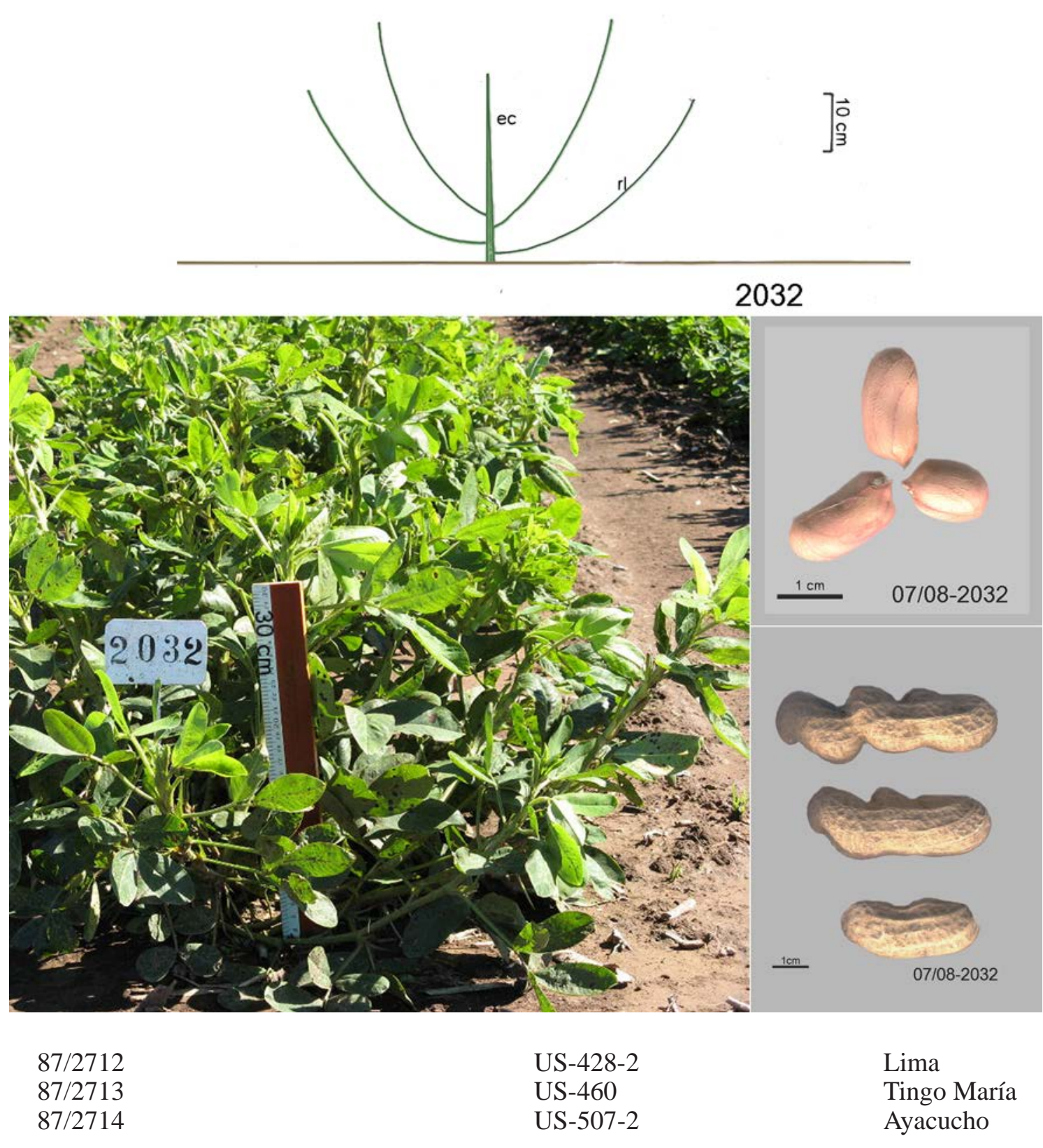


\section{Pálido limeño}

Planta: tipo "Colorado limeño", poco ramificada. Eje central poco aparente. Tallo violáceo. Clavo violáceo. Estípulas con cerdas.

Cajas: Más o menos grandes, con 3-4-2-1 granos, hasta 4,4 cm long., con jorobas, con algo de pico y carena, poco reticuladas. Granos hasta 1,66 cm long., con tegumento rosado pálido.
Manfredi 07/08 2033
$87 / 2716$
US-424
Lima

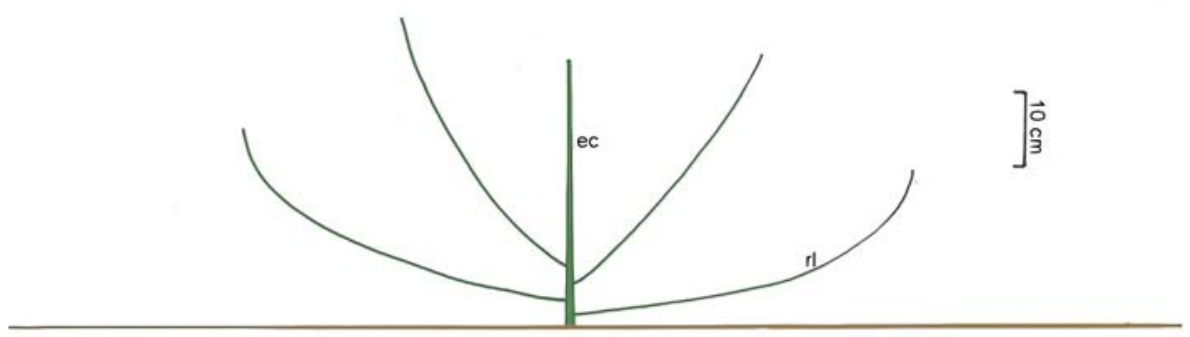

2033

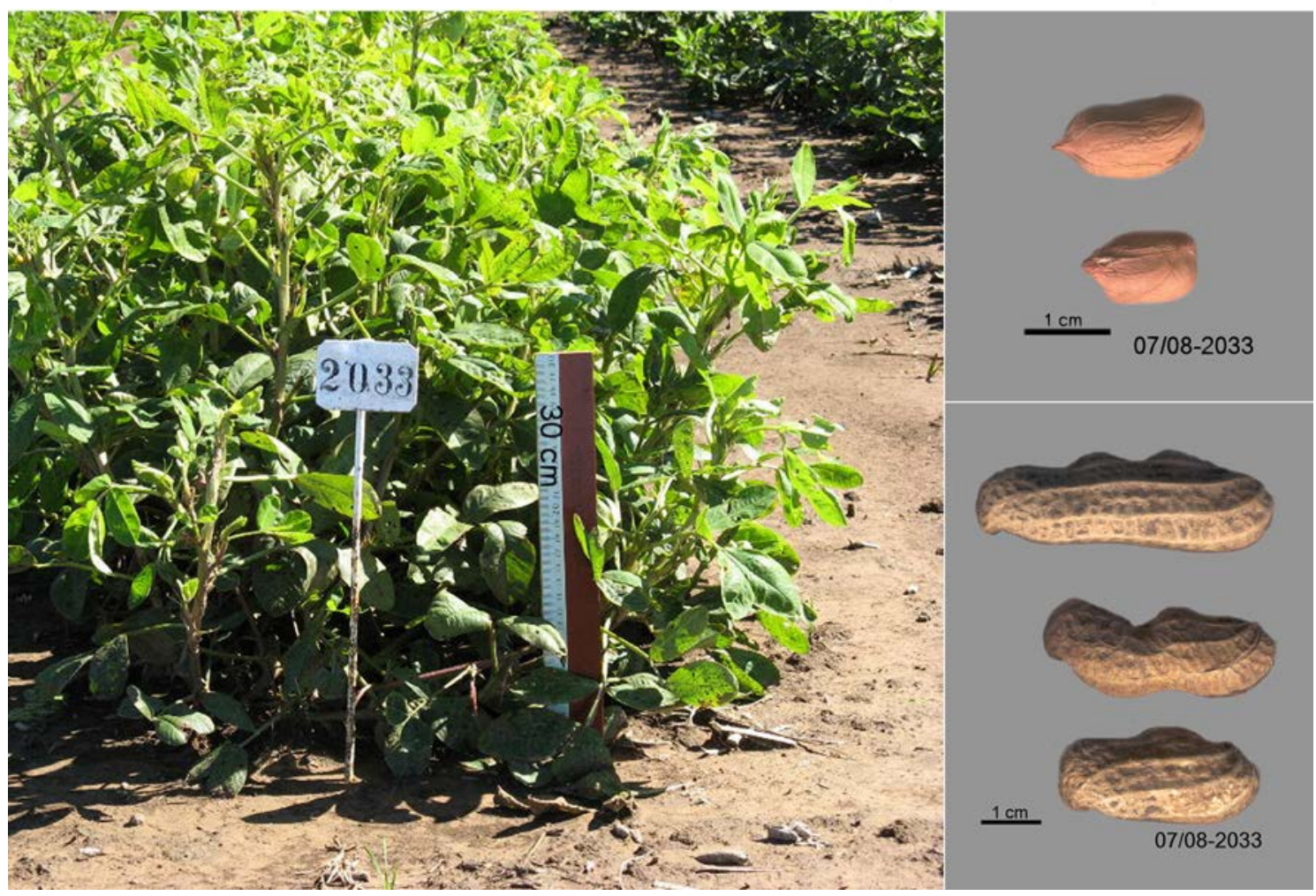




\section{Pálido con pico}

Planta: abierta. Eje central alto, muy aparente. Cuatro ramas $n+1$, casi rastreras, con ramas reproductivas breves, solamente. Estípulas sin cerdas. Clavo violáceo.

Cajas: más o menos chicas, hasta 3,80 cm long., con 2-3-1 granos, con pico bien marcado reticuladas. Granos hasta 1,61 cm long., con tegumento pálido.
Manfredi 07/08 2034 87/2720
US-469
Tarapoto
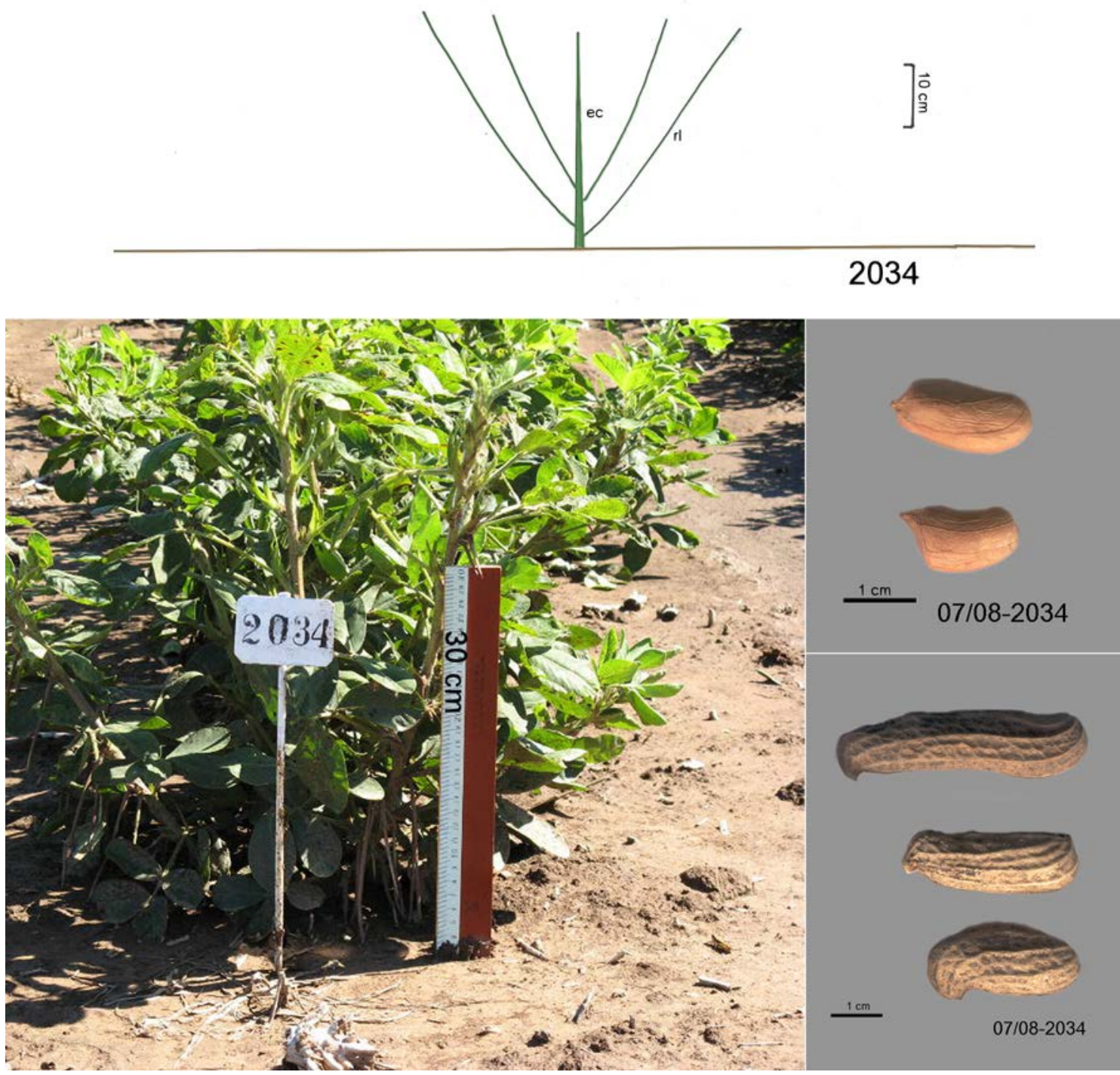


\section{Pálido La Convención}

Planta: erecta abierta, tipo "Colorado La Convención". Eje central aparente. Ramas n+1 con ramas $n+2$ vegetativas y reproductivas. Estípulas con pocas cerdas. Clavo violáceo.

Cajas: medianas a grandes, hasta 4,90 cm long., ccon 3-4-2-1-granos, redondas, sin pico, lisas. Granos hasta 1,70 cm long., tegumento rosado pálido, con líneas longitudinales oscuras.
Manfredi 07/08 2035 87/2704
US-411-1
Quillabamba
Manfredi 07/08 2036 87/2705
US-451
Lima

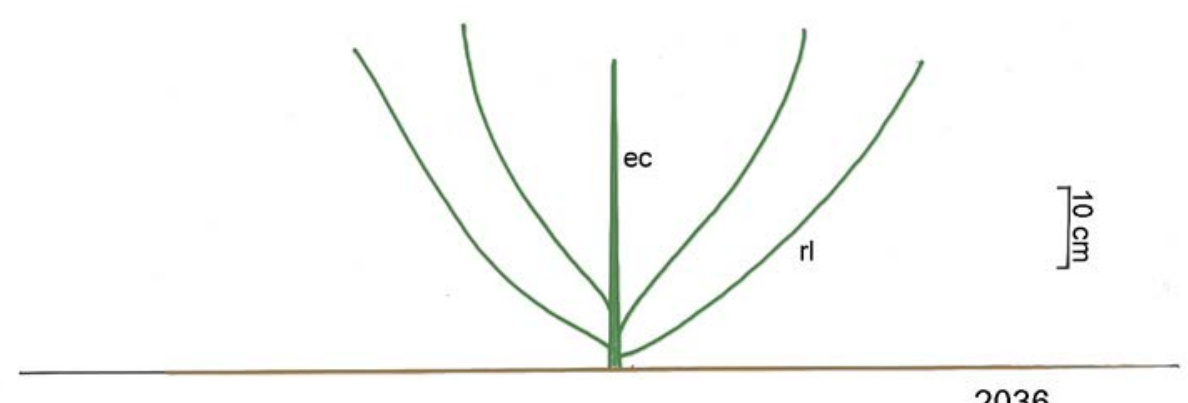

2036

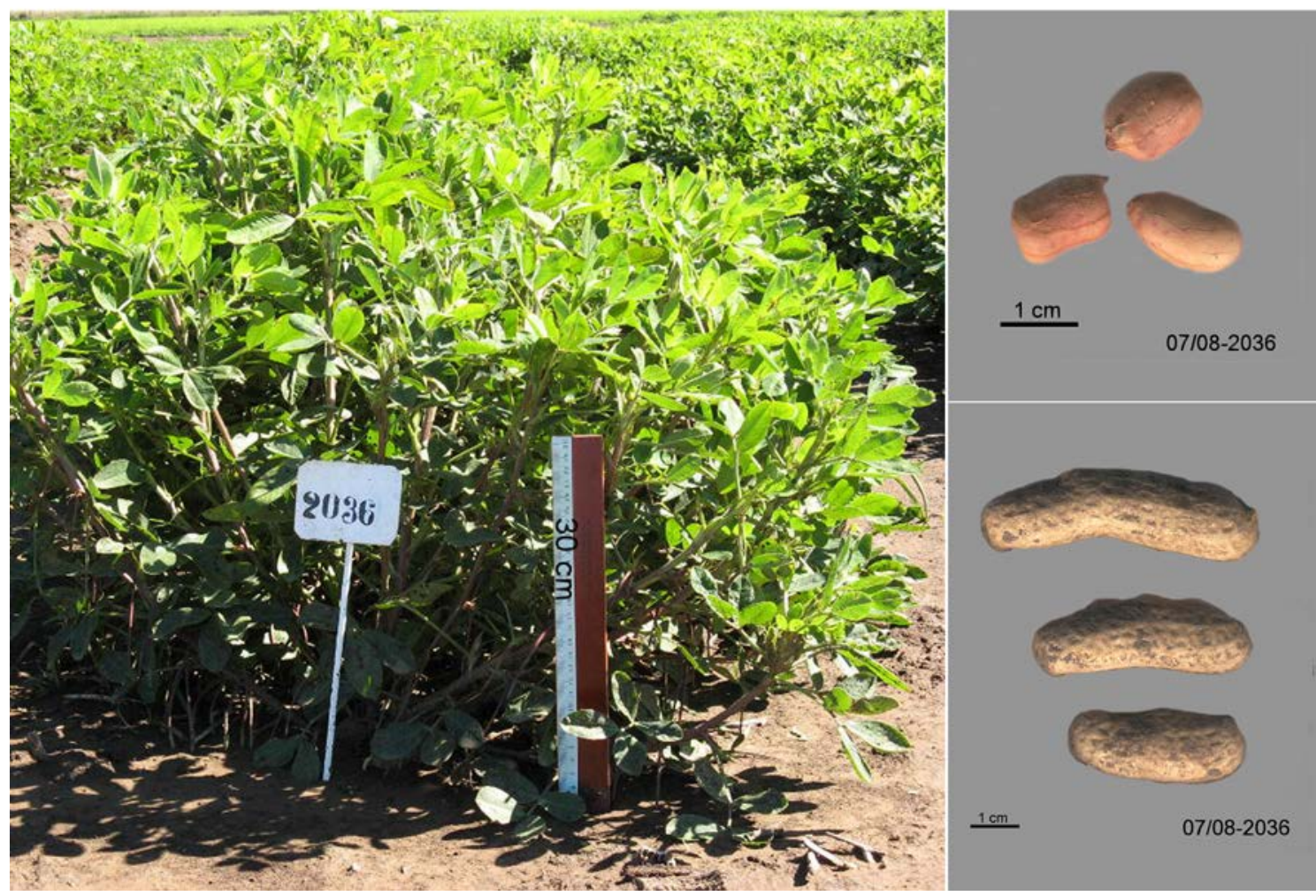




\section{Pálido compacto}

Planta: erecta compacta, ramificada. Eje central no aparente, ( $\sin$ flores). Ramas $\mathrm{N}+1$ poco ramificadas(no presentan ramificación alternada). Estípulas con pocas cerdas. Clavo violáceo.

Cajas: más o menos chicas, hasta 4,30 cm long., con 3-4-2-1 granos, sin pico, algo reticuladas. Granos hasta 1,50 cm long. Tegumento rosado pálido sin líneas longitudiales
Manfredi 07/08 $2037 \quad$ 87/2706
US-515-2
S. Francisco

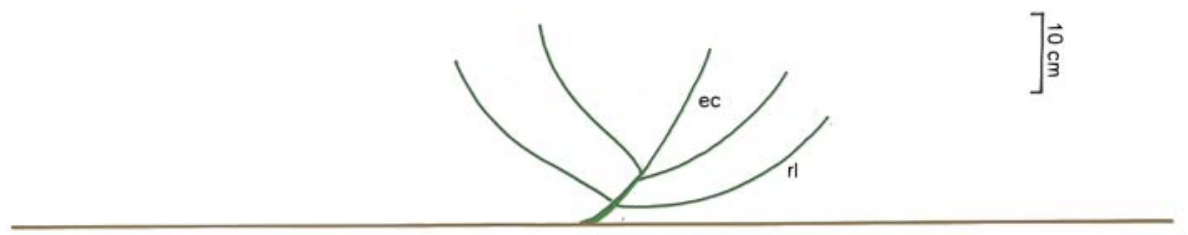

2037

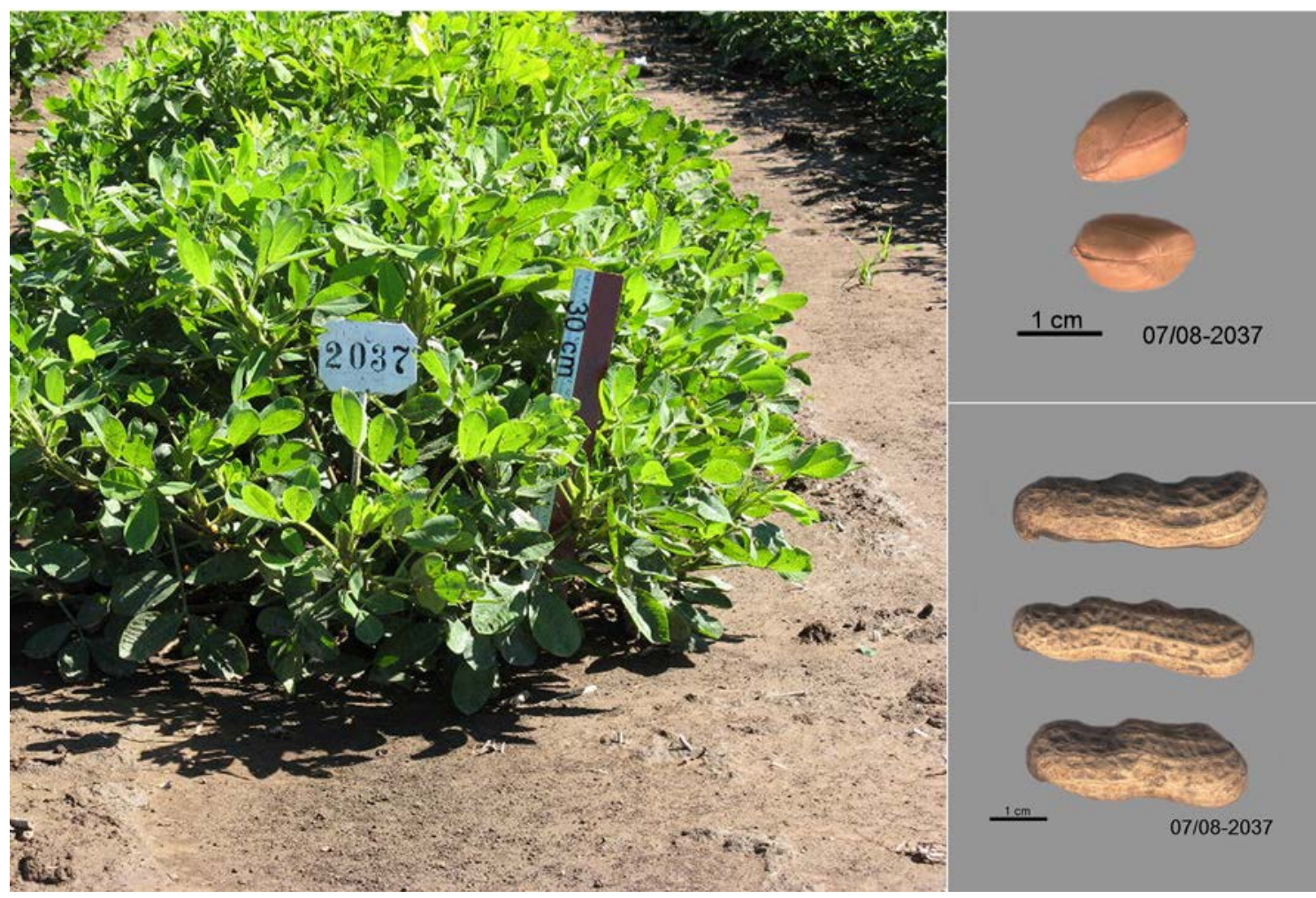




\section{Albo de Quillabamba}

Planta : erecta abierta, tipo "Colorado la Convención". Eje central no aparente. Ramas n+1 con ramas $n+2$ vegetativas. Estípulas con cerdas. Clavo verde.

Cajas: hasta 4,90 cm long., con 3-4-2-1 semillas. Granos hasta 1,63 cm long. Tegumento blanco verdoso, con líneas longitudinales algo oscuras.
Manfredi 07/08 2038
$87 / 2721$
US-411-4
La Convención
Manfredi 07/08 2039
$87 / 2722$
US-419
La Convención

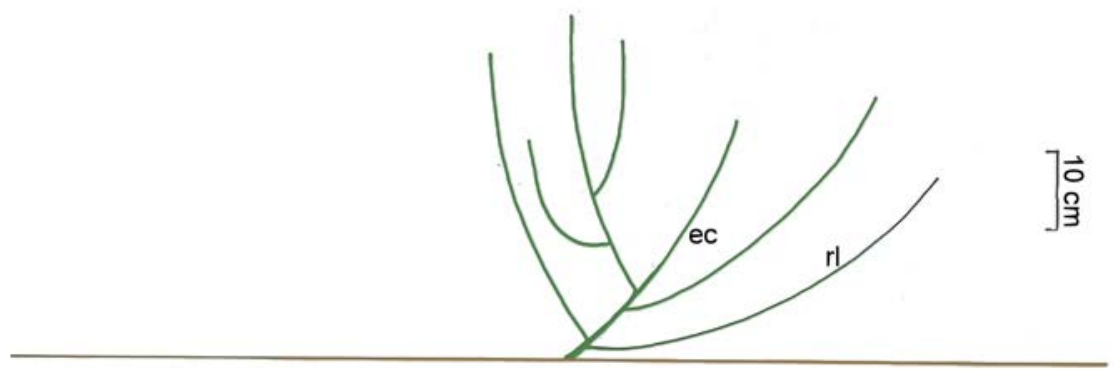

2038

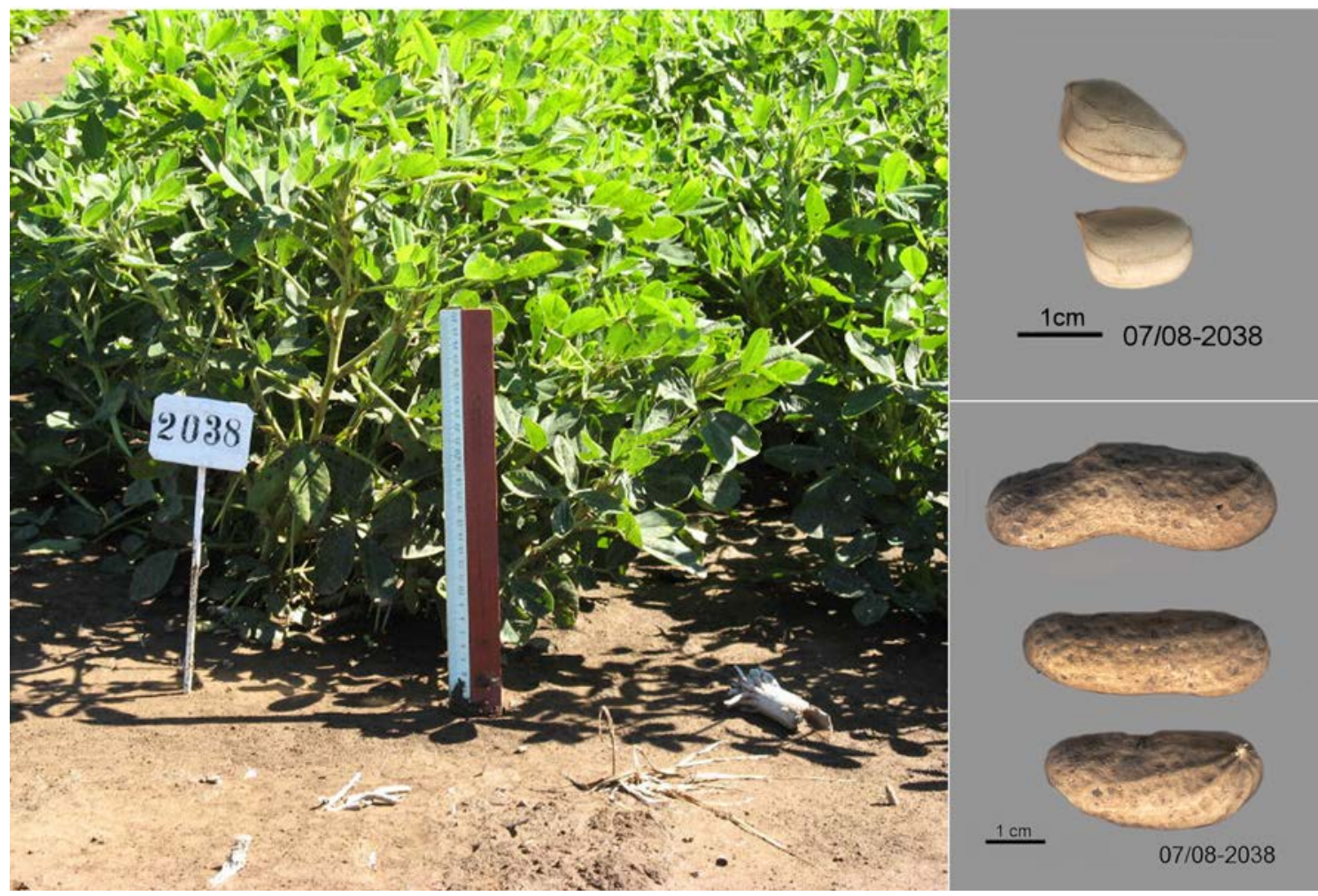

$87 / 2723$

US-410 


\section{Tingo María}

Planta: erecta. Eje central aparente. Ramas semirastreras. Tallo verde. Estípulas con cerdas. Estandarte sin aro. Clavos verdes.

Cajas: hasta 4,80 cm long., con 2-1-3 granos, con algo de pico, sin carena, retículo marcado, con nervaduras longitudinales manifiestas. Granos hasta $1,85 \mathrm{~cm}$ long. Tegumento pálido con líneas cortas violáceas.
Manfredi 07/08 2040 87/2729
Manfredi 07/08 2041 87/2749
$59-402$
Bartra 3
RCM-1412 K(1955) Lima

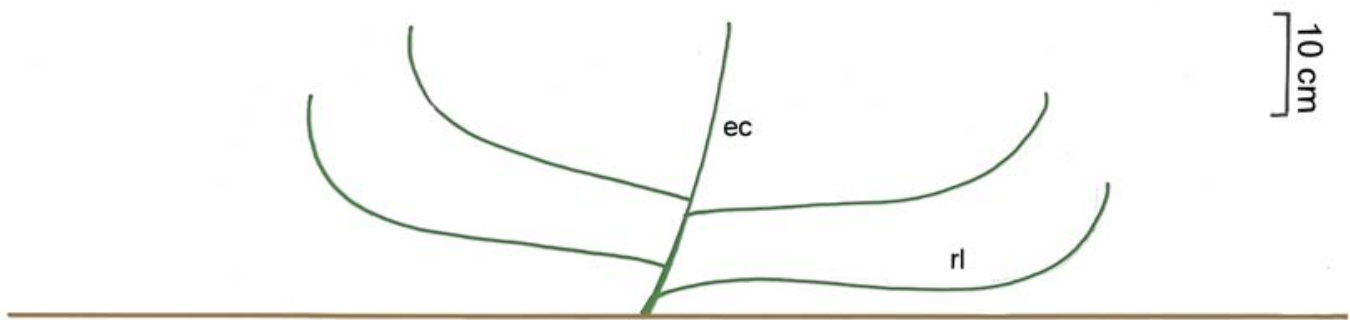

\section{0}

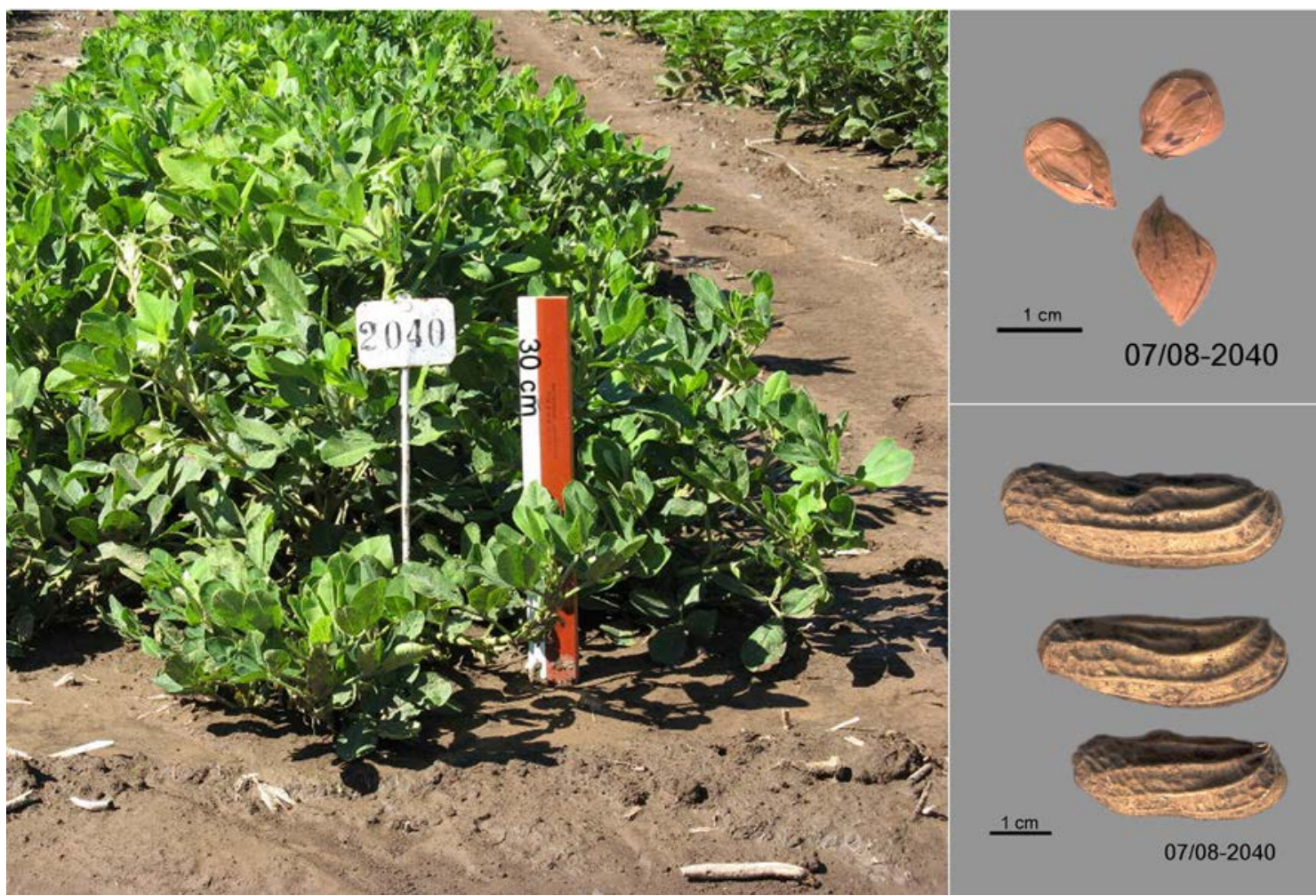

$87 / 2750$

$87 / 2751$

$87 / 2752$

$87 / 2753$

$87 / 2754$
$59 / 406$

RCM 1416

RCM 1423

PI-393531

PI-393641

PI-393647
Lima

Casma

Apurimac 
A. Krapovickas \& al., Las razas de maní de Perú

\begin{tabular}{|c|c|c|}
\hline $87 / 2755$ & Bonavia 1-A & Huarochiri \\
\hline $87 / 2756$ & Bonavia 7-A & Lima \\
\hline $87 / 2757$ & Bonavia 8 & Trujillo \\
\hline $87 / 2758$ & US-424-1 & Lima \\
\hline $87 / 2759$ & US-428-3 & “ \\
\hline $87 / 2760$ & US-451 & “ \\
\hline 87/2761 & US-452 & “ \\
\hline $87 / 2762$ & US-453 & “ \\
\hline $87 / 2764$ & US-454 & “ \\
\hline $87 / 2765$ & US-455 & “ \\
\hline $87 / 2766$ & US-456 & Ayacucho \\
\hline $87 / 2767$ & US-457 & “ \\
\hline $87 / 2768$ & US-459 & “ \\
\hline $87 / 2770$ & US-467 & Tarapoto \\
\hline 87/2772 & US-468 & " \\
\hline $87 / 2775$ & US-470 & “ \\
\hline $87 / 2776$ & US-471 & “ \\
\hline $87 / 2778$ & US-472 & “ \\
\hline $87 / 2779$ & US-473 & “ \\
\hline $87 / 2780$ & US-474 & “ \\
\hline $87 / 2782$ & US-476-2 & “ \\
\hline 87/2783 & US-477-2 & Lamas \\
\hline $87 / 2784$ & US-480 & Tarapoto \\
\hline $87 / 2785$ & US-481 & “ \\
\hline $87 / 2786$ & US-483-4 & Iquitos \\
\hline $87 / 2787$ & US-484 & “ \\
\hline $87 / 2788$ & US-485 & “ \\
\hline $87 / 2789$ & US-486 & “ \\
\hline $87 / 2790$ & US-487 & “ \\
\hline $87 / 2791$ & US-488-2 & “ \\
\hline 87/2792 & US-491-2 & “ \\
\hline $87 / 2795$ & US-492 & “ \\
\hline $87 / 2796$ & US-493-3 & “ \\
\hline $87 / 2797$ & US-494-2 & “ \\
\hline 87/2798 & US-496 & “ \\
\hline 87/2799 & US-497-2 & “ \\
\hline $87 / 2800$ & US-500-2 & “ \\
\hline $87 / 2801$ & US-501 & “ \\
\hline 87/2802 & US-504 & “ \\
\hline 87/2803 & US-505-2 & “ \\
\hline
\end{tabular}




\section{Jaspeado sin cerdas}

Planta: eje central aparente, ramas postradas, arqueadas. Tallo verde. Brote apenas violáceo. Estípulas sin cerdas. Clavo morado.

Cajas: cortas, hasta $4 \mathrm{~cm}$ long., raro hasta 4,5 cm, sin pico ni jorobas, con 2-3-1 granos, hasta 1,68 cm long., violáceos, con la punta más oscura y más claros hacia la base. La intensidad y extensión del violáceo varia.
Manfredi 07/08 2042 87/2804
Manfredi 07/08 2043 89/3205
US-486
G.P.Silva 404
Iquitos
Iquitos
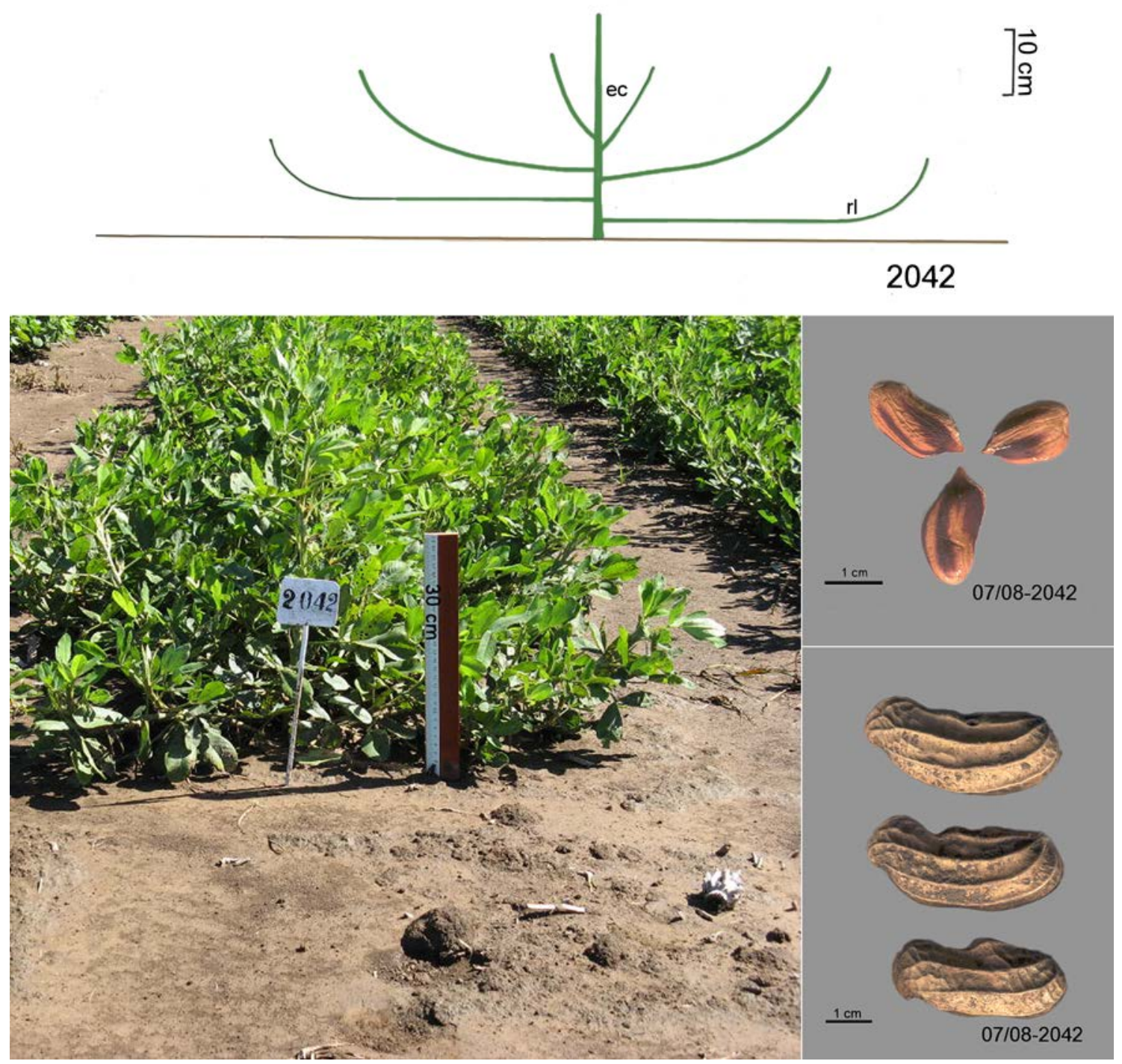


\section{Jaspeado con cerdas}

Planta: erecta. Eje central poco aparente. Ramas rectas, ascendentes. Tallo verde, algo morado hacia la base. Estípulas con cerdas. Brote violáceo. Clavo morado.

Cajas: grandes, hasta $5 \mathrm{~cm}$ long.(raro hastaa 7,5 ccm long..) con jorobas y pico. Nervaduras longitudinales y transversales sobresalientes, con 3-2-1 granos, hasta 2,20 cm long., violáceos, más oscuros hacia el ápice, más claros hacia la base. La intensidad y extención del violáceo es variable.
Manfredi 07/08 2044 87/2810
US-485
Iquitos
Manfredi 07/08 2045 87/2815
US-491-2
Iquitos
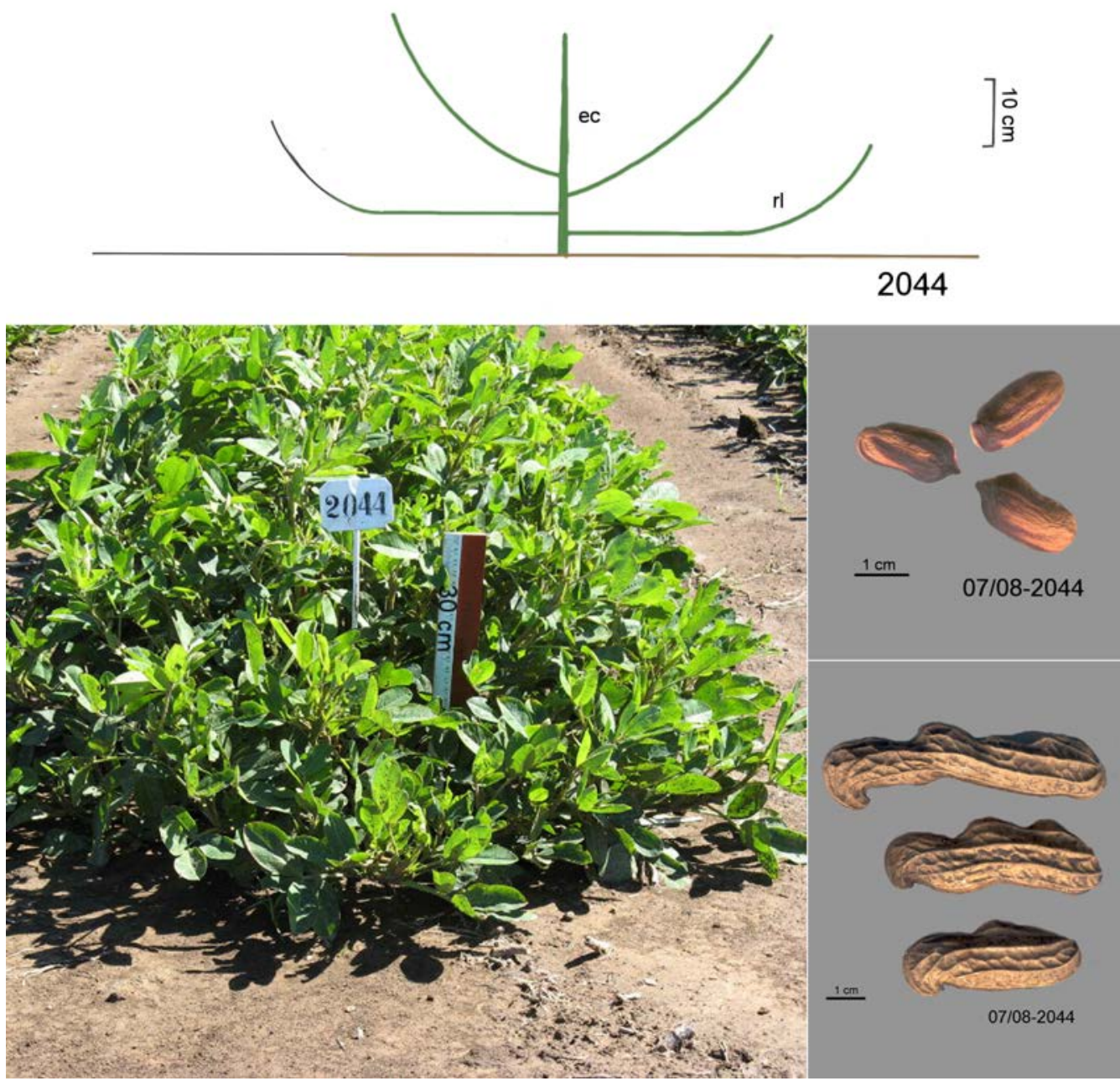

$\begin{array}{ll}87 / 2817 & \text { US-492 } \\ 87 / 2820 & \text { US-494 } \\ 87 / 2824 & \text { US-503-2 }\end{array}$

Iquitos

66

Obs. El color de los granos es muy parecido al del "Jaspeado sin cerdas", del cual se diferencia por la planta más erecta y por sus cajas más largas, con pico y con jorobas. 


\section{Blanco marfíl}

Planta: Erecta compacta, ramificada. Eje central no aparente. Ramas altas. Tallo verde. Estípulas sin cerdas. Clavos verdes.

Cajas: con carena, sin pico, hasta 4,5 cm long. Con 2-3-1 granos, hasta 1,40 cm long., albos, con tinte verdoso.
Manfredi 07/08 2046 87/2889
PI-393517
La Molina
Manfredi 07/08 2047 87/2890
US-472-1
Tarapoto
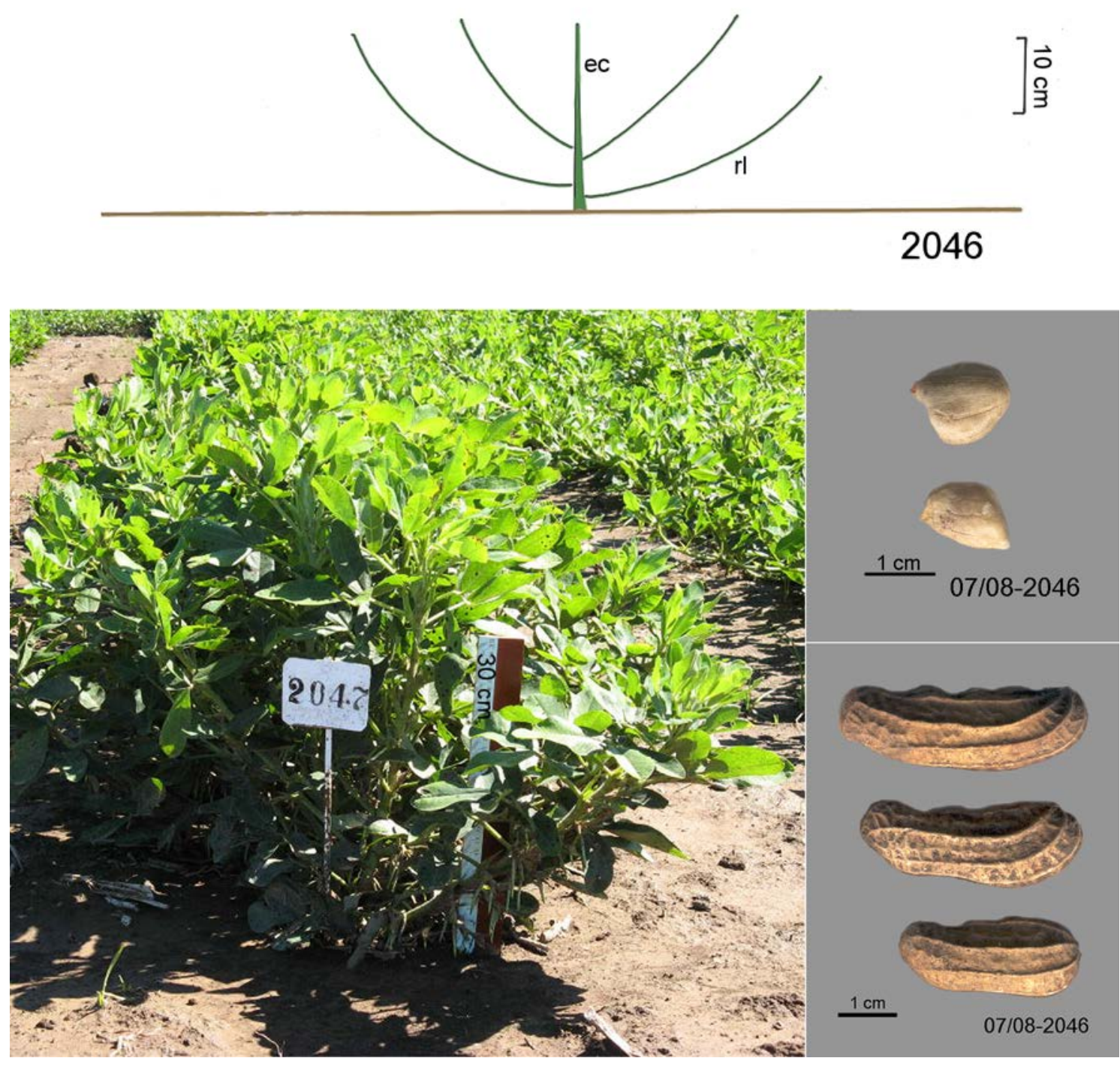


\section{Blanco Tarapoto}

Planta: erecta, desparramada, poco ramificada. Eje aparente, bajo. Ramas sinuosas, tendidas, con muchas ramas reproductivas alargadas. Clavo verde.

Cajas: por lo común no pasan de $4 \mathrm{~cm}$ long. y hasta $5 \mathrm{~cm}$ long., retículo marcado, venas longitudinales finas. Con 2-3-1 granos, hasta 1,90 cm long., pálidos.

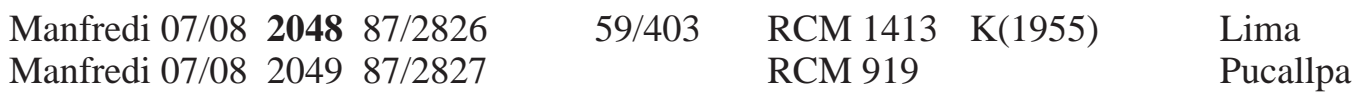
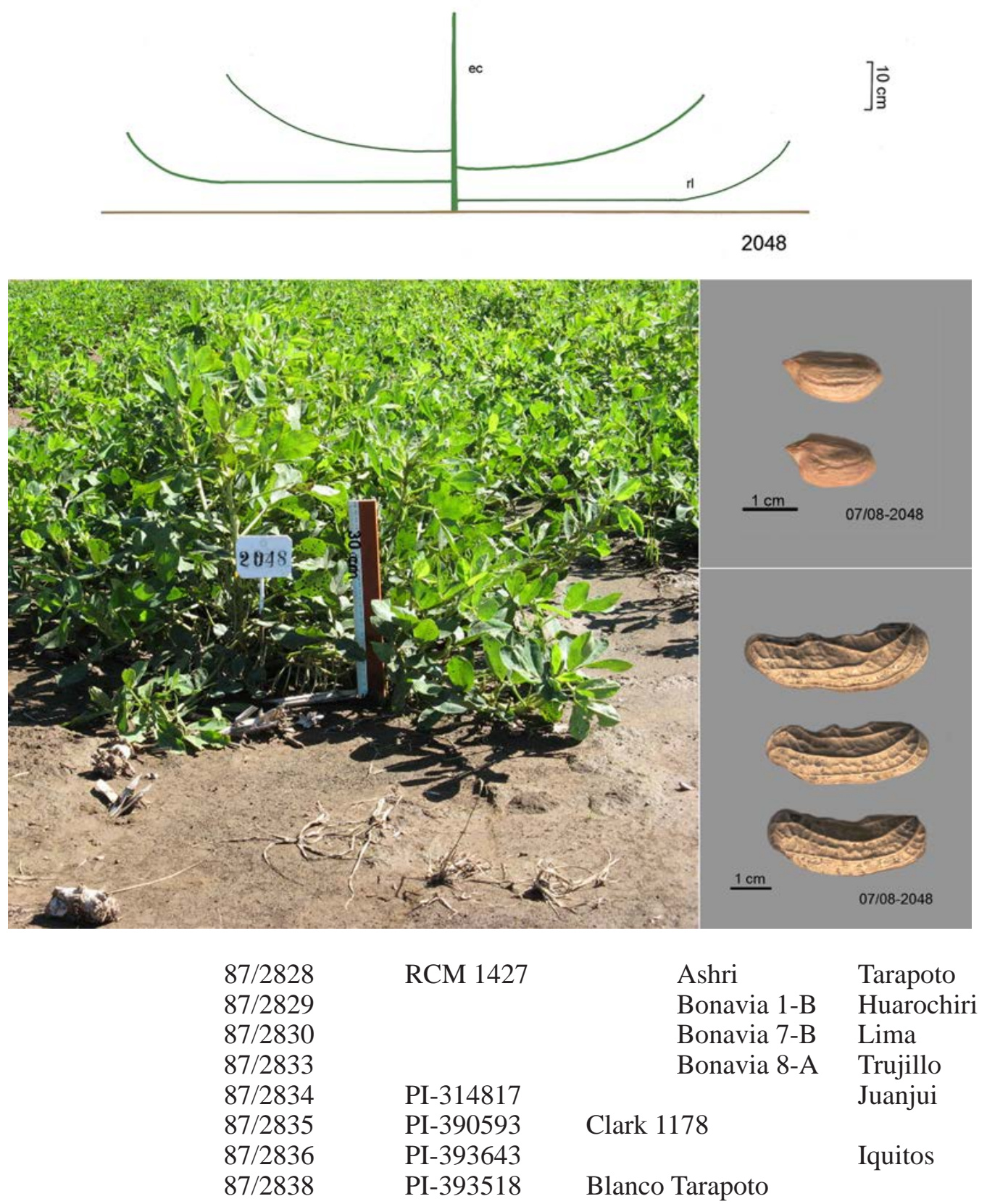


\begin{tabular}{|c|c|c|}
\hline 87/2839 & PI-393520 & Castaño Masisea \\
\hline $87 / 2840$ & PI-393519 & Castaño Masisea \\
\hline $82 / 1532$ & PI-407454 & Blakeslee \\
\hline $87 / 2842$ & US-409 & Cuzco \\
\hline $87 / 2843$ & US-411-2 & Quillabamba \\
\hline 87/2844 ? colorado? & US-415 & La Convención \\
\hline $82 / 1534$ & US-424 & Lima \\
\hline $87 / 2845$ & US-452 & “ \\
\hline $87 / 2846$ & US-453 & “ \\
\hline $87 / 2847$ & US-454 & “ \\
\hline $87 / 2848$ & US-455 & “ \\
\hline $87 / 2849$ & US-457-2 & Aucayacu \\
\hline $87 / 2850$ & US-459-2 & “ \\
\hline 87/2852 & US-460 & Tingo María \\
\hline $87 / 2853$ & US-466 & Tarapoto \\
\hline $87 / 2854$ & US-467 & “ \\
\hline $87 / 2855$ & US-468 & “ \\
\hline $87 / 2856$ & US-470 & “ \\
\hline $87 / 2857$ & US-471 & “ \\
\hline $87 / 2858$ & US-472 & “ \\
\hline 87/2859 & US-473 & “ \\
\hline $87 / 2860$ & US-474 & “ \\
\hline 87/2861 & US-475 & “ \\
\hline 87/2862 & US-476-1 & Lamas \\
\hline 87/2863 & US-477 & “ \\
\hline $87 / 2864$ & US-478 & Yurimaguas \\
\hline $87 / 2865$ & US-479 & “ \\
\hline 87/2866 & US-480 & Tarapoto \\
\hline 87/2867 & US-481 & “ \\
\hline $87 / 2868$ & US-482-1 & Tarapoto \\
\hline 87/2869 & US-483 & Iquitos \\
\hline 87/2970 & US-484 & “ \\
\hline 87/2871 & US-485-2 & “ \\
\hline $82 / 1626$ & US-486 & “ \\
\hline 87/2872 & US-487-2 & “ \\
\hline 87/2873 & US-488-2 & “ \\
\hline 87/2874 & US-490 & “ \\
\hline $87 / 2875$ & US-491 & “ \\
\hline 87/2876 & US-492 & “ \\
\hline 87/2877 & US-493 & “ \\
\hline 87/2878 & US-494-2 & “ \\
\hline $87 / 2879$ & US-496-2 & “ \\
\hline 87/2881 & US-497 & “ \\
\hline 87/2882 & US-499 & “ \\
\hline 87/2883 & US-500-1 & “ \\
\hline 87/2884 & US-501 & “ \\
\hline 87/2885 & US-502-1 & “ \\
\hline 87/2886 & US-503-3 & “ \\
\hline 87/2887 & Bartra 1 & Tarapoto \\
\hline 87/2888 & K 3 (1982) & Cuzco \\
\hline
\end{tabular}




\section{Morado Huayabamba}

Planta: erecta grande, Eje central bien aparente,.Ramas sinuosas, tendidas, con las puntas levantadas, dísticas. Tallo morado. Estípulas con cerdas. Hojas muy grandes, verde oscuro. Brote violáceo. Corola morada. Clavo violáceo.

Cajas: grandes, hasta $5 \mathrm{~cm}$ long. , con jorobas sin pico o con pico incipiente, sin carena. Con 2-3-1- granos, hasta 1,50 cm long., violáceos oscuros, casi negros.
Manfredi 07/08 2050 87/2747
PI-393526
Tripp La Molina

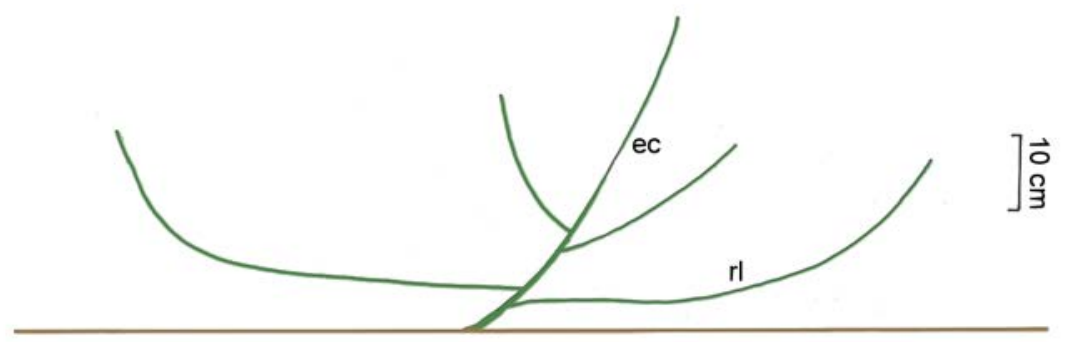

2050

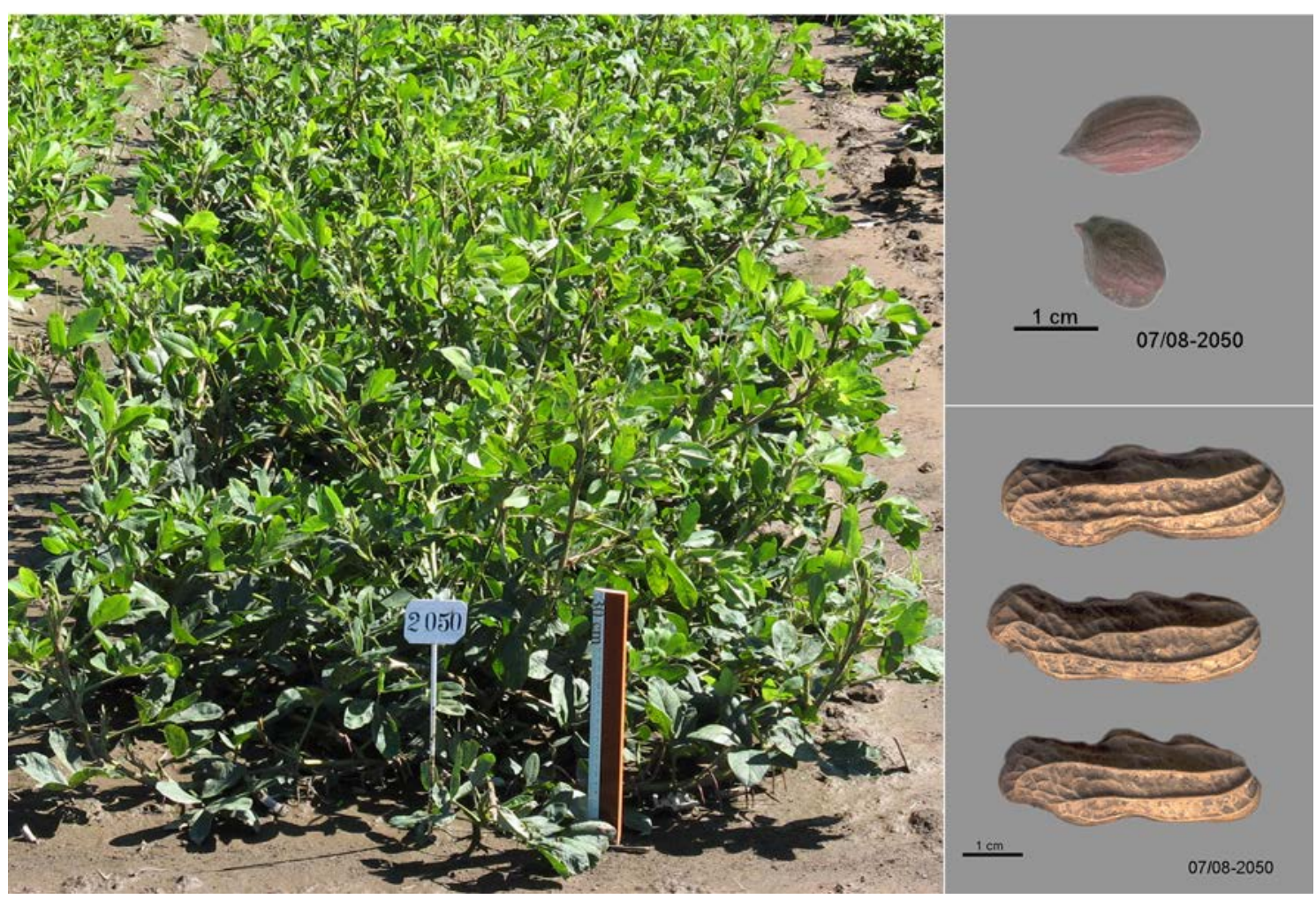




\section{Negro grande}

Planta: erecta, grande. Eje central bien aparente. Ramas tendidas, con las puntas levantadas, dísticas. Tallo violáceo. Cerdas abundantes, en las estípulas, en el pecíolo y hasta en el raquis. Hojas muy grandes. Brote violáceo. Corola morada.

Cajas: hasta 5 cm long., con pico y carena. Con 2-3-1 granos hasta 1,70 cm long. negros.
Manfredi 07/08 2051 87/2748
US-426
Lima

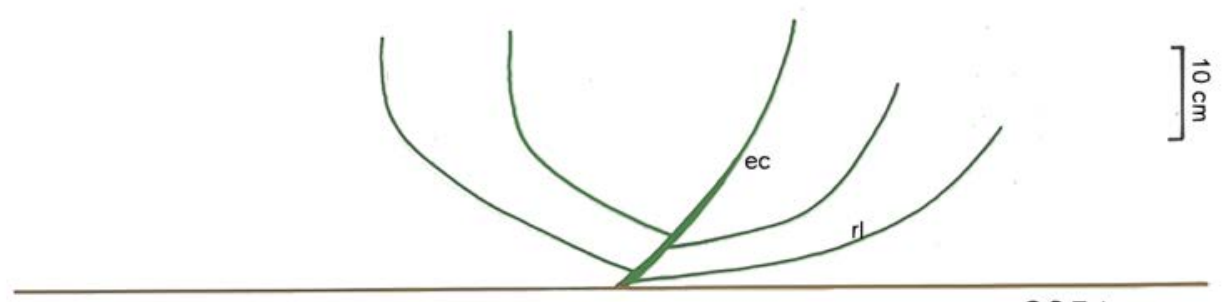

2051

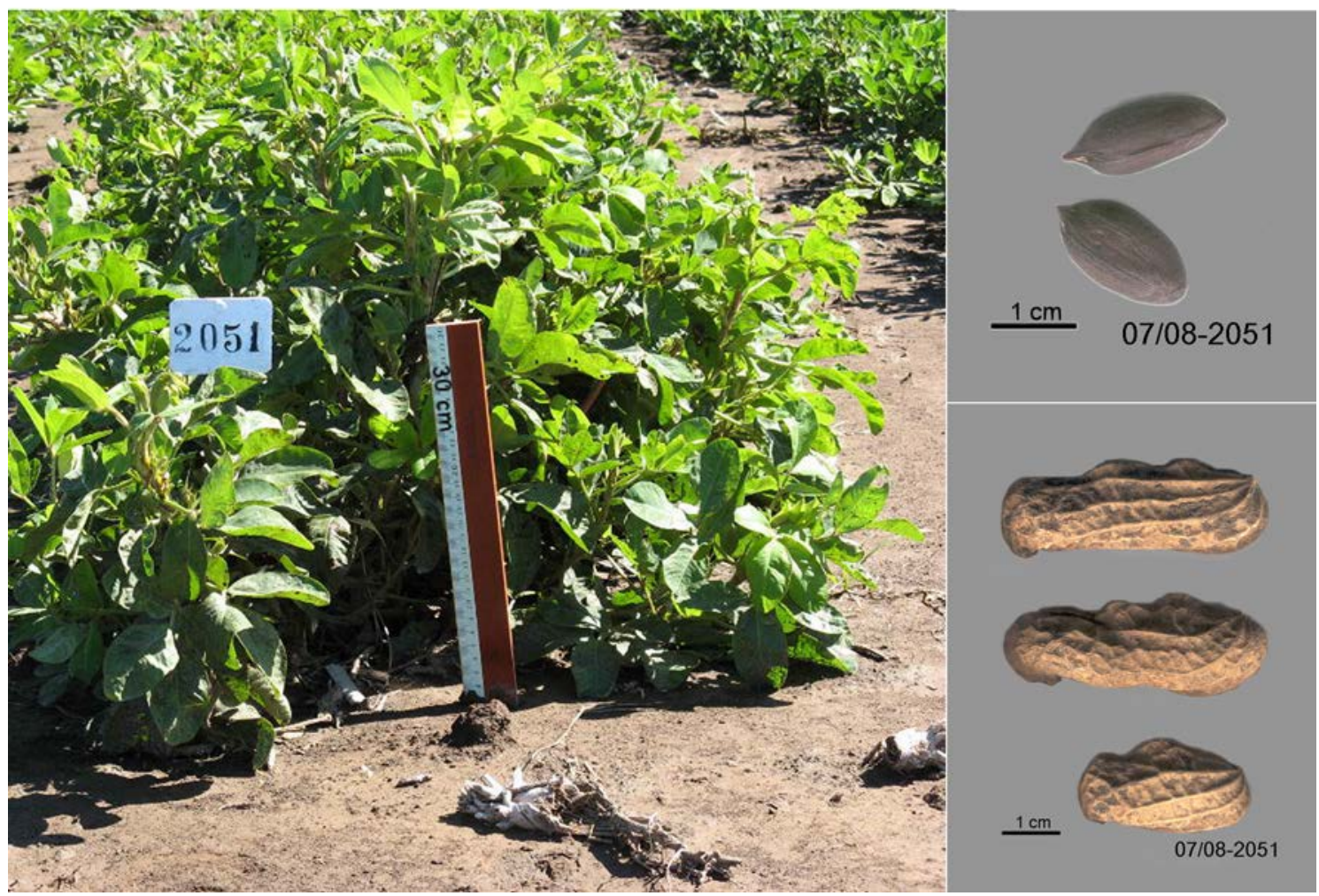




\section{Morado de Iquitos}

Planta: erecta, baja, abierta, poco ramificada. Eje central aparente. Ramas rastreras, medianas. Brote verde. Estípulas sin cerdas. Clavo verde con tinte violáceo.

Cajas: no más de 4 cm long. x 1,5 cm lat., reticuladas, con las nervaduras longitudinales más sobresalientes, con jorobas dorsales poco marcadas, con carena, sin pico o pico apenas insinuado. Con 2-3-1 granos hasta 1,58 cm long. morados.

$\begin{array}{llll}\text { Manfredi 07/08 } 2052 \text { 87/2725 } & \text { US-489 } & & \text { Iquitos } \\ & \text { RCM 1415 } & \text { K(1955) } & \text { Lima }\end{array}$

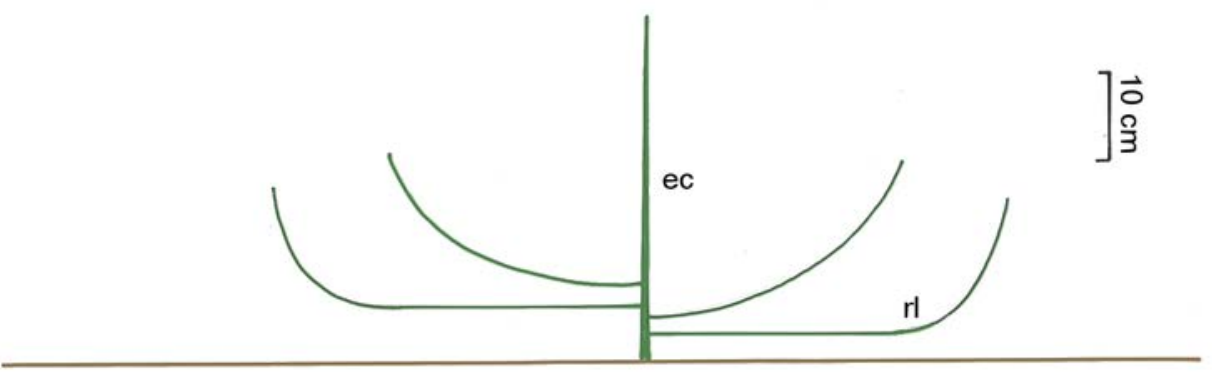

2052

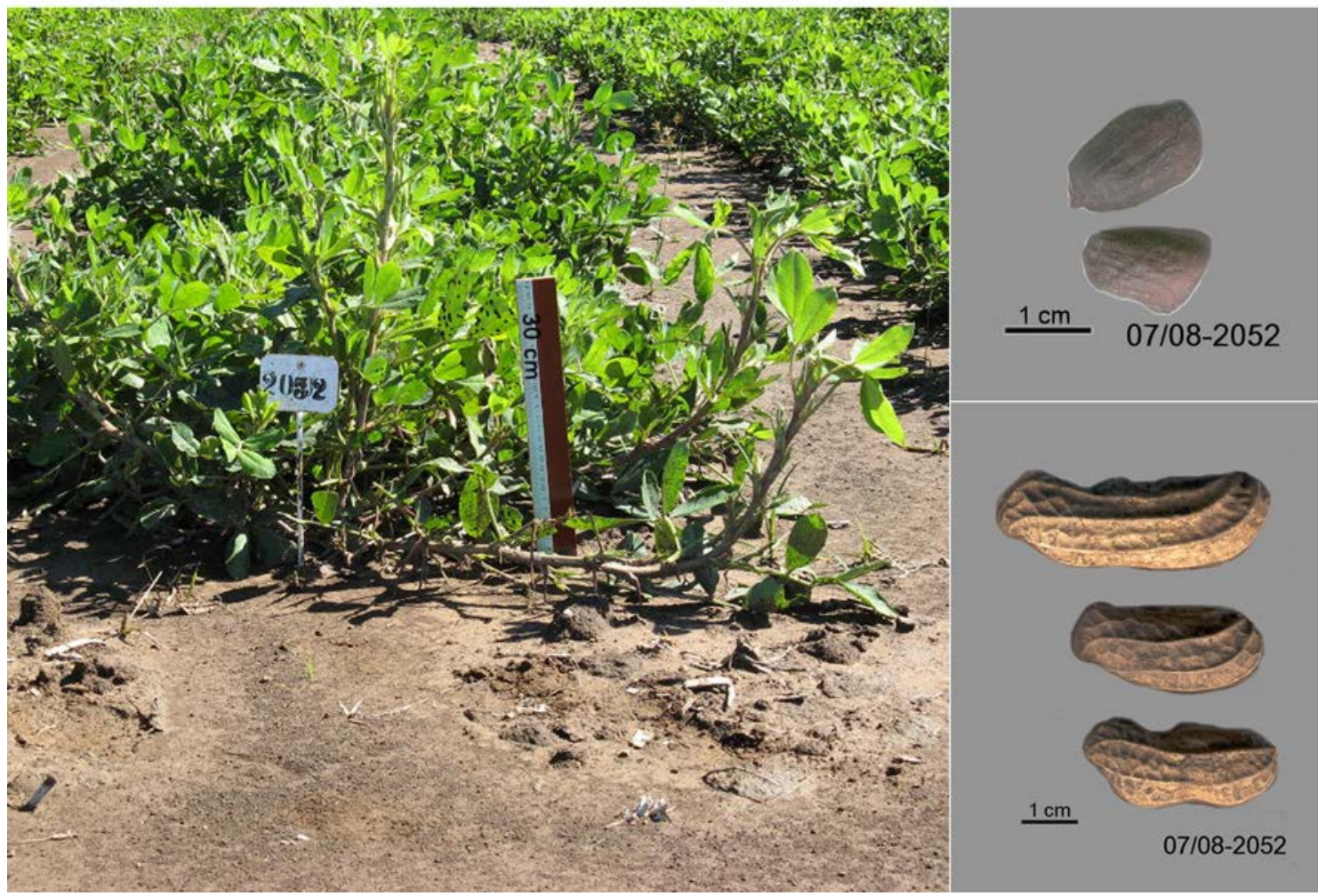

$87 / 2898$

PI-393646

Iquitos

$87 / 2918$

Bartra 4

$87 / 2951$

US-483

Tarapoto

Iquitos 


\begin{tabular}{|c|c|c|}
\hline $87 / 2954$ & US-484 & Iquitos \\
\hline $87 / 2955$ & US-485 & “ \\
\hline $87 / 2958$ & US-487 & “ \\
\hline $87 / 2919$ & US-488 & “ \\
\hline $87 / 2921$ & US-491 & “ \\
\hline 87/2922 & US-492 & “ \\
\hline $87 / 2914$ & US-493-1 & “ \\
\hline $87 / 2925$ & US-494 & “ \\
\hline $87 / 2927$ & US-495-2 & “ \\
\hline 87/2928 & US-496 & “ \\
\hline $87 / 2930$ & US-497-3 & “ \\
\hline 87/2932 & US-498 & “ \\
\hline 87/2934 & US-499-1 & “ \\
\hline $87 / 2935$ & US-500-2 & “ \\
\hline 87/2937 & US-501-1 & “ \\
\hline 87/2939 & US-502 & “ \\
\hline 87/2943 & US-503-1 & “ \\
\hline $87 / 2945$ & US-504 & “ \\
\hline $87 / 2947$ & US-505 & “ \\
\hline
\end{tabular}

Obs. Las cajas son similares a las del “Negro Tarapoto”, pero algo más delgadas. 


\section{Negro de Aucayacu}

Planta: erecta, baja, poco ramificada, Eje central algo aparente. Tallo verde. Brote verde. Estípulas sin cerdas. Corola morada. Clavo verde com algo de violáceo.

Cajas: hasta 4,60 cm long., con pico. Con 2-3-1 granos, hasta 1,60 cm long., negros.
Manfredi 07/08 2054 87/2905
US-459
Aucayacu (Huánuco)
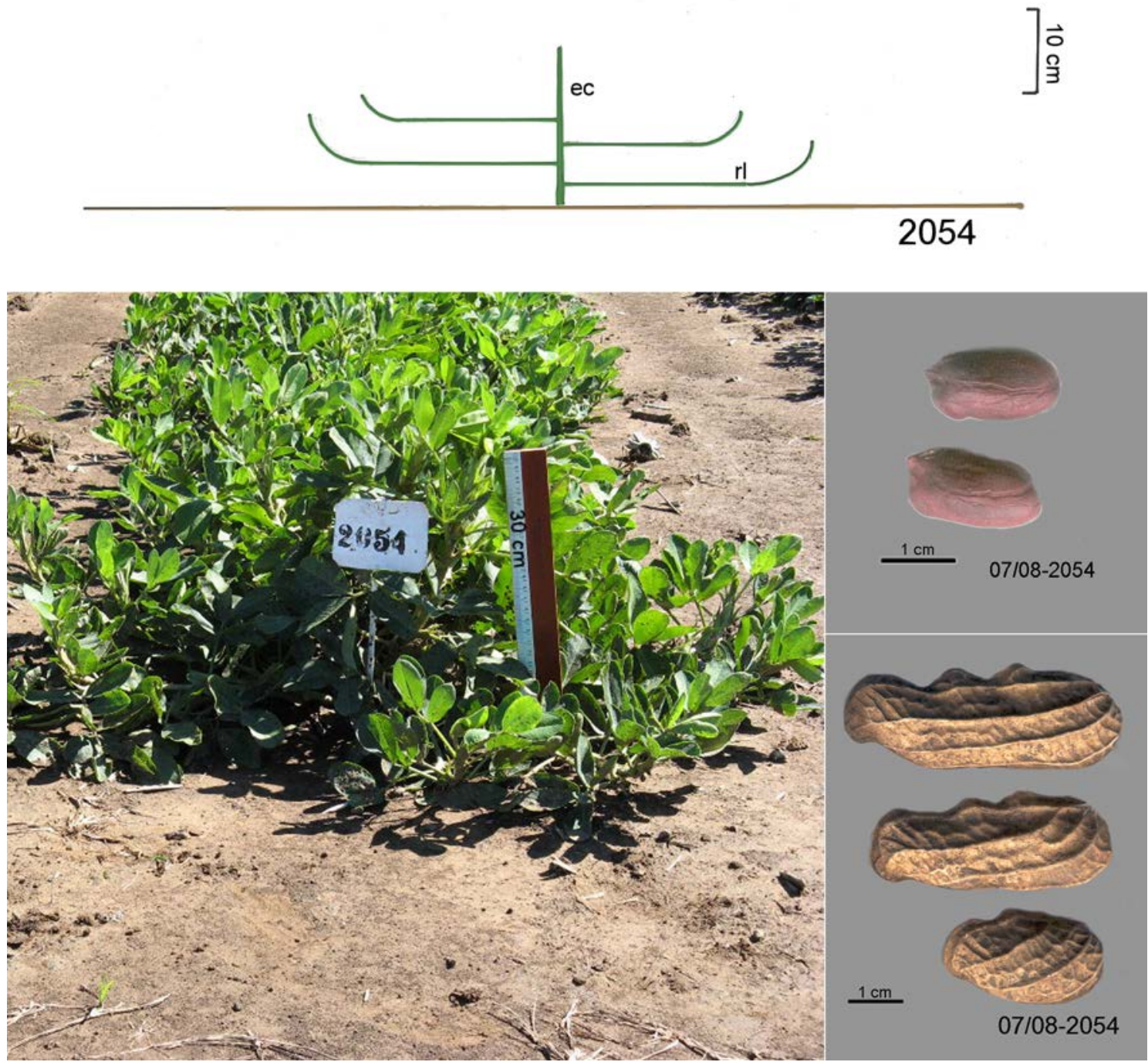


\section{Negro de pocas ramas}

Planta: más o menos ramificada, pocas $n+1$ vegetativas. Eje central aparente. Brote violáceo. Estípulas con cerdas. Corola morada. Clavos morados.

Cajas: grandes, hasta 4,52 cm long., con pico. Retículo con nervaduras longitudinales más marcadas, finas, delicadas. Con 2-3-1 granos, hasta 1,70 cm long. morados (negros no maduros)

\begin{tabular}{|c|c|}
\hline di 07/08 $2055 \quad 87 / 2893$ & RCM-1716 \\
\hline di 07/08 2056 87/2894 & RCM-1717 \\
\hline
\end{tabular}

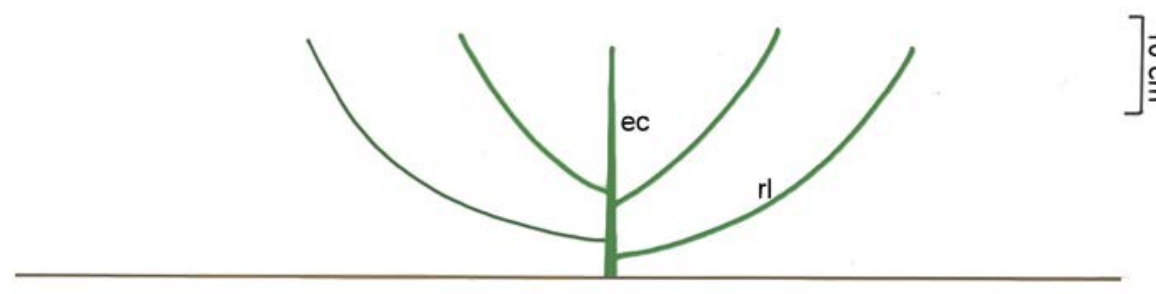

\section{6}
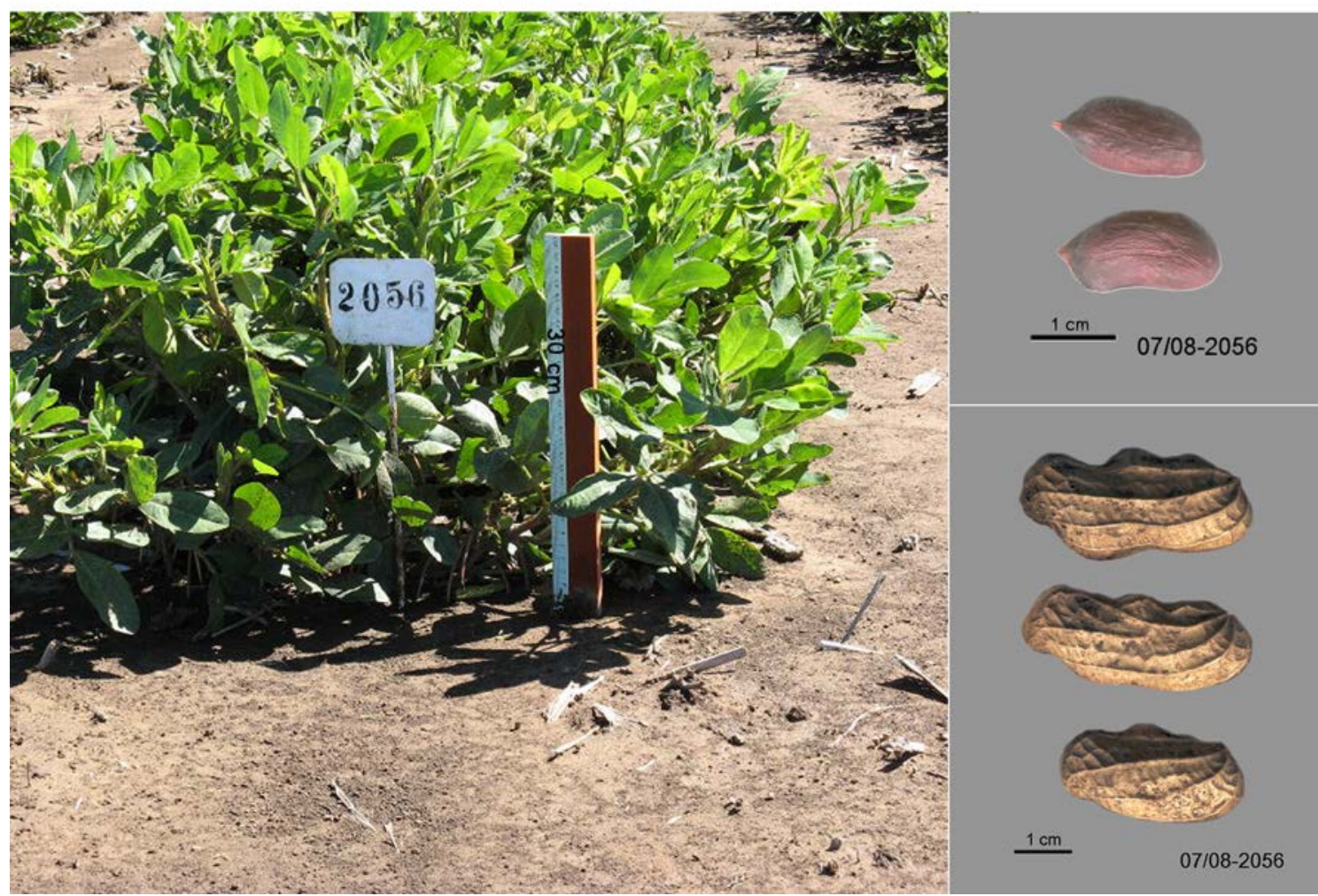

$\begin{array}{ll}87 / 2899 & \text { PI-393516 } \\ 87 / 2906 & \text { US-459 } \\ 87 / 2907 & \text { US-467 } \\ 87 / 2914 & \text { US-479 } \\ 87 / 2950 & \text { US-506 }\end{array}$

La Molina

Aucayacu

Tarapoto

Yurimaguas

Obs. Las cajas son parecidas a las del “Catalán”, pero se diferencian por ser más rectas y presentar nervaduras longitudinales más marcadas. 


\section{Negro Tarapoto}

Planta: erecta, compacta, ramificada. Eje central apenas aparente. Brote verde. Estípulas con cerdas . Estandarte más o menos morado, alas con punta morada.

Cajas: generalmente de unos $4 \mathrm{~cm}$ long. y hasta 5,40 cm long. sin pico. Con 2-3-1-4, hasta 2,10 cm long., morados.

Manfredi 07/08 2057 87/2962 Cat. 59-410 RCM-1417 Peterson "Chincha” Ayacucho Manfredi 07/08 2058 87/2963 411 RCM-1418 “

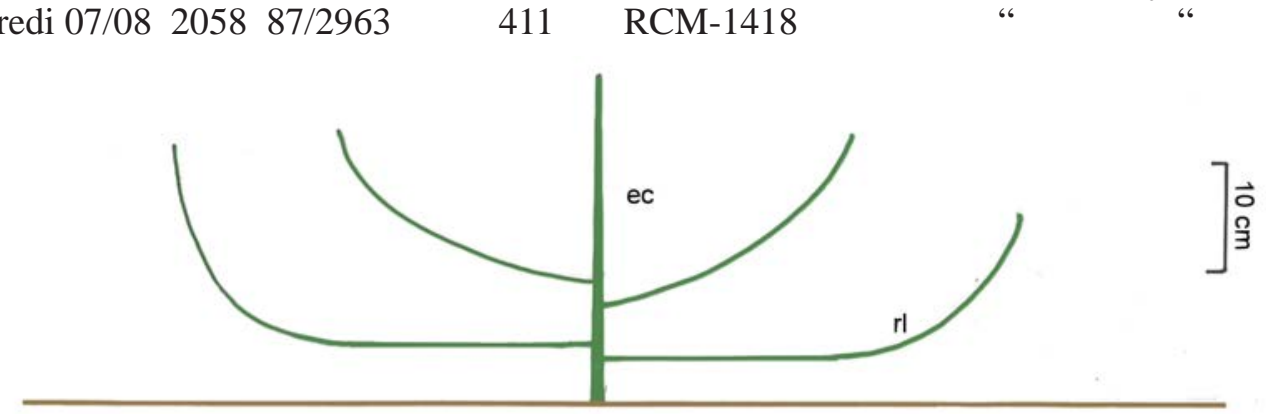

2057

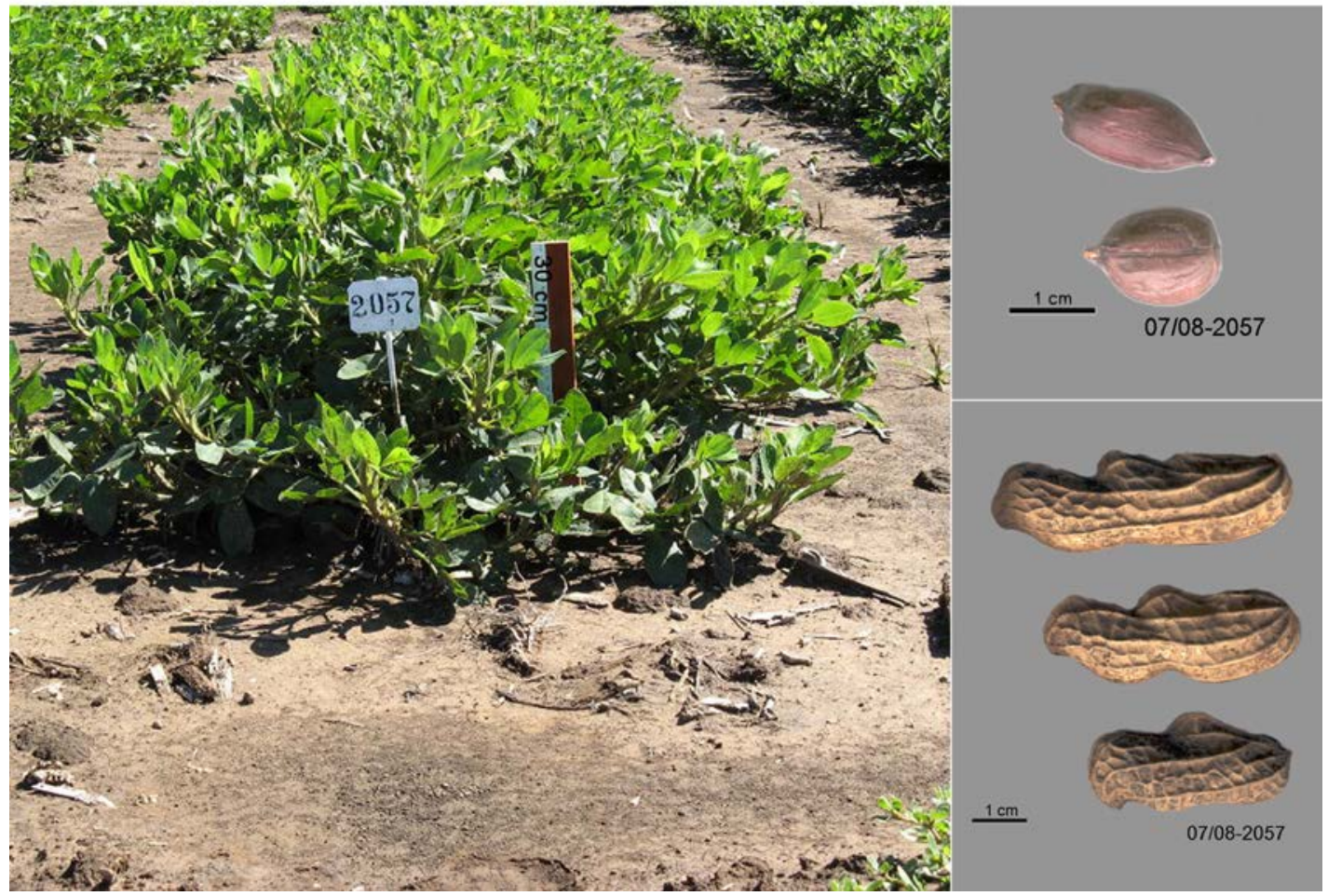

$\begin{array}{ll}87 / 2965 & \text { US-415 } \\ 87 / 2966 & \text { PI-259747 } \\ 87 / 2967 & \text { PI-341879 } \\ 87 / 2968 & \text { PI-350680 } \\ 87 / 2969 & \text { PI-381622 } \\ 87 / 2971 & \text { PI-405132 } \\ 87 / 2972 & \text { US-403 }\end{array}$

La Convención

Tarapoto

$“$
$“$
$“$

Lima 


\section{Yungas}

Planta grande, compacta, ramificada, EC no aparente. Ramas reproductivas cortas. Tallo verde, algo morado. Brote verde. Estípulas con abundantes cerdas. Hojas grandes, verde claro. Estandarte algo morado, alas con la punta morada. Clavos verdes, algo morados.

Cajas: con jorobas sobresalientes, con carena y con pico breve; retículo marcado y líneas longitudinales sobresalientes. Con frecuencia se presentan cajas de hasta $5 \mathrm{~cm}$ long. $\mathrm{x}$ 1,5 cm lat.y pueden llegar a 7 cm long. Con 2-3-1-4 granos hasta 1,76 cm long., violáceos.
Manfredi 07/08 2059 87/2895
Manfredi 07/08 2060 87/2897
RCM-1425
PI-215696
(Ashri) Yungas
Smith 198

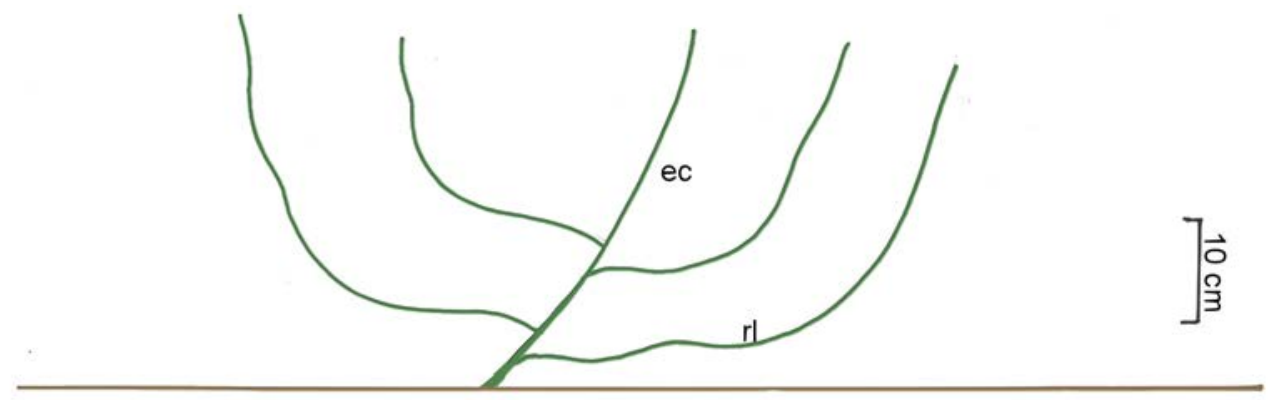

2059

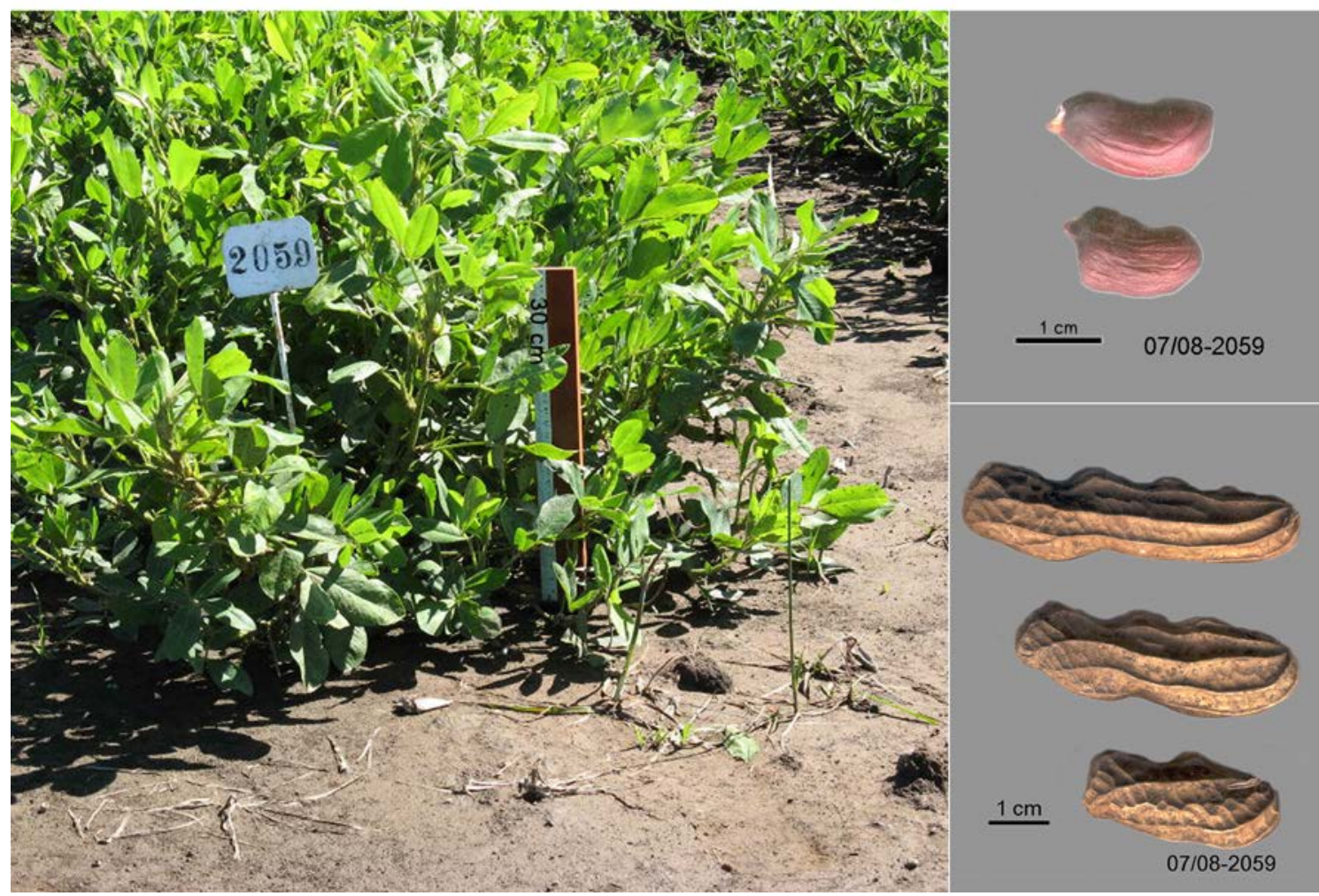

$87 / 2901$

PI-393532

$87 / 2970$

PI-390595

Yungas

W.C. 1206 


\section{Catalan planta abierta}

Planta: erecta, poco ramificada. Eje central alto, aparente. Ramas postradas con las puntas levantadas. Tallo verde, algo morado. Brote verde. Estípulas con cerdas.

Cajas: hasta $6 \mathrm{~cm}$ long. x 1,5 cm lat., con jorobas notables, con carena y pico. Retículo marcado y nervaduras longitudinales prominentes. Con2-3-1-4 granos, hasta $2.08 \mathrm{~cm}$ long., negros.
Manfredi 07/08 2061 87/2896
Bonavia 2
Manfredi 07/08 2062 87/2903
US-452 PI 476144
Huarney
Lima

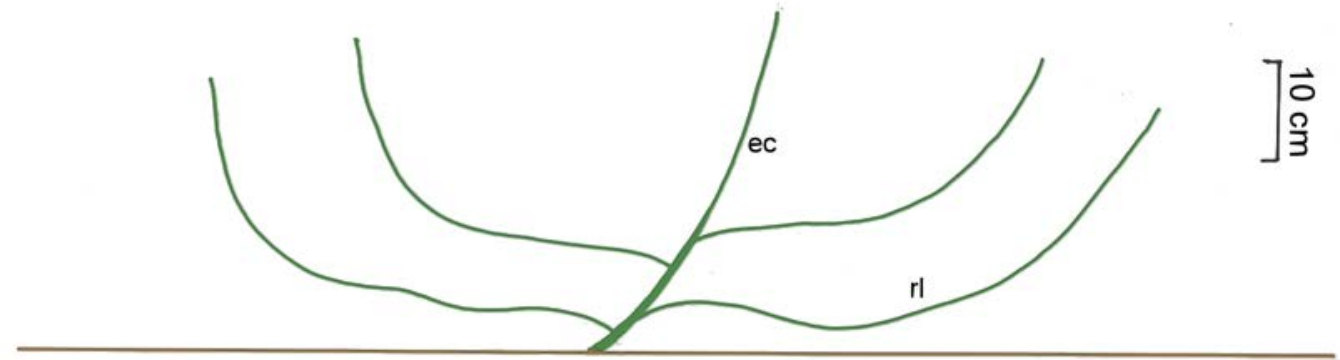

2062

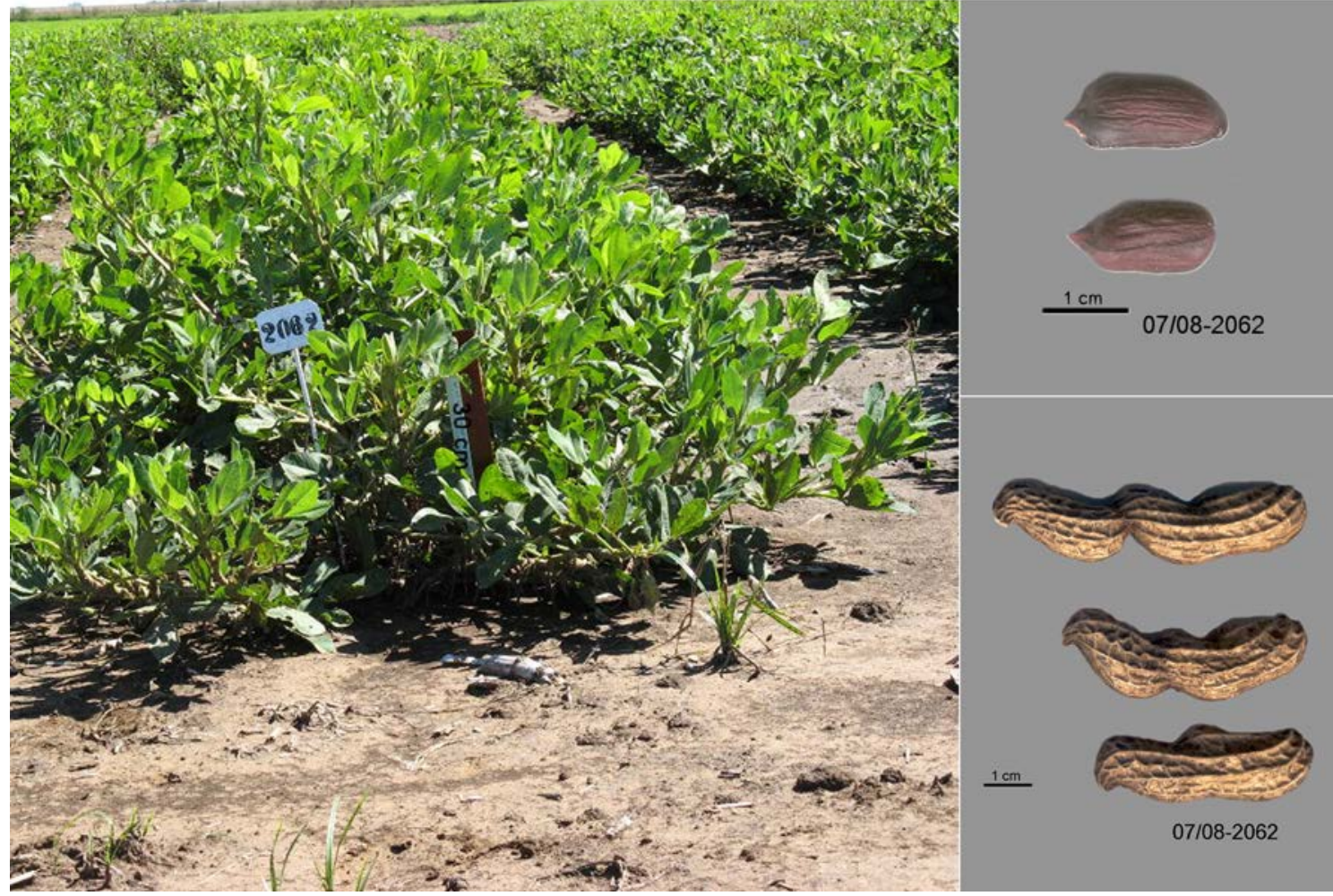

$\begin{array}{ll}87 / 2909 & \text { US-471 } \\ 87 / 2912 & \text { US-477-3 } \\ 87 / 2916 & \text { US-482 } \\ 87 / 2957 & \text { US-486 } \\ 87 / 3235 & \text { Mt. }\end{array}$

Tarapoto

Lamas

Tarapoto

Iquitos

Rioja (Dep. San Martín) 


\section{Catalán}

Planta: erecta, compacta, ramificada. Eje central algo aparente. Ramas más o menos erectas. Brote verde. Estípulas con cerdas abundantes.

Cajas: hasta 5,70 cm long.. Copn 2-3-4-1 granos hasta 2,20 cm long., negros.

$\begin{array}{lllllll}\text { Manfredi 07/08 } & 2063 & 87 / 2891 & \text { Cat.59-404 } & \text { RCM-1414 } & \text { K } & \text { Lima } \\ \text { Manfredi 07/08 } & 2064 & 87 / 2900 & & \text { PI-393530 } & & \text { Tarapoto }\end{array}$
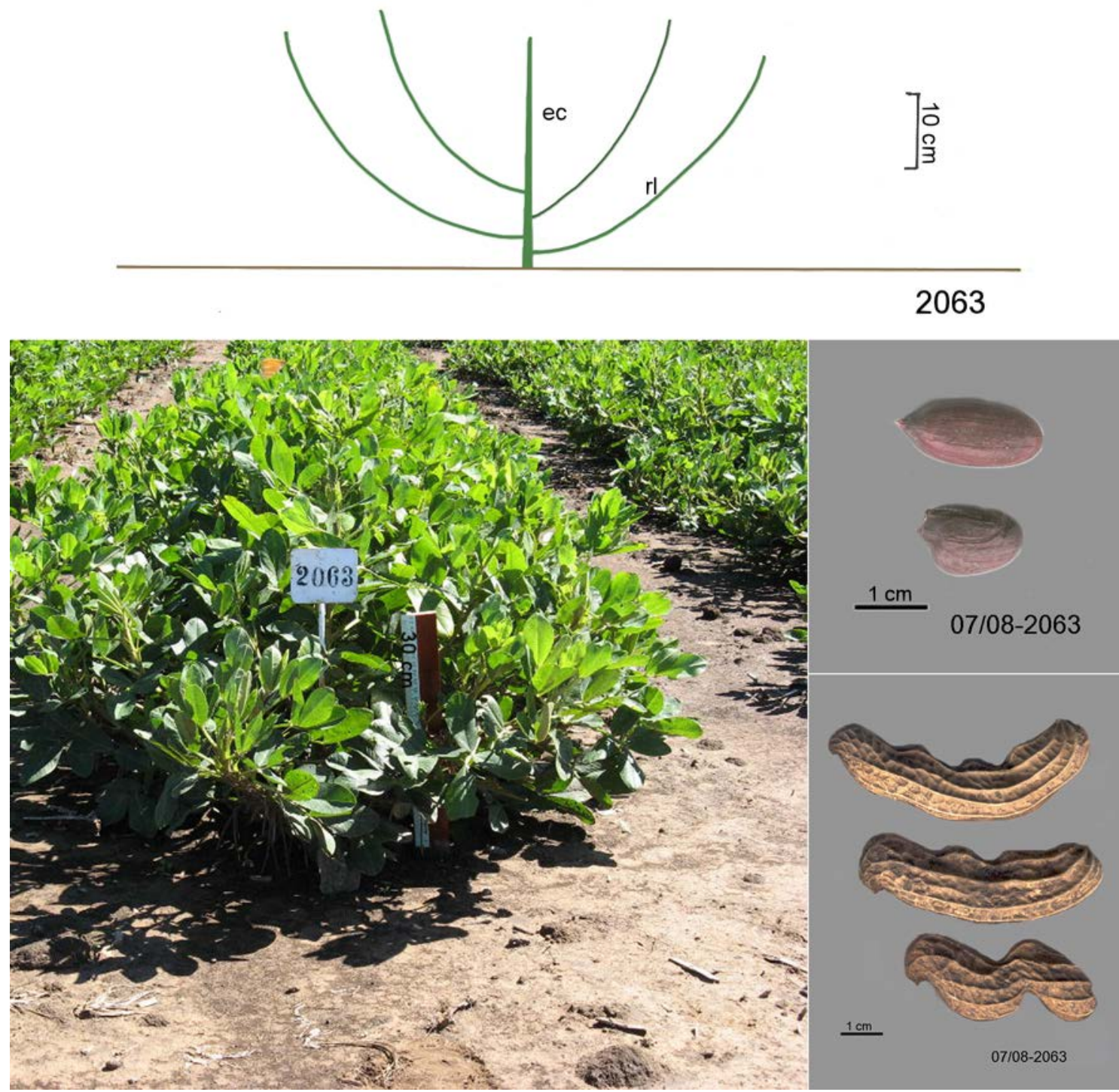

$\begin{array}{ll}87 / 2902 & \text { US-413 } \\ 87 / 2910 & \text { US-476-1 } \\ 87 / 2911 & \text { US-476-2 } \\ 87 / 2915 & \text { US-480 } \\ 87 / 2917 & \text { US-482-2 }\end{array}$

Quillabamba Tarapoto

“

66

66 


\section{Negro erecto}

Planta: erecta, compacta, más o menos grande. Eje central muy aparente. Estípulas con cerdas.

Cajas: hasta 4,60 cm long. Con 2-3-1 granos, hasta 1,60 cm long., violáceo claro.
Manfredi 07/08 2065 87/2908
US-470
Tarapoto

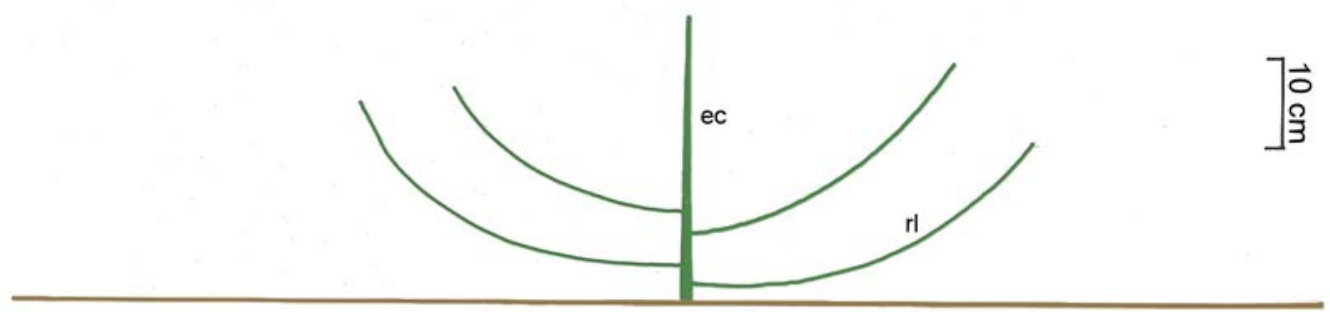

2065
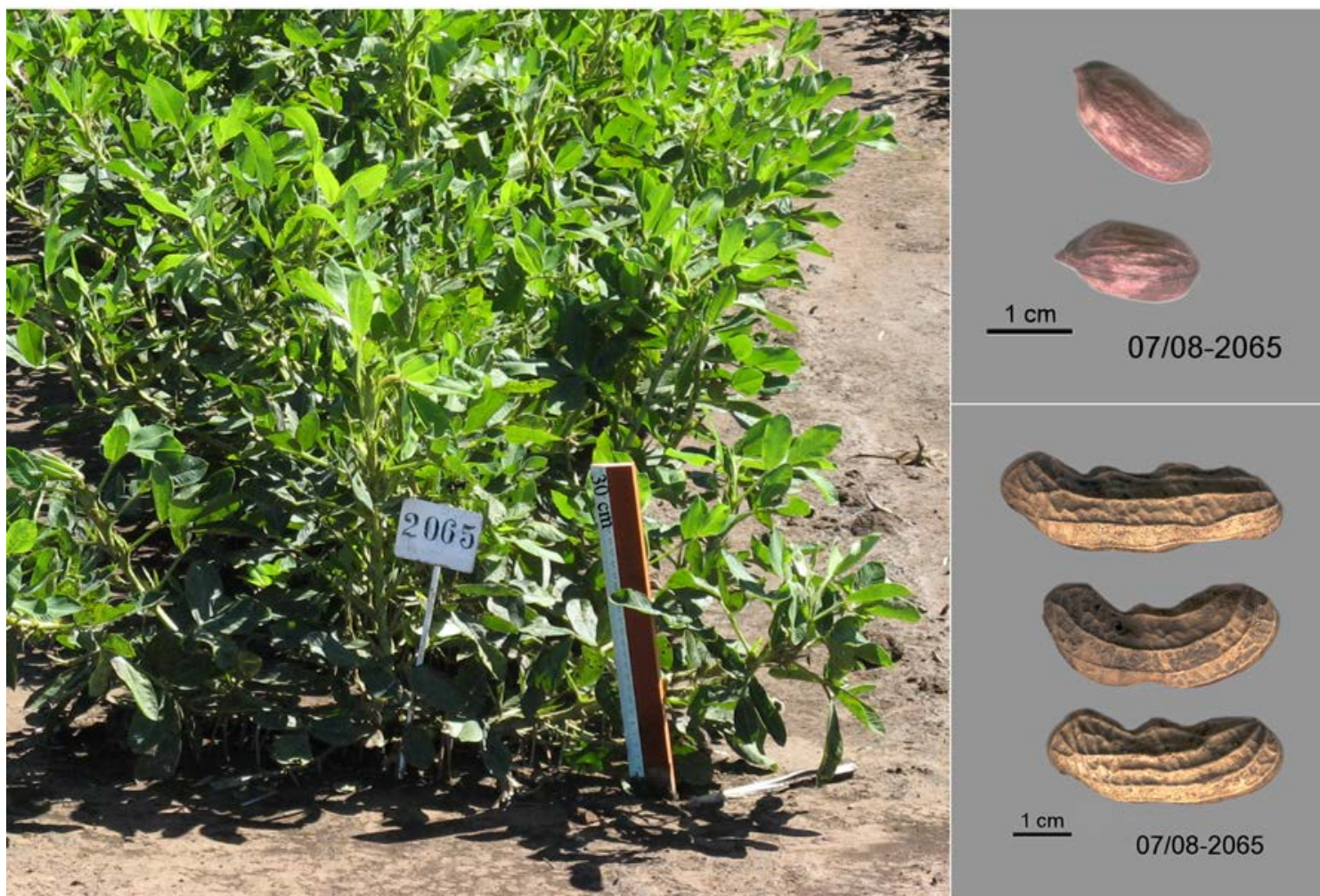


\section{Zaruma}

Planta: erecta, desparramada. Eje central muy aparente, sinuoso. Ramas gruesas, sinuosas. Brote y pecíolo violáceos. Estípulas con cerdas. Corola morada.

Cajas: más o menos cortas, hasta 4,80 cm long., retículo marcado y con nervaduras longitudinales prominentes, con carena y sin pico. Con 2-3-1-4 granos, hasta 1,60 cm long., violáceos con punta clara, variables en la extensión e intensidad del violaceo, aún en una misma planta.

$\begin{array}{llllll}\text { Manfredi 07/08 } 2066 \text { 87/2731 } & \text { Cat.59-413 } & \text { RCM-1419 } & \text { K(1955) } & \text { Lima } \\ \text { Manfredi 07/08 } & 206787 / 2734 & \text { US-403 } & & \text { Lima }\end{array}$
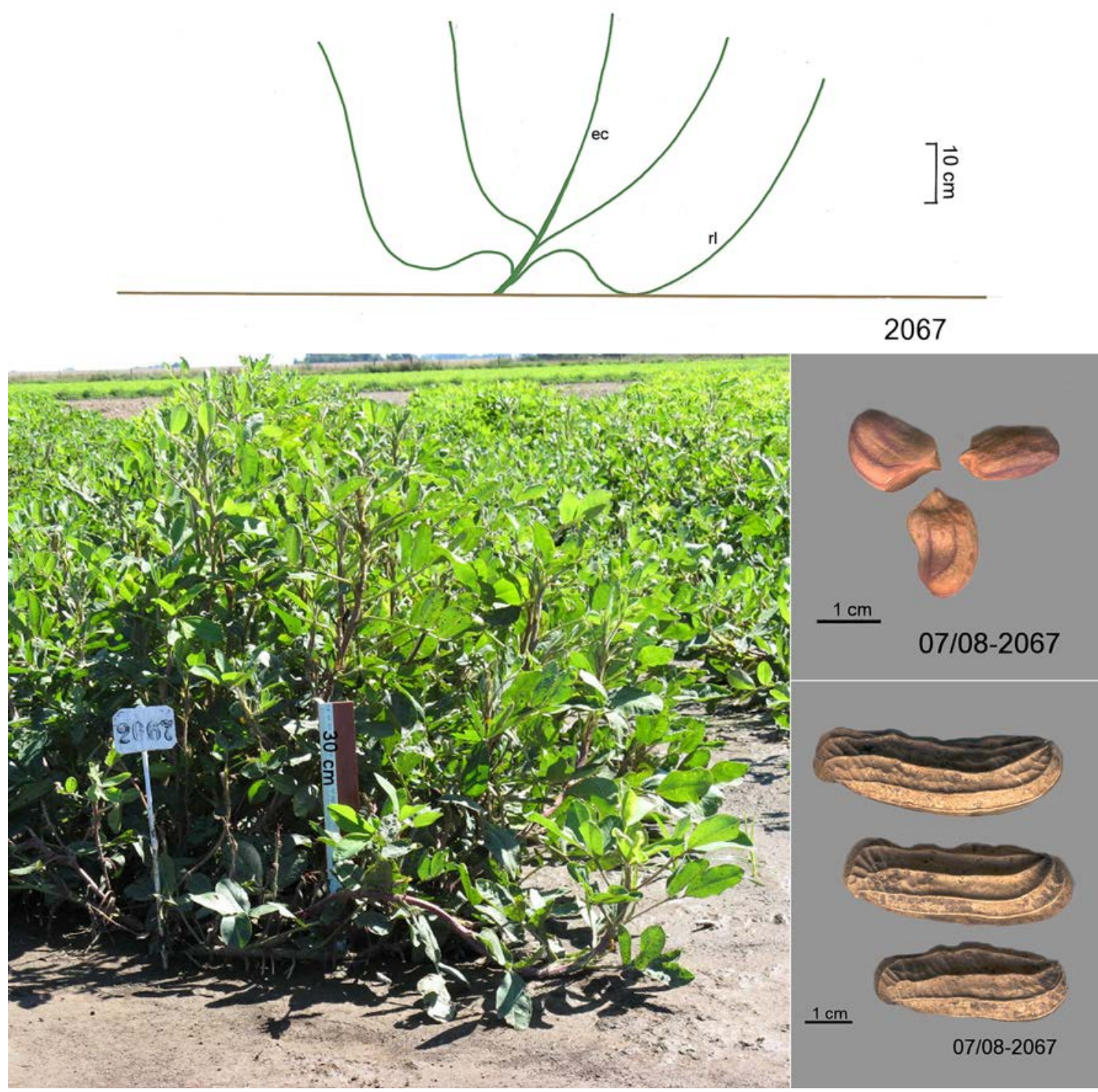

$87 / 2743$

US-425

Lima

$87 / 2745$

PI-393524

Piura

La Molina

87/2966-1

PI-259747 


\section{Huasquillo}

Planta: eje central alto, sinuoso; pocas ramas basales, postradas, sinuosas. Brote y pecíolo violáceo. Estípulas con cerdas. Corola morada.

Cajas: largas, angostas, con jorobas y algo de pico. 3-4 granos largos, negros.
Manfredi 07/08 2068 87/2746
US-403
Lima

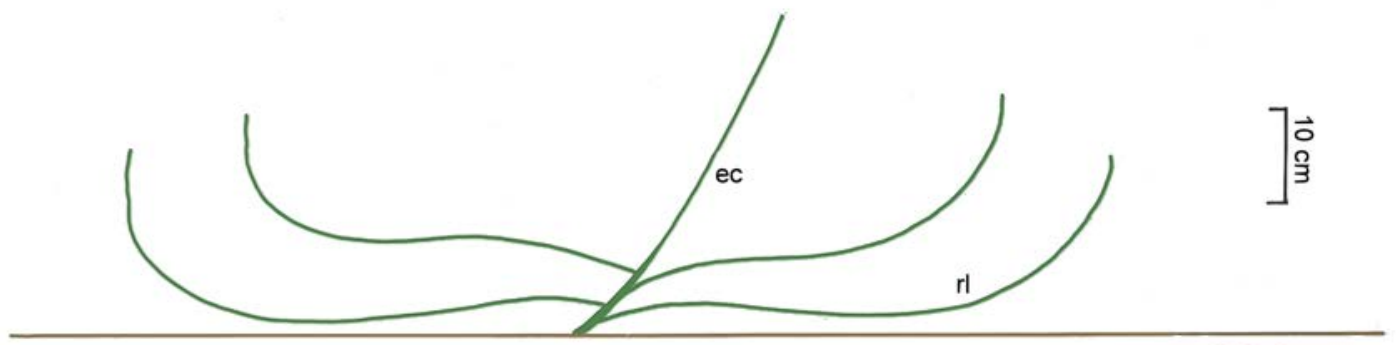

2068

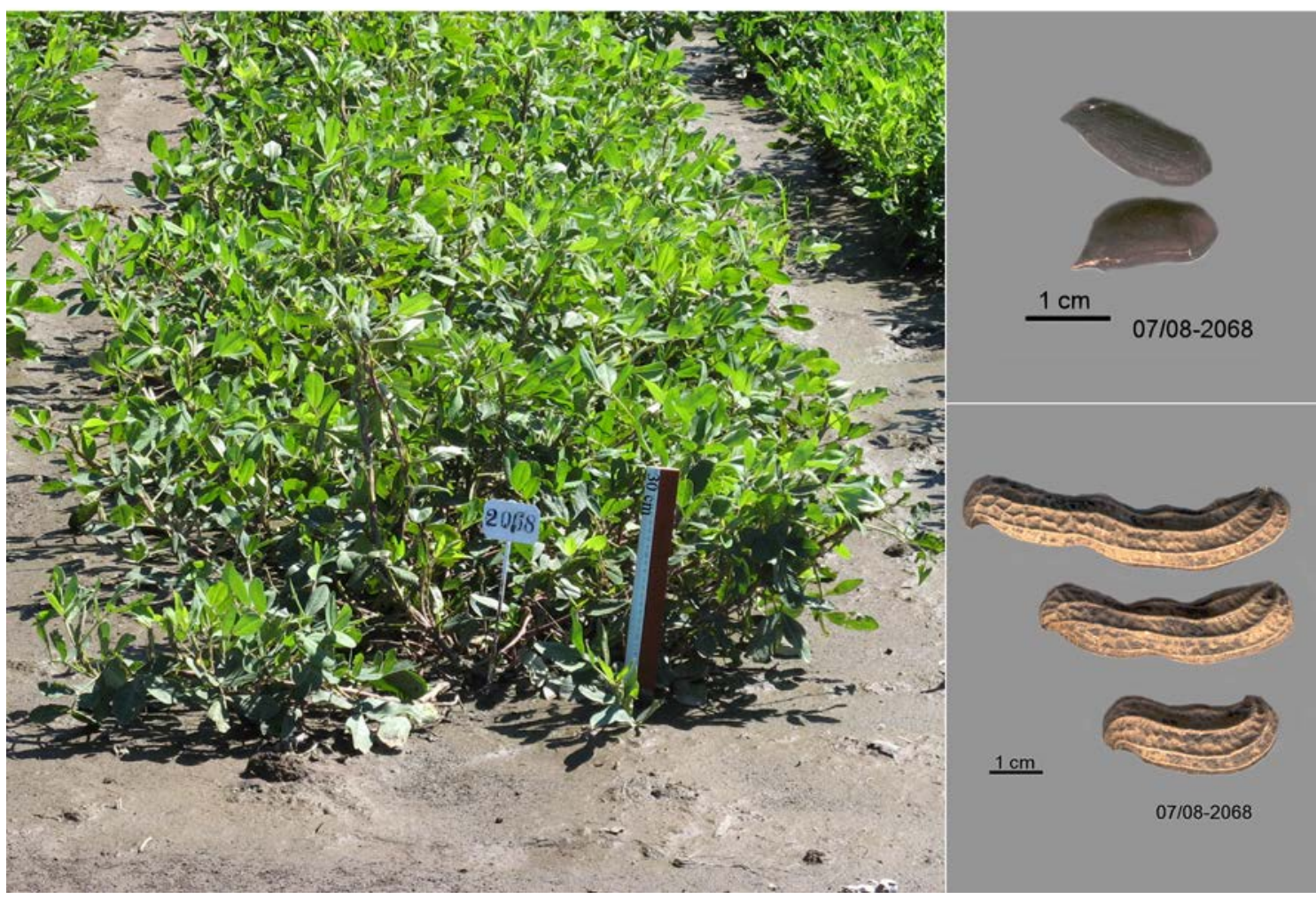




\section{Bibliografía}

ALVA, W. 1988. Discovering the New World's richest unlooted tomb. National Geographic 174(4): 510548.

BANKS, D. J. 1985. The Collection of Arachis hypogaea germoplasm. Technical Report to the International Board for Plant Genetic Resources. Perú-1985. MSS.33 pags.

GROS S , N.R., C.A.GUZMÁN \& J.R.PIETRARELLI.1988 Separación electroforética de proteínas en 65 poblaciones de maní (Arachis hypogaeea L.) de origen boliviano. Su relación taxonómica. Revista Agropecuaria de Manfredi y Marcos Juarez 4: 5-15.

GROSSO,N.R.,A.KRAPOVICKAS,J.R.PIETRARELLI \& C.A. GUZMÁN.1994 Las proteínas seminales del maní (Arachis hypogaea, Leguminosae) y su relación con las categorías infraespecíficas. Bonplandia 8(14): 221-233.

KRAPOVICKAS, A. 2004. Consideraciones prehistóricas sobre el origen del maní cultivado. Academia Nacional de Agronomía y Veterinaria, t. LVIII: 320331.

KRAPOVICKAS. A. \& W. C. GREGORY. 1994. Taxonomía del género Arachis (Leguminosae). Bonplandia 8(1-4): 1-186.

KRAPOVICKAS, A. \& W.C.GREGORY. 2007. Taxonomy of the genus Arachis (Leguminosae). Traslated by D. E. Williams and C. E. Simpson. Bonplandia 16. (Suplemento): 1-205.

KRAPOVICKAS, A. \& V. A. RIGONI. 1960. La nomenclatura de las subespecies y variedades de Arachis hypogaea L. Revista Invest. Agric. 14(2): 197-228.
PIETRARELLI, J. R. 1982. Prospecciones en maní(silvestres y cultivados) con participación de técnicos de la Estación Experimental Agropecuaria de Manfredi (Provincia de Córdoba) Boletín Interno de la coordinación del Programa de Oleaginosas del INTA “OLEICO” Nº17: 37-46.INTA, Manfredi.

PIETRARELLI, J. R. \& A. KRAPOVICKAS. 1990. Catálogo semianalítico de los maníes cultivados (Arachis hypogaea L.) originarios de la región andina (Bolivia, Perú y Ecuador), conservados en la Estación Experimental Agropecuaria de Manfredi (Provincia de Córdoba) R. Argentina. 20 pp.INTA, Manfredi.

SANCHEZ, R. BALDESARI, J, \& O. M. ROYO, 2010. Peanut Genetic Resources Catalogue 2010.E.E.A.Manfredi eds, INTA: 1-144.

SEIJO, J.G., G.L. LAVIA, A. FERNÁNDEZ, A. KRAPOVICKAS,D.DUCASSE\&E.A.MOSCONE. 2004. Physical mapping of the 5 S and 18S-25Sr RNA genes by FISH as evidence that Arachis duranensis and A. ipaensis are the wild diploid progenitors of A.hypogaea (Leguminosae). Amer. J.Bot. 91(9): 1294-1303.

SIMPSON, C.E. 1980. The collection of peanut germplasm 1980.Argentina, Bolivia, Peru. Technical report to the IBPGR, Argentina, Bolivia, Perú. MSS 65 págs.

SIMPSON, C. E. 1981. The Collection of Germplasm 1981. Technical Report to the International Board for Plant Genetic Resources. Perú- Brazil. MSS. 47 pags.

SIMPSON, C. E. \& D. L. HIGGINS. 1984. Catalog of Arachis germplasm collections in South America, 1976-1983. Texas Agricultural Experiment Station. The Texas A\&M University, College Station, Texas, USA.

Original recibido el 3 de abril de 2013; aceptado el 28 de mayo de 2013. 


\title{
ANEXO
}

Listado cronológico de las colecciones de maní de Perú

\author{
ABREVIATURAS \\ Cat. Catálogo \\ Colec. Coleccionista \\ Mdi. Manfredi \\ var. variedad botánica \\ hy var. hypogaea \\ fa var. fastigiata \\ pe var. peruviana \\ ae var. aequatoriana \\ * fotos
}

Cat. Cat. Cat. Cat.(1990) REM Nombre var. raza $59 \quad 73 / 74 \quad 77 / 78 \quad 86 / 87 \quad$ original

Colección Peterson, Ayacucho

$\begin{array}{lllllll}410 & 1417 & 2962 & \mathrm{Pt} & \text { mani chincha } & \text { pe } & \text { Negro Tarapoto } \\ 411 & 1418 & 1963 & \mathrm{Pt} & \text { mani chincha } & \text { pe } & \begin{array}{l}\text { Negro Tarapoto } \\ \text { 417 }\end{array} \\ 41420 & 2631 & \mathrm{Pt} & & \mathrm{fa} & \text { Colorado limeño }\end{array}$

Colección A. Krapovickas, (V-1955)

Perú, dep. Lima, Huaral, 180 m s.m.

$338 \quad 535 \quad 1409 \quad 2611$ hy Rastrero de Huaral

Perú, dep. Lima, Lima, mercado

$\begin{array}{llllll}339 & 536 & 1410 & 2613 & \text { hy } & \begin{array}{l}\text { Rastrero de Huaral } \\ \text { Rastrero de Huaral } \\ 340\end{array} \\ 395 & \text { se perdió } & 1411 & 2614 & \begin{array}{l}\text { hy } \\ \text { hi }\end{array} & \begin{array}{l}\text { Criollo trujillano } \\ \text { “ }\end{array} \\ 396 & \text { se perdió } & & & \text { hi } & \text { Tingo María } \\ 402 & 598 & 1412 & 2749 & \text { pe } & \text { Blanco Tarapoto } \\ 403 & 599 & 1413 & 2826 & \text { pe } & \text { Catalán } \\ 404 & 600 & 1414 & 2891 & \text { pe } & \text { Morado de Iquitos } \\ 405 & 601 & 1415 & 2892 & \text { pe } & \text { Tingo María } \\ 406 & 602 & 1416 & 2750 & \text { pe } & \text { Zaruma } \\ 413 & 1419 & 2731 & 3905 & \text { ae } & \text { Colorado limeño } \\ 418 & 614 & 1421 & 2630 & \text { fa } & \text { Colorado rastrero verde claro } \\ 419 & 615 & 1422 & 2607 & \text { hy } & \end{array}$

\section{Colección enviada por W. C. Gregory}

919

2827 Pucallpa

pe

Blanco Tarapoto

Colección enviada por Mazzani (1957)

$\begin{array}{llllll}1716 & 2893 & 3832 & \text { Tarapoto } & \text { pe } & \text { Negro de pocas ramas } \\ 1717 & 2894 & 3833 & 13-261 & \text { pe } & \text { Negro de pocas ramas }\end{array}$


Colección L. D. Tripp, Agronomy Department Oklahoma State University Stillwater, Oklahoma, U.S.A.(recibido de la Est. Experimental La Molina Perú, 1974).

\begin{tabular}{|c|c|c|c|}
\hline PI. & $\begin{array}{l}\text { Cat.90 } \\
86 / 87\end{array}$ & REM & Nombre original \\
\hline 393516 & 2899 & 3838 & Blanco Huayabamba \\
\hline 333517 & 2889 & 3828 & Blanco Marfil \\
\hline 393518 & 2838 & & Blanco Tarapoto \\
\hline 393519 & 2840 & & Castaño Gigante \\
\hline 393520 & 2839 & & Castaño Masisea \\
\hline 393521 & 2667 & & Copallín Tarapoto \\
\hline 393522 & 2601 & & Haullaga \\
\hline 393523 & 2669 & & Italiano Casma \\
\hline 393524 & 2745 & & Maní Piura \\
\hline 393525 & 2622 & & Morado Gigante \\
\hline 393526 & 2747 & & Morado Huayabamba \\
\hline 393527 & 2624 & & Rojo Gigante \\
\hline 393528 & 2634 & & Rojo Huyabamba \\
\hline 393529 & 2621 & & San Martín \\
\hline 393530 & 2990 & 3839 & Tarapoto \\
\hline 393531 & 2752 & & Tingo María \\
\hline 393532 & 2901 & 3840 & Yungas \\
\hline 393641 & 2753 & & grower near Cosma \\
\hline 393642 & 2633 & & Indians, river Ene \\
\hline 393643 & 2836 & & grower, Iquitos \\
\hline 393646 & 2898 & 3837 & market, Iquitos \\
\hline 393647 & 2754 & & $\begin{array}{l}\text { Apurimac, indians } \\
\text { river, Pichari }\end{array}$ \\
\hline
\end{tabular}

var.

pe $\quad$ Negro pocas ramas

pe Blanco marfil

pe Blanco Tarapoto

pe Blanco Tarapoto

pe Blanco Tarapoto

fa Copallín Tarapoto

hy Huallaga

fa Italiano de Casma

ae Zaruma

hy Morado gigante

pe Morado Huayabamba

hy Rojo gigante

fa Rojo Huaybamba

hy San Martín

pe Catalán

pe Tingo María

pe Yungas

pe Tingo María

fa Colorado limeño

pe Blanco Tarapoto

pe Morado de Iquitos

pe Tingo María

\section{Colección enviada por Ashri (Rehovot- Israel)}

\begin{tabular}{|c|c|c|c|}
\hline $\begin{array}{l}\text { Cat. } \\
77 / 78\end{array}$ & $\begin{array}{l}\text { Cat. } 90 \\
86 / 87\end{array}$ & & \\
\hline 1423 & 2751 & & \\
\hline 1424 & 2632 & & Ayabaca(Piura) \\
\hline 1425 & 2895 & 3834 & Yungas \\
\hline 1426 & 2668 & & Italiano Casma \\
\hline 1427 & 2828 & 3767 & Blanco Tarapoto \\
\hline
\end{tabular}

Colección D. Bonavía, 1978

Dep. Lima, . Huarochiri,2476 m s.m.
1,A 2755
1,B 2829
3768
pe
Tingo María
pe Blanco Tarapoto

Dep. Ancash, Huarmey, 11 m s. m.
2
2896

pe

Catalán planta abierta

Dep. La Libertad, Trujillo, Laredo, 10 m s.m.
3
2626
maní trujillano
hi
Criollo trujillano

Dep. Ancash, Casma, 10 m s.m.

$4, \mathrm{~A}$

2627 hi
Criollo blanco de Casma 
Fabrica de Aceite

\begin{tabular}{|c|c|c|c|c|}
\hline 5,A & 2670 & & fa & Italiano de Casma \\
\hline 7,A & 2756 & & pe & Tingo María \\
\hline $7, \mathrm{~B}$ & 2830 & 3769 & pe & Blanco Tarapoto \\
\hline $7, \mathrm{C}$ & 2831 & 3370 & pe & Blanco Tarapoto \\
\hline 7,D & 2832 & 3771 & pe & Blanco Tarapoto \\
\hline
\end{tabular}

\section{Trujillo}

$\begin{array}{llllll}8 & 2757 & & \text { Jaspeado criollo } & \text { pe } & \text { Tingo María } \\ 8, \mathrm{~A} & 2833 & 3773 & & \text { pe } & \text { Blanco Tarapoto }\end{array}$

Colección enviada por R. O.Hammons, USDA, Crops Reserch Unit, Tifton, Georgia, U.S.A.(23-I-1980). Asecciones resistentes a “ rust”.

$\begin{array}{llllll}\text { PI. } & \text { Cat.90 } & \text { REM } & \text { Nombre original } & \text { var. } & \\ 259747 & 86 / 87 & & & \text { pe } & \text { Negro Tarapoto } \\ \text { “ } & 2966 & 3883 & \text { Tarapoto } & \text { ae } & \text { Zaruma } \\ 341879 & 2966-1 & 3884 & & \text { pe } & \text { Negro Tarapoto } \\ 350680 & 2967 & 3886 & \text { Tarapoto } & \text { pe } & \text { Negro Tarapoto } \\ 381622 & 2968 & 3887 & \text { “ } & \text { pe } & \text { Negro Tarapoto } \\ 405132 & 2969 & 3888 & \text { “ } & \text { pe } & \text { Negro Tarapoto } \\ 215696 & 2971 & & \text { Smith 198 } & \text { pe } & \text { Yungas } \\ 314817 & 2897 & & \text { "DHT 200” Juanjui } & \text { pe } & \text { Blanco Tarapoto } \\ 390593 & 2834 & & \text { "Winter-Clark 1178” } & \text { pe } & \text { Blanco Tarapoto } \\ 390595 & 2975 & 3889 & \text { "W-C 1206” } & \text { pe } & \text { Yungas } \\ 407454 & 1532 & 3893 & \text { "Blakeslee-4” } & \text { pe } & \text { Blanco Tarapoto }\end{array}$

Colección C. E. Simpson \& J. R. Pietrarelli, (V-1980). (Simpson, 1980).

\section{Lima, “Chypi” Company, 14-V-1980}

$\begin{array}{llllll}\text { US } & \text { PI. } & \begin{array}{l}\text { Cat. } 90 \\ 86 / 87\end{array} & \text { REM } & & \\ 403 & 476015 & 2671 & 3658 & \text { fa } & \text { Italiano de Casma } \\ \text { “ } & \text { “ } & 2972 & 3891 & \text { pe } & \text { Negro Tarapoto } \\ 404 & 4 & 2746 & 3908 & \text { ae } & \text { Huasquillo } \\ & 476016 & 2672 & 3659 & \text { fa } & \text { Italiano de Casma }\end{array}$

Cuzco, Mercado Central , C. E. Simpson, J.R.Pietrarelli \& O. Arriola (16-V-1980)

$\begin{array}{lccccl}405 & 476017 & 2673 & 3660 & \text { fa } & \text { Colorado La Convención } \\ 406 & 476018 & 2674 & 3602 & \text { fa } & \text { Colorado La Convención } \\ \text { “ } & \text { “ } & 2602 & 3662 & \text { hy } & \text { Colorado rastrero La Convención } \\ 407 & 476019 & 2676 & 3663 & \text { fa } & \text { Colorado La Convención } \\ 408 & 476020 & 2677 & 3664 & \text { fa } & \text { Colorado La Convención } \\ \text { “ } & \text { “ } & 2709 & & \text { fa } & \text { Pálido clavo verde } \\ \text { 409 } & 476021 & 2678 & 3665 & \text { fa } & \text { Colorado La Convención } \\ \text { “ } & \text { “ } & 2842 & 3783 & \text { pe } & \text { Blanco Tarapoto }\end{array}$

Dep. Cuzco, Prov. La Convención, Quillabamba, mercado Modelo, 950 m s.m. (19-V-1980)C. E. Simpson, J.R. Pitrarelli \& O.Arriola

$\begin{array}{cccccl}410 & 476022 & 2680 & 3666 & \text { fa } & \text { Colorado La Convención } \\ \text { “ } & 2723 & 3698 & \text { fa } & \text { Albo de Quillabamba }\end{array}$


Dep. Cuzco, Prov. La Convención, Quillabamba, mercado Maracana, (19-V-1980), C. E Simpson, J. R. Pietrarelli \& O. Arriola

$\begin{array}{llllll}\text { US } & \text { PI } & \begin{array}{l}\text { Cat. } 90 \\ 86 / 87\end{array} & \text { REM } & \text { var. } & \\ & & & & \\ 411 & 476023 & 2681 & 3667 & \text { fa } & \text { Colorado La Convención } \\ 411-1 & \text { “ } & 2704 & 3686 & \text { fa } & \text { Pálido La Convención } \\ 411-2 & \text { “ } & 2843 & 3784 & \text { pe } & \text { Blanco Tarapoto } \\ 411-4 & \text { “ } & 2721 & 3696 & \text { fa } & \text { Albo de Quillabamba } \\ 412 & 476024 & 2683 & 3668 & \text { fa } & \text { Colorado La Convención } \\ 413 & 476025 & 2902 & 3841 & \text { pe } & \text { Catalán }\end{array}$

Dep. Cuzco, Prov. La Convención, Chontayoc, sector Cinquitone, Valle de la Convención (20-V-1980), C. E. Simpson, J.R. Pietrarelli \& O. Arriola.
414
$476026 \quad 2684$
3669
fa
Colorado La Convención

Dep. Cuzco, Prov. La Convención, Misalniyoc, sector Illapani, Valle de la Convención, (20-V-1980) C.E.Simpson, J. R. Pietrarelli \& O. Arriola

$\begin{array}{cccccl}415 & 476027 & 2685 & 3670 & \text { fa } & \text { Colorado La Convención } \\ \text { “ } & \text { “ } & 2844 & 3785 & \text { pe } & \text { Blanco Tarapoto } \\ & \text { “ } & 2964 & 3881 & \text { pe } & \text { Negro Tarapoto }\end{array}$

Dep. Cuzco, Prov. La Convención, Maniccyo, Valle La Convención (20-V-1980).

C. E. Simpson, J. R. Pietrarelli \& O. Arriola
416
$476028 \quad 2686$
3671
fa
Colorado La Convención

Dep. Cuzco, Prov. La Convención, Chirumbia, Valle La Convención, (20-V-1980).

C. E. Simpson, J. R. Pietrarelloi, \& O. Arriola,

$\begin{array}{llllll}417 & 476029 & 2606 & 3604 & \text { hy } & \text { Colorado rastrero La Convención } \\ 418 & 476030 & 2687 & 3672 & \text { fa } & \text { Colorado La Convención }\end{array}$

Dep. Cuzco, Prov. La Convención, Loroquachaua, Valle de la Convención (20-V-1980).

C.E.Simpson, J. R. Pietrarelli \& O. Arriola.

$\begin{array}{llllll}419 & 476031 & 2722 & 3697 & \text { fa } & \text { Albo de Quillabamba } \\ 420 & 476032 & 2688 & 3673 & \text { fa } & \text { Colorado La Convención }\end{array}$

Dep. Cuzco, Prov. La Convención, Chirumbia, Valle de la Convención (20-V-1980)

C. E. Simpson, J.R. Pietrarelli \& O. Arriola.

$$
421 \quad 476033 \quad 2689 \quad 3674 \quad \text { fa } \quad \text { Colorado La Convención }
$$

Dep. Cuzco, Prov. La Convención, sector Vilcabamba Estación Experimental Sahuayaco (20-V-1980) C. E. Simpson, J. R. Pietrarelli \& O. Arriola.

$422 \quad 476034 \quad 2603 \quad 3603$ hy Colorado rastrero La Convención

Lima, mercado Central(22-V-1980)C. E. Simpson \& J. R. Pietrarelli.

$\begin{array}{llllll}423 & 476035 & 2635 & 3625 & \text { fa } & \text { Colorado limeño } \\ 424 & 476036 & 2690 & & \text { fa } & \text { Colorado limeño }\end{array}$




$\begin{array}{lcllll}\text { US } & \text { PI } & \begin{array}{l}\text { Cat. } 90 \\ 86 / 87\end{array} & \text { REM } & \text { var. } & \\ \text { “ } & \text { “ } & 2716 & & \text { fa } & \text { Pálido limeño } \\ 424-1 & \text { “ } & 2758 & & \text { pe } & \text { Tingo María } \\ 424-2 & \text { “ } & 2710 & & \text { fa } & \text { Pálido clavo verde } \\ 425 & 476037 & 2636 & & \text { fa } & \text { Colorado limeño } \\ 426 & 476038 & 2638 & 3627 & \text { fa } & \text { Colorado limeño } \\ \text { “ } & \text { “ } & 2748 & 3711 & \text { pe } & \text { Negro grande } \\ 427 & 476039 & 2640 & 3628 & \text { fa } & \text { Colorado limeño } \\ 428 & 476040 & 2641 & & \text { fa } & \text { Colorado limeño } \\ 428-1 & \text { “ } & 2703 & & \text { fa } & \text { Rosado limeño } \\ 428-2 & \text { “ } & 2712 & & \text { fa } & \text { Pálido clavo verde } \\ 428-3 & \text { “ } & 2759 & 3722 & \text { pe } & \text { Tingo María } \\ 429 & 476041 & 2643 & 3631 & \text { fa } & \text { Colorado limeño }\end{array}$

Lima, Mercado de Casma (12-V-1981) C. E. Simpson, J.R. Pietrarelli \& Zurita.

$\begin{array}{cccccl}451 & 476143 & 2691 & & \text { fa } & \text { Italiano de Casma } \\ \text { “ } & \text { “ } & 2705 & 3723 & \text { fa } & \text { Pálido La Convención } \\ 452 & 476144 & 2760 & & \text { pe } & \text { Tingo María } \\ \text { “ } & 2692 & & \text { fa } & \text { Italiano de Casma } \\ \text { “ } & \text { “ } & 2761 & & \text { pe } & \text { Tingo María } \\ \text { “ } & 2845 & 3786 & \text { pe } & \text { Blanco Tarapoto } \\ & \text { “ } & 2692 & 3842 & \text { pe } & \text { Catalán planta abierta }\end{array}$

Lima, Mercado Central (12-V-1981) C. E. Simpson, J. R. Pietrarelli \& Zurita. (Simpson, 1981)

$\begin{array}{cccccl}453 & 476145 & 2694 & 3725 & \text { fa } & \text { Italiano de Casma } \\ \text { “ } & \text { “ } & 2762 & & \text { pe } & \text { Tingo María } \\ 4 & \text { “ } & 2846 & 3787 & \text { pe } & \text { Blanco Tarapoto } \\ 454 & 476146 & 2695 & 3726 & \text { fa } & \text { Italiano de Casma } \\ \text { “ } & \text { “ } & 2764 & & \text { pe } & \text { Tingo María } \\ \text { “ } & \text { “ } & 2847 & 3788 & \text { pe } & \text { Blanco Tarapoto } \\ 455 & 476147 & 2696 & 3681 & \text { fa } & \text { Italiano de Casma } \\ \text { “ } & \text { “ } & 2765 & 3727 & \text { pe } & \text { Tingo María } \\ \text { “ } & \text { “ } & 2848 & 3789 & \text { pe } & \text { Blanco Tarapoto }\end{array}$

Dep. Huánuco, Aucayacu, 484 m s.m. (14-V-1980) C. E. Simpson, J.R. Pietrarelli \& Zurita

$\begin{array}{cccccl}456 & 476148 & 2644 & 3632 & \text { fa } & \text { Colorado limeño } \\ \text { “ } & \text { “ } & 2697 & 3682 & \text { fa } & \text { Italiano de Casma } \\ 4 & \text { “ } & 2766 & 3728 & \text { pe } & \text { Tingo María } \\ 457 & 476149 & 2767 & 3729 & \text { pe } & \text { Tingo María } \\ 457-2 & \text { “ } & 2849 & 3790 & \text { pe } & \text { Blanco Tarapoto } \\ 459 & 476151 & 2768 & & \text { pe } & \text { Tingo María } \\ \text { “ } & \text { “ } & 2905 & & \text { pe } & \text { Negro de Haucayacu } \\ \text { “ } & \text { “ } & 2906 & & \text { pe } & \text { Negro pocas ramas } \\ 459-2 & \text { “ } & 2850 & & \text { pe } & \text { Blanco Tarapoto }\end{array}$

Dep. Huánuco, Tingo María, mercado , 534 m s. M.(16-V-1981), C. E. Simpson, J. E. Pietrarelli \& Zurita

$\begin{array}{cccccl}460 & 476152 & 2645 & 3633 & \text { fa } & \text { Colorado limeño } \\ \text { “ } & \text { “ } & 2713 & 3692 & \text { fa } & \text { Pálido clavo verde } \\ \text { “ } & \text { “ } & 2852 & 3793 & \text { pe } & \text { Blanco Tarapoto }\end{array}$


Dep. Huánuco, Huánuco, mercado Viejo, 2000 m s.m. (16-V-1981)C.E.Simpson, J. R. Pietrarelli \& Zurita

$\begin{array}{llllll}\text { US } & \text { PI } & \text { Cat. } 90 & \text { REM } & \text { var. } & \\ 461 & 476153 & 86 / 87 & & \text { hy } & \text { Rastrero grande de Huánuco }\end{array}$

Dep. Huánuco, Huánuco, merdaco Nuevo (16-V1981) C. E. Simpson, J. R. Pietrarelli \& Zurita

\begin{tabular}{|c|c|c|c|c|c|}
\hline 462 & 476154 & 2617 & 3613 & hy & Overo de Huánuco \\
\hline 463 & 476155 & 2609 & & hy & Cojín colorado \\
\hline 464 & 476156 & 2610 & & hy & Cojín colorado \\
\hline
\end{tabular}

Dep. San Martín, Tarapoto, mercado, 350 m s. m. (18-V-1981)C. E. Simpson, J. R. Pietrarelli \& Zurita

\begin{tabular}{|c|c|c|c|c|c|}
\hline 466 & 476158 & 2654 & & fa & Colorado Tarapoto \\
\hline “ & & 2853 & 3794 & pe & Blanco Tarapoto \\
\hline $466-1$ & “ & 2726 & 3701 & fa & Colorado con vetas \\
\hline 467 & 476159 & 2770 & 3731 & pe & Tingo María \\
\hline “ & “ & 2854 & 3795 & pe & Blanco Tarapoto \\
\hline “ & “ & 2907 & 3845 & pe & Negro de pocas ramas \\
\hline $\begin{array}{c}468 \\
،\end{array}$ & $\underset{،}{476160}$ & $\begin{array}{l}2772 \\
2855\end{array}$ & 3732 & pe & Tingo María \\
\hline 469 & 476161 & 2656 & 3643 & fa & Colorado Tarapoto \\
\hline “ & & 2720 & 3695 & fa & Pálido con pico \\
\hline 470 & 476162 & 2775 & & pe & Tingo María \\
\hline 471 & 476163 & 2776 & 3847 & pe & Tingo María \\
\hline “ & “ & 2857 & & pe & Blanco Tarapoto \\
\hline “ & “ & 2909 & & pe & Catalán planta abierta \\
\hline 472 & 476164 & 2778 & & pe & Tingo María \\
\hline “ & “ & 2858 & & pe & Blanco Tarapoto \\
\hline $472-1$ & “ & 2890 & & pe & Blanco marfíl \\
\hline 473 & 476165 & 2779 & 3736 & pe & Tingo María \\
\hline “ & & 2859 & 3799 & pe & Blanco Tarapoto \\
\hline $\begin{array}{c}474 \\
\text { ، }\end{array}$ & 476166 & 2780 & 3737 & pe & Tingo María \\
\hline 475 & 476167 & 2861 & & pe & $\begin{array}{l}\text { Blanco Tarapoto } \\
\text { Blato }\end{array}$ \\
\hline $476-1$ & 476168 & 2862 & & pe & Blanco Tarapoto \\
\hline “ & “ & 2910 & & pe & Catalán \\
\hline $476-2$ & “ & 2782 & & pe & Tingo María \\
\hline & “ & 2911 & & pe & Catalán \\
\hline
\end{tabular}

Dep. San Martín, Lamas, 626 m s.m. (20-V1981)C.E. Simpson, J. R. Pietrarelli \& Zurita

\begin{tabular}{|c|c|c|c|c|c|}
\hline 477 & 476169 & 2863 & & pe & Blanco Tarapoto \\
\hline $477-2$ & “ & 2783 & & pe & Tingo María \\
\hline $477-3$ & “ & 2912 & 3850 & pe & Catalán planta abierta \\
\hline
\end{tabular}

Dep. Loreto. Yurimaguas, Estación Experimental (20-V-1981) C:E. Simpson, J. R. Pietrarelli \& Zurita.

$478 \quad 476170 \quad 2864 \quad 3804 \quad$ pe $\quad$ Blanco Tarapoto 
Dep. Loreto, Yurimaguas, 150 m s.m. (20-V-1981), C.E. Simpson, J. R. Pietrarelli \& Zurita.

$\begin{array}{llllll}\text { US } & \text { PI } & \begin{array}{l}\text { Cat. } 90 \\ 86 / 87\end{array} & \text { REM } & \text { var. } & \\ 479 & 476171 & 2865 & 3805 & \text { pe } & \text { Blanco Tarapoto } \\ \text { “ } & \text { “ } & 2914 & 3852 & \text { pe } & \text { Negro de pocas ramas }\end{array}$

Dep. San Martín, Tarapoto, mercado (21-V-1981) C. E. Simpson, J.R.Pietrarelli \& Zurita

$\begin{array}{lccccl}480 & 476172 & 2784 & 3741 & \text { pe } & \text { Tingo María } \\ \text { “ } & \text { “ } & 2866 & 3806 & \text { pe } & \text { Blanco Tarapoto } \\ 481 & 476173 & 2915 & 3853 & \text { pe } & \text { Catalán } \\ \text { “ } & \text { “ } & 2785 & 3742 & \text { pe } & \text { Tingo María } \\ 482 & 476174 & 2816 & 3807 & \text { pe } & \text { Blanco Tarapoto } \\ 482-1 & \text { “ } & 2868 & 3854 & \text { pe } & \text { Catalán planta abierta } \\ 482-2 & \text { “ } & 2917 & 3855 & \text { pe } & \text { Blanco Tarapoto } \\ & & & & \text { pe } & \text { Catalán }\end{array}$

Dep. Loreto, Iquitos, mercado Belén, 87 m s.m. (23-V-1981)C. E. Simpson, J.R.Pietrarelli \& Zurita.

\begin{tabular}{|c|c|c|c|c|c|}
\hline 483 & 476175 & 2869 & 3809 & pe & Blanco Tarapoto \\
\hline & & 2951 & 3874 & pe & Morado de Iquitos \\
\hline $483-4$ & “ & 2786 & 3743 & pe & Tingo María \\
\hline 484 & 476176 & 2787 & 3744 & pe & Tingo María \\
\hline & & 2870 & 3810 & pe & Blanco Tarapoto \\
\hline “ & “ & 2954 & 3875 & pe & Morado de Iquitos \\
\hline 485 & 476177 & 2788 & & pe & Tingo María \\
\hline & & 2810 & & pe & Jaspeado com cerdas \\
\hline “ & “ & 2955 & 3876 & pe & Morado de Iquitos \\
\hline $485-2$ & “ & 2871 & 3811 & pe & Blanco Tarapoto \\
\hline 486 & 476178 & 2789 & & pe & Tingo María \\
\hline “ & “ & 2804 & & pe & Jaspeado sin cerdas \\
\hline “ & “ & 2957 & & pe & Catalán planta abierta \\
\hline 487 & 476179 & 2790 & 3747 & pe & Tingo María \\
\hline & “ & 2958 & 3878 & pe & Morado de Iquitos \\
\hline $487-2$ & “ & 2872 & 3812 & pe & Blanco Tarapoto \\
\hline 488 & 476180 & 2664 & 3651 & fa & Colorado Tarapoto \\
\hline & “ & 2919 & 3857 & pe & Morado de Iquitos \\
\hline $488-2$ & “ & 2791 & 3748 & pe & Tingo María \\
\hline & “ & 2873 & & pe & Blanco Tarapoto \\
\hline 489 & 476181 & 2724 & 3699 & fa & Colorado de Iquitos \\
\hline “ & & 2725 & 3700 & pe & Morado de Iquitos \\
\hline 490 & 476182 & 2874 & 3814 & pe & Blanco Tarapoto \\
\hline 491 & 476183 & 2875 & & pe & Blanco Tarapoto \\
\hline “ & “ & 2921 & 3858 & pe & Morado de Iquitos \\
\hline $491-1$ & “ & 2657 & & fa & Colorado Tarapoto \\
\hline & “ & 2815 & & pe & Jaspeado con cerdas \\
\hline $491-2$ & “ & 2792 & 3744 & pe & Tingo María \\
\hline 492 & 476184 & 2795 & & pe & Tingo María \\
\hline “ & & 2817 & 3859 & pe & Jaspeado con cerdas \\
\hline “ & “ & 2876 & 3816 & pe & Blanco Tarapoto \\
\hline “ & “ & 2922 & & pe & Morado de Iquitos \\
\hline 493 & 476185 & 2877 & 3817 & pe & Blanco Tarapoto \\
\hline 493-1 & & 2924 & 3860 & pe & Morado de Iquitos \\
\hline $493-3$ & “ & 2796 & 3751 & pe & Tingo María \\
\hline 494 & 476186 & 2820 & 3763 & pe & Jaspeado con cerdas \\
\hline
\end{tabular}




\begin{tabular}{|c|c|c|c|c|c|}
\hline US & PI & $\begin{array}{l}\text { Cat. } 90 \\
86 / 87\end{array}$ & REM & var. & \\
\hline “ & “ & 2925 & 3861 & pe & Morado de Iquitos \\
\hline $494-2$ & “ & 2797 & 3752 & pe & Tingo María \\
\hline & “ & 2878 & & pe & Blanco Tarapoto \\
\hline $495-2$ & 476187 & 2927 & & pe & Morado de Iquitos \\
\hline
\end{tabular}

Dep. Loreto, Iquitos, mercado Mordelo (24-V-1981) C. E. Simpson, J. R. Pietrarelli \& Zurita.

$\begin{array}{lccccl}496 & 476188 & 2798 & 3753 & \text { pe } & \text { Tingo María } \\ \text { “ } & \text { “ } & 2928 & 3863 & \text { pe } & \text { Morado de Iquitos } \\ 496-2 & 2879 & 3819 & \text { pe } & \text { Blanco Tarapoto } \\ 497 & 476189 & 2881 & 3820 & \text { pe } & \text { Blanco Tarapoto } \\ 497-2 & \text { “ } & 2799 & 3754 & \text { pe } & \text { Tingo María } \\ 497-3 & \text { “ } & 2930 & & \text { pe } & \text { Morado de Iquitos } \\ 498 & 476190 & 2932 & & \text { pe } & \text { Morado de Iquitos } \\ 499 & 476191 & 2615 & 3611 & \text { hy } & \text { Cojín colorado } \\ \text { “ } & \text { “ } & 2882 & 3821 & \text { pe } & \text { Blanco Tarapoto } \\ 499-1 & \text { Morado de Iquitos } \\ 500-1 & 476192 & 2934 & 3866 & \text { pe } & \text { Morado } \\ 500-2 & \text { “ } & 2883 & 3822 & \text { pe } & \text { Blanco Tarapoto } \\ \text { “ } & \text { “ } & 2900 & 3755 & \text { pe } & \text { Tingo María } \\ & & 2935 & 3867 & \text { pe } & \text { Morado de Iquitos }\end{array}$

Dep. Loreto, Iquitos, mercado Central (24-V-1981) C. E. Simpson, J. R. Pietrarelli \& Zurita.

$\begin{array}{llllll}501 & 476193 & 2801 & 3756 & \text { pe } & \text { Tingo María } \\ \text { “ } & \text { “ } & 2884 & 3823 & \text { pe } & \text { Blanco Tarapoto } \\ 501-1 & 2937 & 3868 & \text { pe } & \text { Morado de Iquitos } \\ 502 & 476194 & 2939 & 3869 & \text { pe } & \text { Morado de Iquitos } \\ 502-1 & \text { “ } & 2885 & 3824 & \text { pe } & \text { Blanco Tarapoto } \\ 503-1 & 476195 & 2943 & 3870 & \text { pe } & \text { Morado de Iquitos } \\ 503-2 & \text { “ } & 2824 & 3764 & \text { pe } & \text { Jaspeado con cerdas } \\ 503-3 & \text { “ } & 2886 & 3825 & \text { pe } & \text { Blanco Tarapoto } \\ 504 & 476196 & 2802 & & \text { pe } & \text { Tingo María } \\ \text { “ } & \text { “ } & 2495 & 3871 & \text { pe } & \text { Morado de Iquitos } \\ 505 & 476197 & 2947 & 3872 & \text { pe } & \text { Morado de Iquitos } \\ 505-2 & \text { “ } & 2803 & 3758 & \text { pe } & \text { Tingo María }\end{array}$

Dep. Loreto, caserío Cañaveral, río Amazonas, $10 \mathrm{Km}$ aguas arriba de Iquitos (25-V 1981), C. E. Simpson, J. R. Pietrarelli \& Zurita.

$506 \quad 476198 \quad 2950 \quad 3873$ pe Negro de pocas ramas

Dep. Ayacucho mercado, 2700 m s.m. (28-V-1981) C. E. Simpson \& J.E. Pietrarelli

$\begin{array}{lccccl}507-1 & 476199 & 2646 & 3634 & \text { fa } & \text { Colorado limeño } \\ 507-2 & \text { “ } & 2714 & 3693 & \text { fa } & \text { Pálido clavo verde } \\ 508 & 476200 & 2658 & 3645 & \text { fa } & \text { Colorado limeño } \\ 509 & 476201 & 2647 & & \text { fa } & \text { Colorado limeño } \\ 510 & 476202 & 2653 & 3641 & \text { fa } & \text { Colorado limeño } \\ \text { “ } & \text { “ } & 2698 & 3646 & \text { fa } & \text { Colorado La Convención }\end{array}$

Dep. Ayacucho, Santa Rosa, rio Apurimac, 10 Km río arriba de San Francisco(29-V -1981)C. E. Simpson \& J. R. Pietrarelli.

512-1 $476204 \quad 2648 \quad 3636 \quad$ fa $\quad$ Colorado limeño 
Dep. Ayacucho, Ccatanrumi, 15 Km río abajo de San Francisco (30-V-1981)C. E. Simpson \& J. R. Pietrarelli.

\begin{tabular}{|c|c|c|c|c|c|}
\hline US & PI & Cat. 90 & REM & var. & \\
\hline 513 & 476205 & $\begin{array}{l}86 / 8 \\
2666\end{array}$ & 3653 & fa & Co \\
\hline
\end{tabular}

Dep. Ayacucho, San Francisco, mercado, 400 m s.m. (31-V-1981)C. E. Simpson \& J. R. Pietrarelli.

$\begin{array}{lccccl}514 & 476206 & 2660 & 3647 & \text { fa } & \text { Colorado limeño } \\ 515-1 & 476207 & 2649 & 3637 & \text { fa } & \text { Colorado limeño } \\ 515-2 & \text { “ } & 2706 & 3688 & \text { fa } & \text { Pálido compacto } \\ 516 & 476208 & 2650 & 3638 & \text { fa } & \text { Colorado limeño } \\ 517-1 & 476209 & 2661 & 3648 & \text { fa } & \text { Colorado limeño } \\ 518 & 476210 & 2662 & & \text { fa } & \text { Colorado La Convención }\end{array}$

\section{Colección G. P. Silva (CENARGEN)}

Dep. Loreto, Iquitos

US

404

$89 / 3205$

pe Jaspeado sin cerdas

Colección A. Krapovickas

Cuzco, mercado (8-VII-1982)

\begin{tabular}{|c|c|c|c|c|}
\hline 1 & 2605 & & hy & Colorado rastrero La Convención \\
\hline & 2699 & & fa & Colorado La Convención \\
\hline 2 & 2701 & 3902 & fa & Colorado La Convención \\
\hline & 2616 & & hy & Overo rastrero \\
\hline 3 & 2700 & & fa & Colorado La Convención \\
\hline & 2888 & 3827 & pe & Blanco Tarapoto \\
\hline
\end{tabular}

Colección Banks, 9-16-III-1985. colección no incorporada a Manfredi.

(Banks, 1985).

Pas.

1251 Lima, mercado "red and white, from Bolivia".

1252 Lima, mercado.

1253 Lima, mercado."from Cuzco".

1254 Casma valley, peruvian Valencia.

1255 Casma valley, peruvian Valencia, dark purple.

1256 Casma valley,"rojo italiano".

1257 Casma , "rojo italiano".

1258 Chimbote, mercado "maní morado", hirsuta type.

1259 Chimbote, mercado "maní morado" brawnish-purple

1260 Virú, brawnish-purple, hirsuta type

1261 Paijan, purple, hirsuta type.

1262-1 Trujillo, pink

1262-2 Trujillo, dark-purple.

1263 Trujillo, red.

1264 Trujillo, dark-purple, hirsuta type.

1265 Trujillo, brawnish-purple, hirsuta type.

1266 Casma, jaspeado tang. 
1267 Lima, Est. Exp. Agric. La Molina.Chirumbia, Cuzco, red, same as PI.476029

1268 Lima, Est. Exp. Agric. La Molina "Criollo nacional”(morado), hirsuta type.

1269 Lima, Est. Exp. Agric. La Molina “Criollo nacional” (rosado), pink.

1270 Lima, Est. Exp. Agric. La Molina "Criollo nacional” (rosado), pink.

1271 Lima, Est. Exp. Agric. La Molina “Morado gigante” dark-purple.

1272 Lima, Est. Exp. Agric. La Molina "Rojo gigante”, red

1273 Lima, Est. Exp. Agric. La Molina “Rojo rastrero”, red

1274 Lima, Est. Exp. Agric. La Molina Cañete (rosado)pink

1275 Lima, Est. Exp. Agric. La Molina Huayllamba, Cuzco,pink

1276 Lima, Est. Exp. Agric. La Molina Huayllamba, Cuzco,pink

1277 Lima, Est. Exp. Agric. La Molina Sahuayaco, Cuzco, red, same as PI: 476034

1278 Lima, Est. Exp. Agric. La Molina Yungas (morado)

1279 Lima, Est. Exp. Agric. La Molina Yungas (rosado)

1280 Lima, Univ. Nac.Agraria La Molina, Ancash, red, Valencia.

1281 Lima, Univ. Nac.Agraria La Molina, Cajamarca, purple, peruvian- Valencia.

1282 Lima, Univ. Nac.Agraria La Molina, Amazonas, red, Valencia.

1283-1 Lima, Univ. Nac.Agraria La Molina, Amazonas, tan, peruvian Valencia

1283-2 Lima, Univ. Nac.Agraria La Molina, Amazonas, red, Valencia

1284 Lima, Univ. Nac.Agraria La Molina, red, peruvian- Valencia, morado 5

1285 Lima, Univ. Nac.Agraria La Molina, red “italiano”, peruvian -Valencia.

\section{Colección Bartra, 1986}

Dep. San Martín, Tarapoto

$\begin{array}{lllll} & \text { Cat. } 90 & \text { REM } & \text { var. } & \\ 1 & 86 / 87 & & & \\ 2 & 2887 & 3826 & \text { pe } & \text { Blanco Tarapoto } \\ 3 & 2728 & & \text { fa } & \text { Colorado Tarapoto } \\ 4 & 2729 & & \text { pe } & \text { Tingo María } \\ & 2918 & 3856 & \text { pe } & \text { Morado de Iquitos }\end{array}$

\section{Colección, Arturo Martínez}

\section{Dep. San Martín, Rioja}

